$$
\begin{gathered}
\text { Universidade de São Paulo } \\
\text { Instituto de Física de São Carlos }
\end{gathered}
$$

Tiago de Campos

\title{
Nanowires de InP: cálculo do espectro de absorção via método k.p
}





\section{Tiago de Campos}

\section{Nanowires de InP: cálculo do espectro de absorção via método k.p}

Dissertação apresentada ao Programa de PósGraduação em Física do Instituto de Física de São Carlos da Universidade de São Paulo, para obtenção do título de Mestre em Ciências.

Área de Concentração: Física Aplicada

Opção: Física Computacional

Orientador: Prof. Dr. Guilherme Matos Sipahi

Versão Corrigida

(versão original disponível na Unidade que aloja o Programa)

São Carlos 
AUTORIZO A REPRODUÇÃO E DIVULGAÇÃO TOTAL OU PARCIAL DESTE TRABALHO, POR QUALQUER MEIO CONVENCIONAL OU ELETRÔNICO PARA FINS DE ESTUDO E PESQUISA, DESDE QUE CITADA A FONTE.

Ficha catalográfica elaborada pelo Serviço de Biblioteca e Informação do IFSC, com os dados fornecidos pelo(a) autor(a)

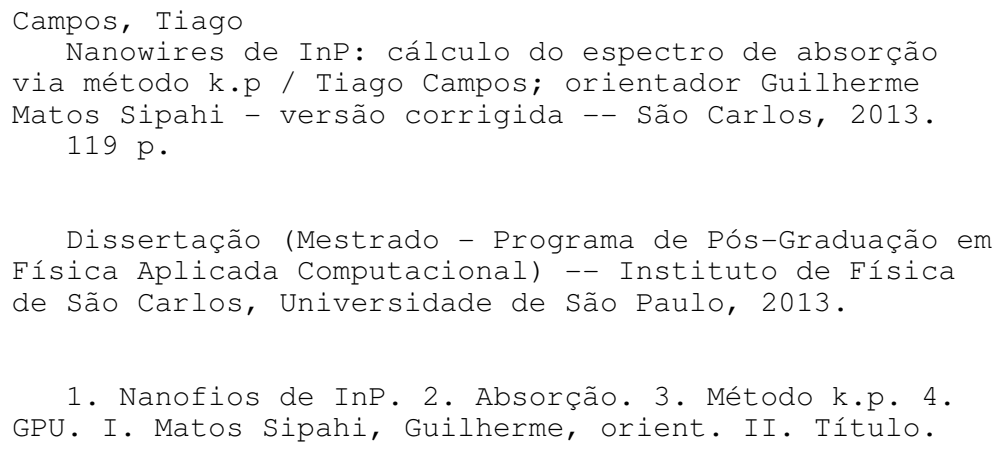

1. Nanofios de InP. 2. Absorção. 3. Método k.p. 4. GPU. I. Matos Sipahi, Guilherme, orient. II. Título. 
Dedico esta dissertação à minha mãe, Renata, e aos meus avós maternos Francisco e Sebastiana. 



\section{AGRADECIMENTOS}

Começo agradecendo do fundo do meu coração à minha mãe, Renata, e ao meu falecido pai, Agostinho. Sem o esforço de vocês, especialmente o dela, eu não estaria onde estou. Não esquecendo dos meus avós maternos, Francisco e Sebastiana, e da minha querida irmã, Talita, que também me apoiaram muito. Amo vocês.

Agradeço imensamente minha noiva, Jéssica, por ter aparecido na minha vida na hora certa. Sem você o mundo seria cinza. Te amo muito.

Expresso meu agradecimento especial ao José Pedro pelo grande apoio que tem dado à nossa família, obrigado.

Destaco duas pessoas que me ajudaram muito: meu roommate de casa e laboratório, Paulo Eduardo; e nosso orientador, Guilherme Matos Sipahi. Obrigado pelo apoio e discussões, sem vocês esse estudo não seria possível.

Meus companheiros e companheiras desta longa jornada que foi a graduação e o mestrado (por ordem alfabética): Carlos Maciel, Denis Candido, Fernando Henrique, Frederico Toledo, Guilherme Bagnato, Gustavo Foresto, José Ricardo, Lucas Assirati, Marcello Xeleta, Maria Luiza, Raul Prado, Renata Batista e Wellyson Alencar; agradeço vocês também.

Um agradecimento especial ao Thiago Mosqueiro que me ajudou com todas as dúvidas sobre LaTeX. Sem a sua ajuda o processo seria mais complicado.

Agradeço, também, o pessoal do IFSC que me auxiliou: Silvio, Ricardo, Patricia, Sonia, Maria Cristina e Italo.

Agradeço o CNPq pelo apoio financeiro.

E por último, mas não menos importante, agradeço a todos os brasileiros que lutam por um Brasil melhor. 

O valor da ciência

“...Para mim, o maior feito da ciência é permitir que a humanidade veja que nosso mundo é compreensível. Que por meio da ciência e do pensamento racional, podemos entender como o Universo funciona. Se você não entende como o mundo funciona, então tudo passa a ser um mistério. Se tudo é mágico e misterioso, então você passa a deixar de usar a lógica. E tudo se resume a crer. Nossa sanidade depende do conhecimento do que ocorre à nossa volta. Que não é apenas questão de destino, que há razão para muitas coisas. A razão é ciência. Compreender a razão das coisas é ciência..."

Trecho traduzido livremente do documentário Brave New World with Stephen Hawking e narrado por: Jim Al-Khalili, Joy Reidenberg e David Attenborough.

O Diabo está nos detalhes.

Provérbio popular 



\section{RESUMO}

CAMPOS, T. Nanowires de InP: cálculo do espectro de absorção via método k.p. 2013. 119 p. Dissertação (Mestrado em Ciências) - Instituto de Física de São Carlos, Universidade de São Paulo, São Carlos, 2013.

Nos últimos anos, os avanços nas técnicas de crescimento de semicondutores permitiram a fabricação de nanoestruturas isoladas de alta qualidade e com confinamento radial. Essas estruturas quase unidimensionais, conhecidas como nanowires (NWs) têm aplicações tecnológicas vastas, tais como nano sensores químicos e biológicos, foto-detectores e lasers. Seu uso em aplicações tecnológicas requer a compreensão de características óticas e eletrônicas e um estudo teórico mais profundo se faz necessário. O objetivo desse estudo é calcular teoricamente o poder de absorção para NWs de InP e comparar os resultados para as fases cristalinas zincblende (ZB) e wurtzita (WZ) nas suas direções de crescimento equivalentes. Usamos neste estudo a formulação do método k.p que descreve as duas fases cristalinas em um mesmo Hamiltoniano, a aproximação da função envelope e a expansão em ondas planas. O poder de absorção foi calculado a partir das transições entre as bandas de valência e condução através da regra de ouro de Fermi. Mesmo o método k.p sendo o menos custoso computacionalmente, quando comparado com seus correspondentes ab initio, o tamanho das matrizes envolvidas nos cálculos pode ultrapassar a barreira dos giga elementos. Para lidar com essas matrizes, foi implementado um método de resolução de sistemas lineares iterativo, o LOBPCG, utilizando o poder de processamento disponível nas placas gráficas atuais. O novo modo de resolução apresentou ganhos consideráveis em relação ao desempenho observado com os métodos de diagonalização diretos em testes com confinamento em uma única direção. A falta de um pré-condicionador adequado limita o seu uso em NWs. Os cálculos de absorção para NWs na fase ZB apresentaram uma anisotropia em seu espectro de absorção de mais de 90\%, enquanto os na fase WZ apresentaram dois regimes distintos de anisotropia, governados pelo aparecimento de um estado oticamente proibido no topo da banda de valência. Em suma, os resultados obtidos com o modelo teórico proposto nesse estudo apresentam as propriedades óticas reportadas na literatura, inclusive o estado oticamente proibido observado em outros sistemas na fase WZ com um alto confinamento quântico. 
Palavras-CHaVe: Nanofios de InP, Absorção, Método k.p, GPU. 


\section{ABSTRACT}

CAMPOS, T. InP nanowires: absorption spectrum calculation via k.p method. 2013. 119 p. Dissertação (Mestrado em Ciências) - Instituto de Física de São Carlos, Universidade de São Paulo, São Carlos, 2013.

In recent years, the advances of growth techniques allowed the fabrication of high quality single nanostructures with quantum confinement along lateral directions. These quasi onedimensional structures known as nanowires (NWs) have vasts technological applications, such as biological and chemical nanosensors, photo detectors and lasers. The applications involving NWs require the comprehension of their optical and electronic properties and, therefore, a deep theoretical understanding should be pursued. The aim of this study is to provide optical absorption theoretical calculations for $\ln P$ NWs, comparing the results for zincblende (ZB) and wurtzite (WZ) crystal phases, in their equivalent growth directions. We use the k.p method formulation that allow the description of both structures with the same Hamiltonian, the envelope function approximation and the plane wave expansion. The absorption power was calculated for transitions between valence and conduction bands using Fermi's Golden Rule. Although the k.p method demands less computational effort, when compared to $a b$ initio calculations, the k.p matrices can break the giga elements barrier. To deal with these matrices, we implemented an linear system solver method, the LOBPCG, using the processing power available in current GPUs. The new resolution method showed a considerable gain comparing the performance of direct diagonalization methods, when tested in systems with confinement in one direction. The lack of an adequate preconditioner limits its use in NWs. The absorption spectra calculations for ZB NWs presented a $90 \%$ plus anisotropy, whilst WZ NWs have two distinct regimes, ruled by the presence of an optically forbidden state at valence band maximum. In summary, the results obtained with the theoretical model in this study are in great agreement with optical properties reported in the literature, including the optically forbidden state observed in other WZ systems with high quantum confinement.

KEYWORDS: InP nanowires, Absorption, k.p method, GPU. 



\section{LISTA DE FIGURAS}

2.1 Sistemas de coordenada para estruturas cristalinas com simetria ZB e WZ (17). a) Célula unitária convencional do ZB com o sistema de coordenadas usual, que passa pelos vértices do cubo, e o que passa pela diagonal principal do cubo. b) Célula unitária convencional da WZ com seu sistema de coordenadas usual. . . . . . . . . . . . . . . . . . . . . . . . . . .

3.1 Configurações das possíveis heteroestruturas (76). a) Poço quântico, b) Fio quântico e c) Ponto quântico.

5.1 Distribuição de transistores nas CPUs e GPUs. Vemos, a esquerda, o esquema básico de uma CPU: praticamente metade dos transistores são dedicados à memória (cache) e o restante dividido entre controle e processamento; já as GPUs, a direita, possuem praticamente todos os transistores

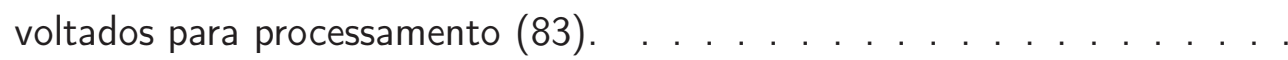

5.2 Arquitetura dos chips FERMI. Cada faixa contem: porção verde que represente as unidades de processamento, porção laranja representando o escalonador local e uma porção azul clara representando os registradores e o cache L1. A parte laranja lateral é o escalonador global que distribuirá a execução entre os multiprocessadores. Em destaque está um esquema detalhado de um SM, mostrando todas as suas unidades fundamentais (84). . . . . . . .

5.3 As abstrações do modelo de programação. a) cada programa possui uma sub-divisão em blocos threads que por sua vez são sub-divididos em threads que cooperam na execução; b) Os espaços dentro de um SM são reservados para acessos das threads de um bloco. Já os espaços fora de um SM são para acessos globais; c) a GPU organiza a execução dos blocos de threads automaticamente, distribuindo a carga de trabalho entre os SMs. . . . . .

7.1 Hamiltoniano expandido em 1 onda plana $(K=-1,0,1)$ para confinamento 1D. Nesta representação fixa-se o vetor de base e o valor de $K$ e varia-se os valores de $|\Delta K|$. As cores iguais não representam valores iguais, e sim o

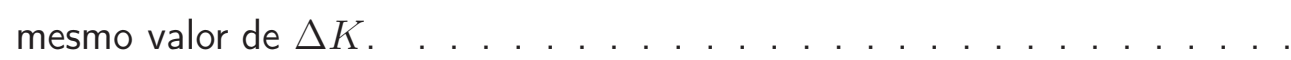


7.2 Modelo out-of-core para um Hamiltoniano expandido em uma onda plana com confinamento 1D. O Hamiltoniano é construído linha a linha e multiplicado pelo vetor tentativa de auto estados. Cada cor representa um termo do Hamiltoniano total e a variação de um cor específica representa a variação do valor de $K^{\prime}$.

8.1 Perfil de confinamento para os elétrons em uma heteroestrutura de $\mathrm{GaAs} / \mathrm{Al}_{0.35} \mathrm{Ga}_{0.65} \mathrm{As}$. Este perfil será usado para testar os tempos de execução do programa de cálculo usando os métodos de diagonalização na CPU e os de minimização, tanto na CPU quanto na GPU.

8.2 Comparação entre os tempos de execução de uma iteração do LOBPCG na CPU e na GPU. As linhas vermelhas representam a execução nas GPU, e as azuis na CPU. Os gráficos b) e d) estão em escala logarítmica para compararmos visualmente a inclinação das curvas. O programa foi executado em duas placas de vídeo distintas: uma com menos recursos, GTX 285 e outra com mais recursos, GTX 580; e em dois processadores distintos: um com menos recursos, Core2Duo e outro com mais recursos, Core i5. . . . .

8.3 Comparação entre os tempos de execução do CHEEVX e do LOBPCG. A linha vermelha corresponde à execução do CHEEVX na CPU, a azul de 20 iterações do LOBPCG na mesma CPU e a verde de 20 iterações do LOBPCG na GPU mais rápida. Em b) temos os tempos de execução em escala logarítmica para compararmos visualmente a inclinação das curvas. .

8.4 Estrutura da banda de valência para o bulk de InP em ZB[111](a) e WZ[0001](b) (67).

8.5 Coeficiente de absorção para um bulk de InP ZB. A curva em vermelho denota o poder de absorção para luz com polarização em $\hat{x}$ ou $\hat{y}$; já a curva em azul, o poder de absorção para luz polarizada em $\hat{z}$. As setas no gráfico indicam as transições, no ponto $\Gamma$, de cada banda de valência para a banda de condução

8.6 Coeficiente de absorção para um bulk de InP em WZ. A curva em vermelho denota o poder de absorção para luz com polarização em $\hat{x}$ ou $\hat{y}$; já a curva em azul, o poder de absorção para luz polarizada em $\hat{z}$. As setas no gráfico indicam as transições, no ponto $\Gamma$, de cada banda de valência para a banda de condução . . . . . . . . . . . . . . . . . . . . 
8.7 Seção transversal do NWs. Os NWs que serão analisados possuem seção transversal hexagonal. . . . . . . . . . . . . . . . . . . .

8.8 Gaps calculados para os NWs. A escala da esquerda representa os valores do gap em eV e a da direita os respectivos comprimentos de onda associados aos valores valores do gap. . . . . . . . . . . . . . . . . .

8.9 Absorção para um fio com $L_{x}=5 \mathrm{~nm}$. A estrutura de bandas estão gráficadas em a) para os NWs em WZ e em b) para ZB, o grau de polarização linear com efeitos de CO e CQ está representado em c), e o coeficiente de absorção para NWs de InP em WZ e em ZB está representado em d) e e) respectivamente. $\mathrm{O}$ inset mostra um zoom em torno do valor de energia do gap para o GPL do NW em ZB. . . . . . . . . . . . . . . . . . . . . . . . . . . . . .

8.10 Absorção para um fio com $L_{x}=8 \mathrm{~nm}$. A estrutura de bandas estão gráficadas em a) para os NWs em WZ e em b) para ZB, o grau de polarização linear com efeitos de $C O$ e $C Q$ está representado em c), e o coeficiente de absorção para NWs de InP em WZ e em ZB está representado em d) e e) respectivamente. $\mathrm{O}$ inset mostra um zoom em torno do valor de energia do gap para o GPL do NW em ZB. . . . . . . . . . . . . . . . . . . . . . . . . . . .

8.11 Absorção para um fio com $L_{x}=10 \mathrm{~nm}$. A estrutura de bandas estão gráficadas em a) para os NWs em WZ e em b) para ZB, o grau de polarização linear com efeitos de CO e CQ está representado em c), e o coeficiente de absorção para NWs de InP em WZ e em ZB está representado em d) e e) respectivamente. $\mathrm{O}$ inset mostra um zoom em torno do valor de energia do gap para o GPL do NW em ZB. . . . . . . . . . . . . . . . . . . . . . . .

8.12 Absorção para um fio com $L_{x}=15 \mathrm{~nm}$. A estrutura de bandas estão gráficadas em a) para os NWs em WZ e em b) para ZB, o grau de polarização linear com efeitos de CO e CQ está representado em c), e o coeficiente de absorção para NWs de InP em WZ e em ZB está representado em d) e e) respectivamente. O inset mostra um zoom em torno do valor de energia do gap, para o GPL do NW em ZB, que está de acordo com o observado por Wang et al (60) para a mesma espessura de NW. . . . . . . . . . . . . 
8.13 Redução da banda de energia para a primeira zona de Brillouin de uma rede uni-dimensional. Um efeito semelhante acontece na presença do CQ. O sistema confinado possui uma nova zona de Brillouin menor que a zona do material bulk. Na figura, a é o vetor de base da rede de Bravais no espaço real $(65) \ldots \ldots \ldots \ldots \ldots \ldots \ldots \ldots . \ldots \ldots \ldots$

8.14 Energia do topo das duas primeiras bandas de valência em função do tamanho, $L_{x}$, do NW em a) WZ e em b) ZB. Note que para a WZ há um cruzamento entre as bandas de energia entre os valores $L_{x}=10 \mathrm{~nm}$ e $L_{x}=11 \mathrm{~nm}$ que não ocorre para o ZB. Doughnut shape e gaussian shape se referem à forma da função de onda no ponto $\Gamma$, veja figura 8.17 . . . . . . . . . . .

8.15 Níveis de energia de um poço quântico, suas funções de ondas e densidades de probabilidade. a) Poço quântico uni-dimensional: estado fundamental não possui nó; estado excitado possui. A banda de condução, no nosso modelo, se comporta como uma partícula na caixa. b) Densidade de probabilidade, no ponto $\Gamma$, para o primeiro estado da banda de condução de um NW na fase WZ, se assemelha a uma gaussiana. c) Densidade de probabilidade, no ponto $\Gamma$, para o segundo estado da banda de condução de um NW na fase WZ, possui um nó. . . . . . . . . . . . . . . . . . . .

8.16 Bandas de energia de um cristal. A figura a) exemplifica o surgimento das bandas de energia a partir da superposição dos orbitais atômicos (66). A figura b) mostra a estrutura de bandas do InP bulk (103). Note que o topo da banda de valência não é o estado fundamental do sistema.

8.17 Densidade de probabilidade, no ponto $\Gamma$, para um NW na fase WZ com $L_{x}=8 \mathrm{~nm}$. Nesta figura estão presentes os dois primeiros estados da banda de valência. a) Densidade de probabilidade do primeiro estado da banda de valência. b) Densidade de probabilidade do segundo estado da banda de valência. Neste caso, as densidades de probabilidade da banda de valência não seguem o mesmo comportamento da banda de condução. . . . . . . . . .

8.18 Composição dos dois primeiros estados da banda de valência da WZ como função de $L_{x}$. Há uma mudança brusca na composição dos estados entre $L_{x}=10 \mathrm{~nm}$ e $L_{x}=12 \mathrm{~nm}$. O primeiro estado da banda de valência, vb1(2), até $L_{x}=11 \mathrm{~nm}$ é aquele cujo formato se assemelha à um donut. Em $L_{x}=12 \mathrm{~nm}$ vb1(2) passa a ser o que se assemelha à uma gaussiana. Todos os estados tendem à composição do bulk. . . . . . . . . . . . . . . . . . 
8.19 Composição dos dois primeiros estados da banda de valência do ZB como função de $L_{x}$. Não há descontinuidade na composição dos estados, eles tendem suavemente à composição do bulk. . . . . . . . . . . . . . . . . .

8.20 Contribuição de energia em função do tamanho $L_{x}$ do NW. As linhas em vermelho e verde representam as contribuições dos elementos da diagonal e a linha em magenta representa a contribuição do termo de interação. Em a) e b) temos as contribuições de energia dos três termos, em c) e d) temos o valor absoluto da razão entre o valor da diagonal com a interação. Note que para o estado donut as contribuições da diagonal são próximas, já o gaussiano possui o termo $h 11(44)$ sempre maior que a interação. A contribuição do termo $h 22(55)$ possui o mesmo comportamento nos dois estados. . . . . 



\section{LISTA DE TABELAS}

8.1 Parâmetros k.p para $\mathrm{GaAs}$ e $\mathrm{Al}_{0.35} \mathrm{Ga}_{0.65} \mathrm{As}(96) \ldots \ldots$. . . . . . . . . . . 78

8.2 Relação entre o número de ondas planas em 1D e seus equivalentes em 2D

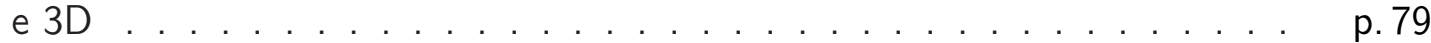

8.3 Parâmetros k.p para InP ZB e WZ. Os parâmetros para o ZB foram derivados usando as relações $(2.2 .9) \ldots \ldots \ldots$. . . . . . . . . . . . . . . . . . . . . . . . 



\section{SUMÁRIO}

$\begin{array}{lll}1 \text { Introdução } & \text { p. } 25\end{array}$

2 O método k.p $\quad$ p. 29

2.1 Derivação do método k.p . . . . . . . . . . . . . . . . . . p. 29

2.1.1 Tratamento via teoria de perturbação . . . . . . . . . . . . . . p. p. 31

2.2 Matrizes do método k.p . . . . . . . . . . . . . . p. . 33

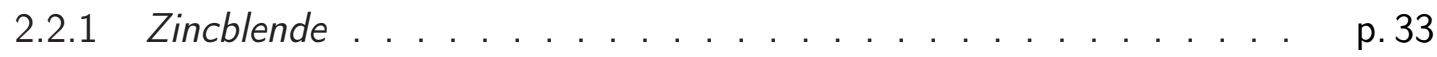

2.2 .2 Wurtzita . . . . . . . . . . . . . . . . . 35

2.2.3 Expressando ZB [111] e WZ [0001] na mesma matriz . . . . . . . p. p. 37

3 Função envelope e expansão em ondas planas $\quad$ p. 39

3.1 A aproximação da função envelope . . . . . . . . . . . . . . . . . . . . p. 39

3.2 Matriz k.p na aproximação da função envelope . . . . . . . . . . . . . . . p. 41

3.3 Expansão em ondas planas . . . . . . . . . . . . . . . . . . . p. 44

4 Propriedades derivadas da estrutura de bandas $\quad$ p. 49

4.1 Poder de absorção . . . . . . . . . . . . . . . . . . . . p. 49

4.1 .1 Força de oscilador . . . . . . . . . . . . . . . . p. 51

4.1 .2 Grau de polarização linear . . . . . . . . . . . . . . . . . p.54

4.2 Contribuições de energia . . . . . . . . . . . . . . . . . . p. . p5

5 Uma abordagem paralela $\quad$ p. 59

5.1 Arquitetura das placas gráficas . . . . . . . . . . . . . p. 59

5.1 .1 FERMI . . . . . . . . . . . . . . . . . . p. 60

5.2 Modelo de programação . . . . . . . . . . . . . . . . . . . p. 61 
6 O método de minimização $\quad$ p. 65

6.1 Sistemas lineares como um problema de diagonalização . . . . . . . . . p. 65

6.2 Resolução iterativa . . . . . . . . . . . . . . . . . . . . . p. 66

6.2 .1 Preliminares . . . . . . . . . . . . . . . . . . . 67

6.2.2 Minimizando iterativamente . . . . . . . . . . . . p. 68

6.2.2.1 Steepest descent . . . . . . . . . . . . . . p. 69

6.2.2.2 Gradiente Conjugado ... . . . . . . . . . . p. 69

6.2 .3 Pré-Condicionador . . . . . . . . . . . . . . . . . . . . . p.70

6.3 LOBPCG . . . . . . . . . . . . . . . . . . . p. 71

$\begin{array}{lll}7 & \text { O programa de cálculo } & \text { p. } 73\end{array}$

7.1 Modelo out-of-core . . . . . . . . . . . . . . . . . p. 73

8 Resultados $\quad$ p. 77

8.1 Com o LOBPCG . . . . . . . . . . . . . . . . p. 77

8.1 .1 Poço quântico . . . . . . . . . . . . . . . . . . . . p.78

8.2 Coeficiente de absorção . . . . . . . . . . . . . . . . . . p. 81

8.2.1 $\operatorname{lnP}$ bulk . . . . . . . . . . . . . . . . . . . . . . p. 82

8.2.2 Free-standing nanowires de $\ln \mathrm{P} \ldots \ldots$. . . . . . . . . . 84

8.2.3 Cruzamento das bandas de energia . . . . . . . . . . . p. 90

9 Conclusões $\quad$ p. 97

10 Trabalhos futuros $\quad$ p. 99

$\begin{array}{ll}\text { REFERÊNCIAS } & \text { p. } 101\end{array}$

Apêndice A - Teoria de perturbação $\quad$ p. 111

A.1 O complemento de Schur . . . . . . . . . . . . . . . p. 111

A.2 Resultados tradicionais da teoria de perturbação . . . . . . . . . . . . . p.111 
A.3 Löwdin . . . . . . . . . . . . . . . . . . . . . . . . . . . . . . . . . . . . . . p. 113

A.4 Sumarizando . . . . . . . . . . . . . . . . . . . . . . . . . . . . . . . . . p. 114

Apêndice B - Ortogonalidade da função de onda no formalismo da função envelope 



\section{Capítulo 1}

\section{Introdução}

As primeiras nanoestruturas semicondutoras foram sintetizadas nos anos de 1970 e logo foram incorporadas a dispositivos devido às suas características óticas e eletrônicas distintas (1). Nos anos que se seguiram, os NWs (do inglês nanowires) foram pouco estudados, principalmente pelas dificuldades em se obter uma nanoestrutura de alta qualidade. Em meados de 2000, com os avanços nos processos de fabricação, NWs com diâmetros da ordem de 10 nanômetros foram reportados e o interesse nessas nanoestruturas voltou a crescer (2-4).

Geralmente, os compostos das famílias III-V cristalizam na fase zincblende (ZB) em sua forma bulk com exceção dos III-nitretos, que cristalizam na fase wurtizita (WZ). Os primeiros relatos de NWs possuindo somente uma fase cristalina e com diâmetros da ordem de dezenas de nanômetros vem do grupo de Charles M. Lieber $(5,6)$ onde eles relatam o crescimento, na direção [111], de vários compostos III-V na fase zincblende. Durante o crescimento de NWs desses compostos a fase cristalina predominante nem sempre é a ZB, e sim a WZ $(7,8)$ e recentemente vemos avanços na obtenção de NWs com alta qualidade ótica e com uma única fase cristalina (9).

As dificuldades no processo de fabricação desses NWs de alta qualidade levaram ao surgimento de uma nova classe de nanoestruturas chamadas de NWs politípicos. Elas se destacam pela mudança de fase cristalina, entre WZ e ZB, ao longo da direção de crescimento e possuem diâmetros da ordem de dezenas de nanômetros. Esses NWs politípicos abriram as portas para uma nova área de estudos e de dispositivos baseados na separação espacial dos portadores, ao longo do NW (10-18).

As aplicações tecnológicas propostas para os NWs são imensas e abrangem praticamente todas as áreas do conhecimento. Alguns exemplos mais recentes são: nano sensores químicos e biológicos (19-22), foto-detectores (23-27), LEDs (do inglês, Light-Emitting Diode)(28, 29), transistores de efeito de campo $(30,31)$, lasers $(32,33)$, nano-antenas $(34)$, células solares (35-40), computação quântica - spintrônica - e miniaturização $(11,41-48)$, e inclusive o estudo de Majorana Férmions (49-51)

Uma das maneiras de obter as propriedades óticas de sistemas semicondutores é iluminando a amostra. Quando um fóton com energia maior ou igual ao gap do material incide sobre 
a amostra, elétrons da banda de valência são excitados para a banda de condução e pares elétron-buraco são criados. Em um semicondutor perfeito, esses pares relaxarão para o seu estado fundamental (elétron no fundo da banda de condução e buraco no topo da banda de valência) e eventualmente se recombinarão emitindo um fóton com energia igual ao gap do material. Na presença de impurezas ou defeitos esse processo de relaxação e recombinação pode ser drasticamente alterado. O processo de incidir luz no material e observar a luz que eles emitem é chamado de fotoluminescência (PL, do inglês photoluminescence) (52).

Com o desenvolvimento de lasers sintonizáveis, tais como o de safira dopado com titânio, uma nova possibilidade de espectroscopia surgiu, a fotoluminescência de excitação (PLE, do inglês photoluminescence excitation). Nela, o espectrômetro é travado para detectar uma determinada energia de emissão enquanto o laser incide luz percorrendo uma certa janela de frequência. Em alguns casos, quando a amostra é de alta qualidade, assume-se que o espectro de PLE é uma aproximação do espectro de absorção da amostra analisada (52).

Os experimentos de luminescência se baseiam no comportamento clássico da radiação, ou seja, na variação entre a constante dielétrica do material em relação ao meio que o cerca. No caso dos NWs, essa abordagem baseada no confinamento ótico (CO), se aplica para fios com diâmetros menores que $100 \mathrm{~nm}$, ou seja, para comprimentos de onda da radiação incidente até o regime do ultra violeta (53-55). Para NWs com diâmetros menores que cerca de 20 nm é necessário uma abordagem mais realística, baseada na estrutura eletrônica do material (56-59), cujos efeitos de confinamento quântico (CQ) são inerentes à teoria.

Os efeitos do CQ se expressam nas bandas de energia de um semicondutor. Na presença de algum tipo de confinamento energético, suas bandas de energia passam a ser combinações lineares das bandas do bulk. Além disso, a simetria do cristal é importante: o ZB, por ter uma simetria cúbica, é isotrópico enquanto que a WZ, com sua simetria hexagonal, apresenta uma anisotropia. Esses efeitos combinados modificam as propriedades das transições entre as bandas de condução e valência.

Em meados de 2001, Wang et al. (60) reportaram uma anisotropia gigante entre luz com polarização paralela e perpendicular ao eixo no NW, tanto no espectro de absorção quanto no espectro de emissão. Essa anisotropia foi explicada com base no CO já que no passado cálculos baseados nos efeitos de $C Q(61,62)$ não predisseram uma diferença tão grande quanto a observada. Muitos se empenharam em estudar as causas dessa anisotropia para NWs em ZB (53-55, 57-59). Ao mesmo tempo, como discutido por C. X. Shan et al., o estudo de NWs em WZ era muito controverso e não sabia ao certo quem o governava, se o CO ou o $C Q$. Se fosse o primeiro, a anisotropia favoreceria o eixo de crescimento; já se fosse o segundo, a 
direção perpendicular ao eixo de crescimento. Em seu artigo, ele defende que o confinamento ótico é o responsável pela anisotropia (63).

O primeiro experimento que comparou os espectros de $\mathrm{PL}$ para NWs tanto em WZ quanto em ZB foi feito por Mishra et al. (32). No experimento, eles mediram os espectro de PL para NWs de InP e mostraram que os em ZB possuem uma anisotropia favorecendo o eixo do NW enquanto que os em WZ favorecem a direção perpendicular ao eixo. Esse resultado é totalmente compatível com o que se espera baseado na combinação dos efeitos de $C O$ e $C Q$, mesmo a amostra tendo NWs com $80 \mathrm{~nm}$ de diâmetro em média. Recentemente, Wilhelm et al. discutiram os processos envolvidos no surgimento dessa anisotropia para vários compostos nas duas estruturas cristalinas (64).

Apesar de vários relatos experimentais mostrarem que os NWs em WZ possuem uma anisotropia, nenhum estudo teórico foi realizado. As argumentações feitas se baseiam na estrutura de bandas do cristal bulk.

O intuito do presente estudo é diminuir o gap de entendimento que existe entre os NWs em WZ e ZB. Realizamos um estudo teórico para NWs em ZB e WZ no regime em que o CQ não pode ser desprezado. Calculamos as propriedades óticas desses NWs e analisamos suas diferenças com o respaldo de uma teoria que inclui os efeitos de CQ. Esta dissertação de mestrado pode ser dividida em duas partes; uma focada no estudo e implementação de um método de minimização para possibilitar a simulação de sistemas complexos, e outra, na obtenção de propriedades óticas de NWs com diâmetro reduzido.

A estrutura de bandas dos NWs é obtida através do método k.p juntamente com a aproximação da função envelope e o formalismo da expansão em ondas planas. Usamos o método k.p por ser computacionalmente menos custoso se comparado com métodos ab initio. A expansão em ondas planas é usada na discretização do espaço e com ela conseguimos descrever qualquer geometria.

Mesmo o k.p sendo o menos custoso, o Hamiltoniano discretizado em ondas planas pode alcançar tamanhos em que o processamento sequencial não é mais adequado. Para superar essa demanda no processamento, implementamos um método de minimização iterativo que faz uso do poder de processamento disponível nas placas de vídeo.

A partir da estrutura de bandas, calculamos o coeficiente de absorção através das transições, mediadas por dipolo, entre as bandas de valência e condução e incluímos os efeitos de amortecimento do campo elétrico na interface de uma material dielétrico.

Para compararmos nossos resultados com os experimentos, calculamos o grau de polari- 
zação linear. Assim, nosso estudo foi validado com o que já está consolidado na literatura e estendemos o modelo para NWs em WZ.

No intuito de discutir os resultados e as conclusões presentes nos capítulos 8 e 9, necessitamos de um entendimento prévio sobre a teoria que será usada. Nos capítulos 2, 3 e 4 apresento os conceitos físicos envolvidos na obtenção do Hamiltoniano que descreve nosso sistema bem como as propriedades que iremos analisar. Nos capítulos 5, 6 e 7 apresento os conceitos envolvidos na implementação do método de minimização utilizando a placa de vídeo. Ainda há questões em aberto que não foram acomodadas nessa dissertação. Recomendações de trabalhos futuros para respondê-las estão no capítulo 10 . 


\section{O método k.p}

Um cristal é um sistema físico constituído não só de elétrons como também de núcleos, e cada uma dessas partículas se move em um campo gerado pelas outras. Para resolver esse problema, de muitos corpos, podemos transformá-lo em um equivalente, de um elétron em um potencial. Essa transformação é feita por meio de três aproximações básicas (veja capítulo 2 da referência (65)): a de Born-Oppenheimer, a de Hartree e a de Hartree-Fock. No que concerne o nosso estudo, o potencial efetivo resultante dessas aproximações contêm as contribuições das interações elétron-íon e elétron-elétron, e possui a periodicidade da rede de Bravais do cristal (66).

Neste capítulo discuto, a partir do Hamiltoniano efetivo para um elétron, a derivação do método k.p e a obtenção das matrizes que descrevem os cristais com simetria zincblende (ZB) e/ou wurtzita (WZ).

\subsection{Derivação do método k.p}

O nosso sistema é composto por elétrons sujeitos à ação de um potencial periódico, e para resolvê-lo usaremos o Hamiltoniano, incluindo efeitos de spin-órbita, que segue abaixo:

$$
H=\frac{p^{2}}{2 m_{o}}+V(\vec{r})+\frac{\hbar}{4 m_{o}^{2} c^{2}}(\vec{\nabla} V \times \vec{p}) \cdot \vec{\sigma}
$$

com o primeiro termo representando a energia cinética do elétron, o segundo, o potencial periódico do cristal e o terceiro, a interação spin-órbita. Note que $\vec{\sigma}$ são as matrizes de Pauli.

A equação de Schrödinger independente do tempo, para o sistema, na forma de equação de autovalores/autovetores, fica:

$$
H \Psi=\left[\frac{p^{2}}{2 m_{o}}+V(\vec{r})+\frac{\hbar}{4 m_{o}^{2} c^{2}}(\vec{\nabla} V \times \vec{p}) \cdot \vec{\sigma}\right] \Psi=E \Psi
$$


Usando o teorema de Bloch

$$
\Psi=\exp (i \vec{k} \cdot \vec{r}) u_{n \vec{k}}(\vec{r})
$$

com $u_{n \vec{k}}(\vec{r})$ um espinor tendo a periodicidade de $V(\vec{r}), \vec{k}$ limitado à primeira zona de Brillouin e $n$ sendo o índice da banda de energia, teremos:

$$
\left[\frac{p^{2}}{2 m_{o}}+V(\vec{r})+\frac{\hbar}{4 m_{o}^{2} c^{2}}(\vec{\nabla} V \times \vec{p}) \cdot \vec{\sigma}\right] e^{i \vec{k} \cdot \vec{r}} u_{n \vec{k}}(\vec{r})=E_{n}(\vec{k}) e^{i \vec{k} \cdot \vec{r}} u_{n \vec{k}}(\vec{r})
$$

Operando $\vec{p}=-i \hbar \vec{\nabla}$ em (2.1.3), a equação (2.1.4) fica:

$$
\begin{gathered}
{\left[\frac{p^{2}}{2 m_{o}}+V(\vec{r})+\frac{\hbar}{m_{o}} \vec{k} \cdot \vec{p}+\frac{\hbar^{2} k^{2}}{2 m_{o}}+\right.} \\
\left.\frac{\hbar}{4 m_{o}^{2} c^{2}}(\vec{\nabla} V \times \vec{p}) \cdot \vec{\sigma}+\frac{\hbar}{4 m_{o}^{2} c^{2}}(\vec{\nabla} V \times \vec{k}) \cdot \vec{\sigma}\right] u_{n \vec{k}}(\vec{r})=E_{n}(\vec{k}) u_{n \vec{k}}(\vec{r})
\end{gathered}
$$

A partir deste ponto vou desprezar o termo dependente de $\vec{k}$ da interação spin-órbita. Sua contribuição, para o sistemas que iremos estudar, é muito pequena. Note que a equação (2.1.5) pode ser reescrita da seguinte forma:

$$
\left[H\left(\vec{k}_{0}\right)+H(\vec{k})\right] u_{n \vec{k}}(\vec{r})=E_{n}(\vec{k}) u_{n \vec{k}}(\vec{r})
$$

onde $H\left(\vec{k}_{0}\right)$ é o Hamiltoniano do cristal em torno de um ponto de interesse.

Assim,

$$
\begin{gathered}
H\left(\vec{k}_{0}\right)=\frac{p^{2}}{2 m_{o}}+V(\vec{r})+\frac{\hbar}{m_{o}} \vec{k}_{0} \cdot \vec{p}+\frac{\hbar^{2} k_{0}^{2}}{2 m_{o}} \\
H(\vec{k})=\frac{\hbar}{m_{o}}\left(\vec{k}-\vec{k}_{0}\right) \cdot \vec{p}+\frac{\hbar^{2}\left(k^{2}-k_{0}^{2}\right)}{2 m_{o}}+\frac{\hbar}{4 m_{o}^{2} c^{2}}(\vec{\nabla} V \times \vec{p}) \cdot \vec{\sigma}
\end{gathered}
$$

A equação (2.1.6) é o nosso Hamiltoniano total do sistema. Queremos expressá-la em uma forma matricial e para isso precisamos escolher uma base.

Seguindo a seção 2.7 da Ref. (65) a escolha de base a ser feita são as funções de 
Luttinger-Kohn,

$$
e^{i\left(\vec{k}-\vec{k}_{0}\right) \cdot \vec{r}} u_{n \vec{k}_{0}}(\vec{r})
$$

pois elas formam um conjunto de base completo e ortonormal tanto para os pontos $\vec{k}$ quanto para as bandas, $n$. Dessa forma, sabendo os fatores de Bloch, $u_{n \vec{k}}(\vec{r})$, em $\vec{k}=\vec{k}_{0}$, podemos encontrar os outros fatores para qualquer ponto $\vec{k}$.

Para tornar as contas mais simples, vou introduzir a seguinte notação:

$$
\begin{aligned}
\langle\vec{r} \mid n \vec{k}\rangle & =u_{n \vec{k}}(\vec{r}) \\
\left\langle n^{\prime} \vec{k} \mid n \vec{k}\right\rangle & =\delta_{n^{\prime} n} \\
|n \vec{k}\rangle & =\sum_{n^{\prime}} c_{n^{\prime} n}\left(\vec{k}-\vec{k}_{0}\right)\left|n^{\prime} \vec{k}_{0}\right\rangle
\end{aligned}
$$

Portando o equação (2.1.6) é reescrita

$$
\left[H\left(\vec{k}_{0}\right)+H(\vec{k})\right]|n \vec{k}\rangle=E_{n}(\vec{k})|n \vec{k}\rangle
$$

Multiplicando a equação (2.1.13) inteira, pela esquerda, por $\left\langle n \vec{k}_{0}\right|$, teremos:

$$
\begin{aligned}
\left\langle n \vec{k}_{0}\left|\left[H\left(\vec{k}_{0}\right)+H(\vec{k})\right]\right| n \vec{k}\right\rangle= & \sum_{n^{\prime}} c_{n^{\prime} n}\left(\vec{k}-\vec{k}_{0}\right)\left[\left(E_{n}\left(\vec{k}_{0}\right)+\frac{\hbar^{2}\left(k^{2}-k_{0}^{2}\right)}{2 m_{o}}\right) \delta_{n^{\prime} n}\right. \\
& +\left\langle n \vec{k}_{0}\left|\frac{\hbar}{m_{o}}\left(\vec{k}-\vec{k}_{0}\right) \cdot \vec{p}\right| n^{\prime} \vec{k}_{0}\right\rangle \\
& \left.+\left\langle n \vec{k}_{0}\left|\frac{\hbar}{4 m_{o}^{2} c^{2}}(\vec{\nabla} V \times \vec{p}) \cdot \vec{\sigma}\right| n^{\prime} \vec{k}_{0}\right\rangle\right] \\
= & c_{n n}\left(\vec{k}-\vec{k}_{0}\right) E_{n}(\vec{k})
\end{aligned}
$$

\subsubsection{Tratamento via teoria de perturbação}

É interessante notar que a equação (2.1.14) é exata para todos os pontos $\vec{k}$ pertencentes à primeira zona de Brillouin. Apesar de ser exata não significa que resolvemos o sistema, porque ainda não sabemos escrever quem são seus elementos de matriz. Além do mais, não estamos interessados em resolver o problema para a zona de Brillouin inteira, mas para pontos 
$\vec{k}$ próximos à $\vec{k}_{0}$. Dessa forma, poderemos usar a teoria de perturbação independente do tempo para simplificar a equação (2.1.14).

O sistemas estudados aqui serão de semicondutores de gap direto, que possuem o máximo da banda de valência e o mínimo da banda de condução no ponto $\vec{k}=\overrightarrow{0}$, ou $\Gamma$. A expansão será feita em torno deste ponto.

Na equação (2.1.13) vimos que o Hamiltoniano do sistema está divido em duas partes, ou seja,

$$
H=H\left(\vec{k}_{0}\right)+H(\vec{k})
$$

uma, $H\left(\vec{k}_{0}\right)$, independente do vetor $\vec{k}$ e outra, $H(\vec{k})$, dependente.

Dessa forma, vamos considerar o termo dependente de $\vec{k}$ da expressão (2.1.15) como perturbação do termo independente de $\vec{k}$. Assim, segundo a teoria de perturbações (que detalhamos no apêndice $A$ ), obteremos a seguinte expressão para os elementos de matriz de $H$, levando em conta até a segunda ordem:

$$
\left\langle\alpha|H| \alpha^{\prime}\right\rangle=E_{\alpha} \delta_{\alpha \alpha^{\prime}}+\left\langle\alpha|H(\vec{k})| \alpha^{\prime}\right\rangle+\sum_{\beta}^{B} \frac{\langle\alpha|H(\vec{k})| \beta\rangle\left\langle\beta|H(\vec{k})| \alpha^{\prime}\right\rangle}{\left(E_{\alpha}-E_{\beta}\right)}
$$

com $\alpha$ e $\alpha^{\prime}$ os estados que iremos descrever e $\beta$ os estados que atuam perturbativamente.

Mais especificamente, vamos considerar como perturbação em primeira ordem todos os termos de $H(\vec{k})$ e em segunda somente o termo k.p. Assim, ficaremos com a seguinte expressão:

$$
\begin{aligned}
\left\langle\alpha|H| \alpha^{\prime}\right\rangle= & \left(E_{\alpha}+\frac{\hbar^{2} k^{2}}{2 m_{0}}\right) \delta_{\alpha \alpha^{\prime}}+\left\langle\alpha\left|\frac{\hbar}{m_{0}} \vec{k} \cdot \vec{p}+\frac{\hbar}{4 m_{0}^{2} c^{2}}(\vec{\nabla} V \times \vec{p})\right| \alpha^{\prime}\right\rangle \\
& +\sum_{\beta}^{B} \frac{\left\langle\alpha\left|\frac{\hbar}{m_{0}} \vec{k} \cdot \vec{p}\right| \beta\right\rangle\left\langle\beta\left|\frac{\hbar}{m_{0}} \vec{k} \cdot \vec{p}\right| \alpha^{\prime}\right\rangle}{\left(E_{\alpha}-E_{\beta}\right)}
\end{aligned}
$$




\subsection{Matrizes do método k.p}

Uma forma elegante de obter a representação matricial do método k.p, dado pela equação (2.1.17), é usando a teoria de grupos (ver Faria Junior, dissertação de mestrado (67)). Dados os estados pertencentes à $\alpha$ e $\beta$, no ponto de expansão, e suas simetrias, é possível obter quais elementos de matriz são nulos e quais não são. Estes serão parametrizados.

A matriz do ZB, em sua forma usual $(68,69)$, é expressa de tal forma a favorecer os eixos que passam pelo vértices do cubo da figura 2.1. No entanto, como alguns sistemas com simetria ZB interessantes são crescidos na direção $[111](9,15,70)$ a representação matricial usual para o ZB não será conveniente.

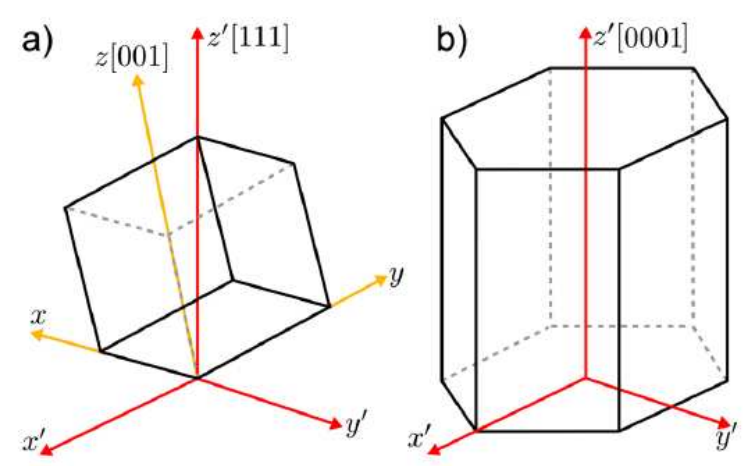

Figura 2.1 - Sistemas de coordenada para estruturas cristalinas com simetria ZB e WZ (17). a) Célula unitária convencional do ZB com o sistema de coordenadas usual, que passa pelos vértices do cubo, e o que passa pela diagonal principal do cubo. b) Célula unitária convencional da WZ com seu sistema de coordenadas usual.

Uma forma de expressar a matriz do ZB na direção [111] é descrita na referência (71), através de uma rotação dos vetores $\vec{k}$ do sistema e de uma rotação da base do ZB para a base da WZ. Em (17) os autores relacionam os elementos de matriz do Hamiltoniano do ZB, expressos na direção [111], com os elementos de matriz do Hamiltoniano da WZ, na direção convencional de crescimento [0001]; e tornam possível expressar tanto o ZB [111] como a WZ [0001] por um mesmo Hamiltoniano com os mesmos conjuntos de parâmetros.

\subsubsection{Zincblende}

Seguindo o trabalho de Luttinger (68), a forma matricial do método k.p para materiais com simetria ZB será expressa incluindo somente as três primeiras bandas de valência nos estados $\alpha$. Uma descrição mais completa, levando em conta tanto as bandas de valência 
quanto a de condução nos estados $\alpha$, pode ser encontrada no trabalho de Kane (69). Aqui, consideraremos a banda de condução parabólica.

Para parametrizar os elementos de matriz não nulos usa-se a base, com a inclusão do spin:

$$
\{|S \uparrow\rangle,|X \uparrow\rangle,|Y \uparrow\rangle,|Z \uparrow\rangle,|S \downarrow\rangle,|X \downarrow\rangle,|Y \downarrow\rangle,|Z \downarrow\rangle\}
$$

O bloco referente à banda de valência da matriz (2.1.17) expressa na base (2.2.1) é bloco diagonal (um bloco para spin up e outro para spin down) com a presença de um termo de acoplamento entre os blocos de spins opostos.

A forma mais comum de apresentar a matriz do método k.p no ponto $\Gamma$ é na base de momento angular, equação (2.2.2), que diagonaliza o termo de acoplamento spin-órbita no ponto $\Gamma$ mantendo a matriz diagonal no ponto de expansão.

$$
\begin{aligned}
\left|b_{1}\right\rangle & =\frac{1}{\sqrt{2}}|(X+i Y) \uparrow\rangle \\
\left|b_{2}\right\rangle & =\frac{i}{\sqrt{6}}|(X+i Y) \downarrow-2 Z \uparrow\rangle \\
\left|b_{3}\right\rangle & =\frac{1}{\sqrt{6}}|(X-i Y) \uparrow+2 Z \downarrow\rangle \\
\left|b_{4}\right\rangle & =\frac{i}{\sqrt{2}}|(X-i Y) \downarrow\rangle \\
\left|b_{5}\right\rangle & =\frac{1}{\sqrt{3}}|(X+i Y) \downarrow+Z \uparrow\rangle \\
\left|b_{6}\right\rangle & =\frac{i}{\sqrt{3}}|-(X-i Y) \uparrow+Z \downarrow\rangle \\
\left|b_{7}\right\rangle & =|S \uparrow\rangle \\
\left|b_{8}\right\rangle & =|S \downarrow\rangle
\end{aligned}
$$

com $i$ a unidade imaginária. Nos levando à representação matricial: 


$$
\left(\begin{array}{cccccccc}
Q & S & R & 0 & i \frac{S}{\sqrt{2}} & -i \sqrt{2} R & 0 & 0 \\
S^{\dagger} & T & 0 & R & i \frac{(T-Q)}{\sqrt{2}} & i \sqrt{\frac{3}{2}} S & 0 & 0 \\
R^{\dagger} & 0 & T & -S & -i \sqrt{\frac{3}{2}} S^{\dagger} & i \frac{(T-Q)}{\sqrt{2}} & 0 & 0 \\
0 & R^{\dagger} & -S^{\dagger} & Q & -i \sqrt{2} R^{\dagger} & -i \frac{S^{\dagger}}{\sqrt{2}} & 0 & 0 \\
-\frac{i S^{\dagger}}{\sqrt{2}} & i \frac{(Q-T)}{\sqrt{2}} & i \sqrt{\frac{3}{2}} S & i \sqrt{2} R & \frac{Q+T}{2}+\Delta & 0 & 0 & 0 \\
i \sqrt{2} R^{\dagger} & -i \sqrt{\frac{3}{2}} S^{\dagger} & i \frac{(Q-T)}{\sqrt{2}} & i \frac{S}{\sqrt{2}} & 0 & \frac{Q+T}{2}+\Delta & 0 & 0 \\
0 & & 0 & 0 & 0 & 0 & E_{g}+A k^{2} & 0 \\
0 & 0 & 0 & 0 & 0 & 0 & 0 & E_{g}+A k^{2}
\end{array}\right)
$$

com os termos da matriz dados por

$$
\begin{aligned}
Q & =-\left(\gamma_{1}+\gamma_{2}\right)\left(k_{x}^{2}+k_{y}^{2}\right)-k_{z}^{2}\left(\gamma_{1}-2 \gamma_{2}\right) \\
T & =\left(\gamma_{2}-\gamma_{1}\right)\left(k_{x}^{2}+k_{y}^{2}\right)-k_{z}^{2}\left(\gamma_{1}+2 \gamma_{2}\right) \\
R & =\sqrt{3}\left[2 i k_{x} k_{y} \gamma_{3}+\gamma_{2}\left(k_{x}^{2}-k_{y}^{2}\right)\right] \\
S & =2 \sqrt{3} i \gamma_{3} k_{z}\left(k_{x}-i k_{y}\right) \\
A & =\frac{1}{m_{e}^{*}}
\end{aligned}
$$

onde $\gamma_{1,2,3}$ são os parâmetros de massa efetiva da banda de valência, $\Delta$ é o splitting de energia devido à interação spin-órbita, $E_{g}$ é o gap de energia do material e $m_{e}^{*}$ é a massa efetiva da banda de condução. A referência de energia é o topo da banda de valência no ponto $\Gamma$.

\subsubsection{Wurtzita}

Para sistemas cristalinos de simetria WZ nós nos basearemos no artigo de Chuang (72). A mesma base, dada pela equação (2.2.1), é usada para parametrizar os elementos de matriz.

Da mesma forma que no ZB, a parte das bandas de valência da matriz (2.1.17) expressa na base (2.2.1) é bloco diagonal (um bloco para spin up e outro para spin down) com a presença de um termo de acoplamento entre os blocos de spin opostos.

A forma mais comum de apresentar a matriz é na base que diagonaliza o splitting do 
campo cristalino no ponto $\Gamma$, equação (2.2.5).

$$
\begin{aligned}
\left|c_{1}\right\rangle & =-\frac{1}{\sqrt{2}}|(X+i Y) \uparrow\rangle \\
\left|c_{2}\right\rangle & =\frac{1}{\sqrt{2}}|(X-i Y) \uparrow\rangle \\
\left|c_{3}\right\rangle & =|Z \uparrow\rangle \\
\left|c_{4}\right\rangle & =\frac{1}{\sqrt{2}}|(X-i Y) \downarrow\rangle \\
\left|c_{5}\right\rangle & =-\frac{1}{\sqrt{2}}|(X+i Y) \downarrow\rangle \\
\left|c_{6}\right\rangle & =|Z \downarrow\rangle \\
\left|c_{7}\right\rangle & =i|S \uparrow\rangle \\
\left|c_{8}\right\rangle & =i|S \downarrow\rangle
\end{aligned}
$$

com $i$ a unidade imaginária.

A representação matricial de (2.1.17) na base (2.2.5) é:

$$
\left(\begin{array}{cccccccc}
F & -K^{\dagger} & -H^{\dagger} & 0 & 0 & 0 & 0 & 0 \\
-K & G & H & 0 & 0 & \Delta & 0 & 0 \\
-H & H^{\dagger} & \lambda & 0 & \Delta & 0 & 0 & 0 \\
0 & 0 & 0 & F & -K & H & 0 & 0 \\
0 & 0 & \Delta & -K^{\dagger} & G & -H^{\dagger} & 0 & 0 \\
0 & \Delta & 0 & H^{\dagger} & -H & \lambda & 0 & 0 \\
0 & 0 & 0 & 0 & 0 & 0 & C_{k} & 0 \\
0 & 0 & 0 & 0 & 0 & 0 & 0 & C_{k}
\end{array}\right)
$$

com os termos da matriz dados por 


$$
\begin{aligned}
F & =\Delta_{1}+\Delta_{2}+\lambda+\theta \\
G & =\Delta_{1}-\Delta_{2}+\lambda+\theta \\
\lambda & =A_{1} k_{z}^{2}+A_{2}\left(k_{x}^{2}+k_{y}^{2}\right) \\
\theta & =A_{3} k_{z}^{2}+A_{4}\left(k_{x}^{2}+k_{y}^{2}\right) \\
K & =A_{5} k_{+}^{2} \\
H & =A_{6} k_{+} k_{z} \\
\Delta & =\sqrt{2} \Delta_{3} \\
C_{k} & =E_{0}+E_{g}+e_{1} k_{z}^{2}+e_{2}\left(k_{x}^{2}+k_{y}^{2}\right) \\
e_{1} & =\frac{1}{m_{e}^{\|}} \\
e_{2} & =\frac{1}{m_{e}^{\perp}} \\
k_{ \pm} & =\left(k_{x} \pm i k_{y}\right)
\end{aligned}
$$

onde $A_{1, \cdots, 6}$ são os parâmetros de massa efetiva da banda de valência, $\Delta_{1}$ é o splitting de energia devido ao campo cristalino, $\Delta_{2,3}$ são os splittings de energia devido à interação spinórbita, $E_{g}$ é o gap de energia e $E_{0}$ é a referência de energia no ponto $\Gamma$.

\subsubsection{Expressando ZB [111] e WZ [0001] na mesma matriz}

Seguindo as referências $(17,71)$ podemos usar a base $(2.2 .5)$ para expressar tanto a WZ [0001], como já foi feito na subseção anterior, quanto o ZB [111]. A única diferença, é a introdução de um novo parâmetro, $A_{z}$, que é nulo para a WZ e não nulo para o ZB.

O elementos de matriz modificados são:

$$
\begin{aligned}
& K \rightarrow K+2 \sqrt{2} A_{z} k_{-} k_{z} \\
& H \rightarrow H+A_{z} k_{-}^{2}
\end{aligned}
$$

Os parâmetros do ZB se relacionam com os da WZ da seguinte forma: 


$$
\begin{aligned}
& \Delta_{1}=0 \\
& \Delta_{2}=\Delta_{3}=\frac{\Delta_{S O}}{3} \\
& A_{1}=-\gamma_{1}-4 \gamma_{3} \\
& A_{2}=-\gamma_{1}+2 \gamma_{3} \\
& A_{3}=6 \gamma_{3} \\
& A_{4}=-3 \gamma_{3} \\
& A_{5}=-\gamma_{2}-2 \gamma_{3} \\
& A_{6}=-\sqrt{2}\left(2 \gamma_{2}+\gamma_{3}\right) \\
& A_{7}=0 \\
& A_{z}=\gamma_{2}-\gamma_{3} \\
& m_{e}^{\|}=m_{e}^{\perp}=m_{e}^{*}
\end{aligned}
$$

E os parâmetros de rede são dados da seguinte maneira (16):

$$
\begin{aligned}
a & =a_{z b} / \sqrt{2} \\
c & =a_{z b} * \sqrt{3}
\end{aligned}
$$

com $a$ e $c$ os parâmetros de rede da WZ e $a_{z b}$ o do ZB. 


\section{Função envelope e expansão em ondas planas}

Para tratar sistemas cristalinos na presença de potenciais cuja periodicidade difere da periodicidade do cristal bulk, necessitaremos de uma abordagem mais abrangente do que o teorema de Bloch. Essa abordagem é o formalismo da função envelope (73-75).

Tratando as funções de onda como combinação dos fatores de Bloch de cada material e de funções que variam lentamente, as funções envelopes, obteremos um conjunto de equações acopladas para estas. Uma das várias formas de resolver esse sistema é usando a expansão em coeficientes de Fourier.

Neste capítulo desenvolvo um formalismo semelhante para tratar sistemas cristalinos formados pela junção de dois ou mais materiais semicondutores e apresentarei os passos principais para o entendimento do mesmo, bem como um método para a sua resolução.

\subsection{A aproximação da função envelope}

Quando dispomos dois ou mais materiais semicondutores em uma sequência, como mostrado na figura 3.1, surge um potencial devido à variação do gap dos materiais. Esse potencial irá afetar os portadores, mudando suas propriedades eletrônicas.

Considerarei que os materiais constituintes da heteroestrutura possuam parâmetros de rede suficientemente próximos para que possa se desprezar os efeitos de strain. Uma derivação com os efeitos de strain pode ser encontrada em $(72,77)$.

Adicionando o efeito de um potencial externo qualquer ao Hamiltoniano definido em (2.1.1), o sistema será agora descrito pelo seguinte Hamiltoniano:

$$
H=\frac{p^{2}}{2 m_{o}}+V(\vec{r})+\frac{\hbar}{4 m_{o}^{2} c^{2}}(\vec{\nabla} V \times \vec{p}) \cdot \vec{\sigma}+\phi(\vec{r})
$$




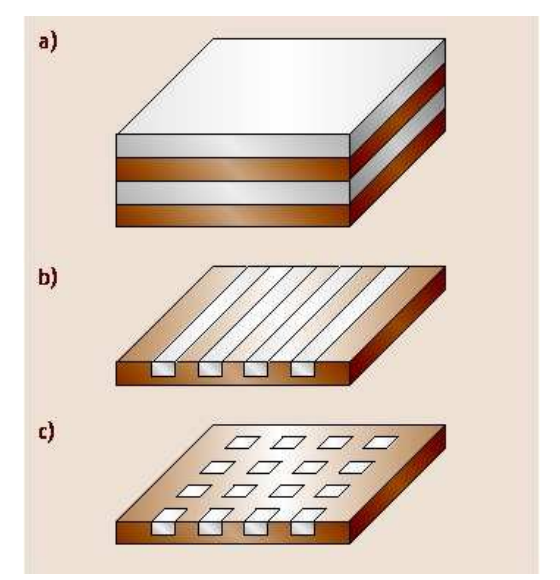

Figura 3.1 - Configurações das possíveis heteroestruturas (76). a) Poço quântico, b) Fio quântico e c) Ponto quântico.

com $\phi(\vec{r})$ o potencial externo.

Neste estudo tratarei $\phi(\vec{r})$ como o potencial que descreve a variação do gap dos materiais, mas na realidade ele pode ser qualquer potencial externo ao sistema que não possua a mesma periodicidade do cristal bulk.

Claramente, as funções de Luttinger-Kohn, (2.1.9), já não formam mais uma base para o Hamiltoniano (3.1.1). Na realidade a função de onda será expandida da seguinte forma:

$$
\Psi(\vec{r})=\sum_{n, m} f_{n}^{m}(\vec{r}) u_{n, \vec{k}_{0}}^{m}(\vec{r})
$$

com $f_{n}(\vec{r})$ sendo a função envelope, $n$, o índice das bandas de energia e $m$, o dos materiais. Por expressar o potencial externo, a função envelope varia mais lentamente que os fatores de Bloch, ou seja, ela modula os fatores de Bloch no domínio da heteroestrutura. Podemos pensar no formalismo da função envelope como uma generalização do teorema de Bloch, (2.1.3), visto que trocamos as exponenciais pela função envelope, $f(\vec{r})$.

Dentro de cada material, a função de onda será expandida em termos de seus fatores de Bloch e da sua contribuição da função envelope, equação (3.1.2). Estamos levando em conta a variação dos fatores de Bloch para cada material, visto que, apesar de considerar parâmetros de redes parecidos, estamos interessados em observar a variação dos termos da matriz k.p ao longo das junções. Baraff e Gershoni (74) argumentam que, apesar de não obterem matematicamente as condições de continuidade para a função envelope, a imposição de hermiticidade no Hamiltoniano final é suficiente para garanti-la. 
Portanto, podemos reescrever a equação (3.1.2) da seguinte maneira:

$$
\Psi(\vec{r})=\sum_{n, m} f_{n}(\vec{r}) u_{n, \vec{k}_{0}}^{m}(\vec{r})
$$

omitindo o índice da função envelope que discrimina a variação nos materiais.

\subsection{Matriz k.p na aproximação da função envelope}

Dada a ortogonalidade da base (apêndice B) vamos calcular os elementos de matriz pertinentes para se obter a representação matricial de (2.1.17) na nova base.

Usando o Hamiltoniano (3.1.1) teremos:

$$
\begin{aligned}
\left\langle F_{m}, m|H| F_{n}, n\right\rangle= & \left\langle F_{m}, m\left|\frac{P^{2}}{2 m_{o}}+V(\vec{R})\right| F_{n}, n\right\rangle \\
& +\left\langle F_{m}, m\left|\frac{\hbar}{4 m_{o}^{2} c^{2}}(\vec{\nabla} V(\vec{R}) \times \vec{p}) \cdot \vec{\sigma}\right| F_{n}, n\right\rangle \\
& +\left\langle F_{m}, m|\phi(\vec{R})| F_{n}, n\right\rangle
\end{aligned}
$$

Vamos calcular cada elemento de matriz separadamente e observar suas peculiaridades. Começando pelo Hamiltoniano não perturbado:

$$
\begin{aligned}
\left\langle F_{m}, m\left|H_{0}\right| F_{n}, n\right\rangle= & \left\langle F_{m}, m\left|\frac{P^{2}}{2 m_{o}}+V(\vec{R})\right| F_{n}, n\right\rangle \\
= & \frac{1}{2 m_{0}}\left\langle F_{m}, m\left|\frac{P^{2}}{2 m_{o}}\right| F_{n}, n\right\rangle+\left\langle F_{m}, m|V(\vec{R})| F_{n}, n\right\rangle \\
= & \left\langle F_{m}\left|\left(\frac{P^{2 m n}(\vec{R})}{2 m_{0}}+V^{m n}(\vec{R})\right)\right| F_{n}\right\rangle \\
& +\frac{1}{2 m_{0}}\left[\langle m \mid n\rangle\left\langle F_{m}\left|P^{2}\right| F_{n}\right\rangle+2\left\langle F_{m}\left|\vec{P}^{m n}(\vec{R}) \cdot \vec{P}\right| F_{n}\right\rangle\right]
\end{aligned}
$$

com 


$$
\begin{gathered}
\vec{P}^{m n}=\langle m|\vec{P}| n\rangle \\
P^{2 m n}=\left\langle m\left|P^{2}\right| n\right\rangle \\
V^{m n}(\vec{R})=\langle m|V(\vec{R})| n\rangle
\end{gathered}
$$

Neste ponto é valido observar que o elemento de matriz (3.2.2) deixou de ser hermitiano. Se fizermos a troca:

$$
\left\langle F_{m}\left|\vec{P}^{m n}(\vec{R}) \cdot \vec{P}\right| F_{n}\right\rangle \rightarrow \frac{1}{2}\left[\left\langle F_{m}\left|\vec{P}^{m n}(\vec{R}) \cdot \vec{P}\right| F_{n}\right\rangle+\left\langle F_{m}\left|\vec{P} \cdot \vec{P}^{m n}(\vec{R})\right| F_{n}\right\rangle\right]
$$

o elemento (3.2.2) volta a ser hermitiano. A simetrização linear surge como um requisito para manter a hermiticidade.

Portanto:

$$
\begin{aligned}
\left\langle F_{m}, m\left|H_{0}\right| F_{n}, n\right\rangle= & \delta_{m n}\left\langle F_{m}\left|E_{0}^{n}(\vec{R})\right| F_{n}\right\rangle+\langle m \mid n\rangle\left\langle F_{m}\left|\frac{P^{2}}{2 m_{0}}\right| F_{n}\right\rangle \\
& +\left\langle F_{m}\left|\frac{\vec{P}^{m n}(\vec{R})}{2 m_{0}} \cdot \vec{P}+\vec{P} \cdot \frac{\vec{P}^{m n}(\vec{R})}{2 m_{0}}\right| F_{n}\right\rangle
\end{aligned}
$$

O termo de spin-órbita dará a contribuição:

$$
\left\langle F_{m}, m\left|H_{S O}\right| F_{n}, n\right\rangle=\left\langle F_{m}\left|h_{S O}^{m n}(\vec{R})\right| F_{n}\right\rangle
$$

com

$$
h_{S O}^{m n}(\vec{R})=\left\langle m\left|\frac{\hbar}{4 m_{o}^{2} c^{2}}(\vec{\nabla} V(\vec{R}) \times \vec{p}) \cdot \vec{\sigma}\right| n\right\rangle
$$

Finalmente, o potencial externo nos dará a contribuição:

$$
\left\langle F_{m}, m|\phi(\vec{R})| F_{n}, n\right\rangle=\langle m \mid n\rangle\left\langle F_{m}\left|\phi^{n}(\vec{R})\right| F_{n}\right\rangle
$$


com a adição do super-índice $n$ expressando que cada banda de energia pode sofrer um efeito distinto do potencial externo.

Agora que temos os elementos de matriz calculados vamos aplicar a teoria de perturbação (ver detalhes no apêndice A). Nessa formulação, escolheremos duas classes de estados, ditas classes $A$ e $B$. Os estados pertencentes à classe $A$, denotados por $\alpha$, descreverão as bandas de energia de interesse, poderão interagir fortemente entre sí e interagirão fracamente com os da classe $B$. Os estados da classe $B$, denotados por $\beta$, conterão todas as outras bandas de energia do semicondutor e serão tratados como perturbação da classe $A$.

Assim, teremos a seguinte expressão:

$$
\sum_{\alpha}^{A}\left\{\delta_{\alpha^{\prime} \alpha} E_{0}^{\alpha}(\vec{R})+\delta_{\alpha^{\prime} \alpha} \phi^{\alpha}+h_{S O}^{\alpha^{\prime} \alpha}+H_{P}^{\alpha^{\prime} \alpha}+\sum_{\beta}^{B} h_{\beta}^{\alpha^{\prime} \alpha}\right\}\left|F_{\alpha}\right\rangle=E\left|F_{\alpha^{\prime}}\right\rangle
$$

com

$$
H_{P}^{\alpha^{\prime} \alpha}=\delta_{\alpha^{\prime} \alpha} \frac{P^{2}}{2 m_{0}}+\frac{1}{2 m_{0}}\left[\vec{P}^{\alpha^{\prime} \alpha}(\vec{R}) \cdot \vec{P}+\vec{P} \cdot \vec{P}^{\alpha^{\prime} \alpha}(\vec{R})\right]
$$

e

$$
h_{\beta}^{\alpha^{\prime} \alpha}=\sum_{i, j}^{x, y, z} P_{i}\left[\frac{\left(P_{i}^{\alpha^{\prime} \beta} P_{j}^{\beta \alpha}\right)(\vec{R})}{\Delta^{\alpha \beta}(\vec{R})}\right] P_{j}
$$

com $\Delta^{\alpha \beta}(\vec{R})$ sendo a diferença de energia entre os estados da classe $\mathrm{A}$ e B.

Podemos rearranjar os termos da equação (3.2.11) da seguinte forma:

$$
\begin{gathered}
\sum_{\alpha}^{A}\left\{\delta_{\alpha^{\prime} \alpha} E_{0}^{\alpha}(\vec{R})+\delta_{\alpha^{\prime} \alpha} \Phi^{\alpha}+h_{S O}^{\alpha^{\prime} \alpha}(\vec{R})+\delta_{\alpha^{\prime} \alpha} \frac{P^{2}}{2 m_{0}}\right. \\
\left.\frac{1}{2 m_{0}}\left[\vec{P}^{\alpha^{\prime} \alpha}(\vec{R}) \cdot \vec{P}+\vec{P} \cdot \vec{P}^{\alpha^{\prime} \alpha}(\vec{R})\right]+\sum_{i, j}^{x, y, z} P_{i}\left[\sum_{\beta}^{B} \tilde{P}_{i j}^{\alpha^{\prime} \beta \alpha}(\vec{R})\right] P_{j}\right\}\left|F_{\alpha}\right\rangle=E\left|F_{\alpha^{\prime}}\right\rangle
\end{gathered}
$$

com

$$
\tilde{P}_{i j}^{\alpha^{\prime} \beta \alpha}(\vec{R})=\frac{\left(P_{i}^{\alpha^{\prime} \beta} P_{j}^{\beta \alpha}\right)(\vec{R})}{\Delta^{\alpha \beta}(\vec{R})}
$$


Note que como a somatória em $i, j$ percorre $x, y, z$, a simetrização em segunda ordem aparece naturalmente.

Agrupando os termos da equação (3.2.14):

$$
\begin{gathered}
V^{\alpha^{\prime} \alpha}(\vec{R})=\delta_{\alpha^{\prime} \alpha} E_{0}^{\alpha}(\vec{R})+\delta_{\alpha^{\prime} \alpha} \Phi^{\alpha}(\vec{R})+h_{S O}^{\alpha^{\prime} \alpha}(\vec{R}) \\
K^{\alpha^{\prime} \alpha}(\vec{R})=\delta_{\alpha^{\prime} \alpha} \frac{P^{2}}{2 m_{0}}+\frac{1}{2 m_{0}}\left[\vec{P}^{\alpha^{\prime} \alpha}(\vec{R}) \cdot \vec{P}+\vec{P} \cdot \vec{P}^{\alpha^{\prime} \alpha}(\vec{R})\right]+\sum_{i, j}^{x, y, z} P_{i}\left[\sum_{\beta}^{B} \tilde{P}_{i j}^{\alpha^{\prime} \beta \alpha}(\vec{R})\right] P_{j} \\
=\frac{1}{2 m_{0}}\left[\vec{P}^{\alpha^{\prime} \alpha}(\vec{R}) \cdot \vec{P}+\vec{P} \cdot \vec{P}^{\alpha^{\prime} \alpha}(\vec{R})\right]+\sum_{i, j}^{x, y, z} P_{i} \gamma_{i j}^{\alpha^{\prime} \alpha}(\vec{R}) P_{j}
\end{gathered}
$$

com

$$
\gamma_{i j}^{\alpha^{\prime} \alpha}=\sum_{\beta}^{B}\left[\frac{\delta_{\alpha^{\prime} \alpha} \delta_{i j}}{2 m_{0}}+\tilde{P}_{i j}^{\alpha^{\prime} \beta \alpha}(\vec{R})\right]
$$

deixando a equação (3.2.14) mais sucinta:

$$
\sum_{\alpha}^{A}\left[K^{\alpha^{\prime} \alpha}(\vec{R})+V^{\alpha^{\prime} \alpha}(\vec{R})\right]\left|F_{\alpha}\right\rangle=E\left|F_{\alpha^{\prime}}\right\rangle
$$

\subsection{Expansão em ondas planas}

Existem diversas maneiras de se tratar a equação (3.2.19). Aqui eu usarei a expansão em ondas planas, mais conhecida como expansão em coeficientes de Fourier. O método é computacionalmente custoso, mas trata sistemas realísticos.

Do ponto de vista matemático, as ondas planas formam um conjunto completo e ortonormal com a primeira e segunda derivadas inclusas no conjunto (74). O fato das derivadas estarem presentes no conjunto é especialmente bem vindo já que temos que resolver um sistema de equações acopladas com derivadas até segunda ordem. Além disso, automaticamente teremos condições de contorno periódicas.

Expandindo todos os termos necessários, teremos: 


$$
\begin{aligned}
& V^{\alpha^{\prime} \alpha}(\vec{r})=\sum_{\overrightarrow{K^{\prime}}} e^{i \vec{K}^{\prime} \cdot \vec{r}} V_{\vec{K}^{\prime}}^{\alpha^{\prime} \alpha} \\
& \vec{P}^{\alpha^{\prime} \alpha}(\vec{r})=\sum_{\overrightarrow{K^{\prime}}} e^{i \overrightarrow{K^{\prime}} \cdot \vec{r}} \vec{P}_{\vec{K}^{\prime}}^{\alpha^{\prime} \alpha}
\end{aligned}
$$

e

$$
\gamma_{i j}^{\alpha^{\prime} \alpha}(\vec{r})=\sum_{\overrightarrow{K^{\prime}}} e^{i \overrightarrow{K^{\prime}} \cdot \vec{r}} \gamma_{i j, \vec{K}^{\prime}}^{\alpha^{\prime} \alpha}
$$

Como estou tratando um sistema composto por mais de um material irei introduzir o conceito de super-célula. Do mesmo jeito que as funções de Bloch são periódicas no célula unitária de um cristal bulk as funções envelopes serão periódicas na super-célula formada pela junção desses materiais com um espaço recíproco discretizado pela variável $\vec{k}$, assim:

$$
\begin{aligned}
f_{\alpha \vec{k}}(\vec{r}) & =e^{i \vec{k} \cdot \vec{r}} g_{\alpha}(\vec{r}) \\
& =e^{i \vec{k} \cdot \vec{r}} \sum_{\vec{K}} e^{i \vec{K} \cdot \vec{r}} g_{\alpha \vec{K}}(\vec{k}) \\
& =\sum_{\vec{K}} e^{i(\vec{k}+\vec{K}) \cdot \vec{r}} g_{\alpha \vec{K}}(\vec{k})
\end{aligned}
$$

Reescrevendo a equação (3.2.19) no espaço real, teremos:

$$
\sum_{\alpha}^{A}\left[K^{\alpha^{\prime} \alpha}(\vec{r})+V^{\alpha^{\prime} \alpha}(\vec{r})\right] f_{\alpha}(\vec{r})=E f_{\alpha^{\prime}}(\vec{r})
$$

Aplicando as expansões (3.3.1) a (3.3.4) em (3.3.5), teremos:

$$
\begin{aligned}
\vec{p} f_{\alpha \vec{k}}(\vec{r}) & =-i \hbar \vec{\nabla}\left[\sum_{\vec{K}} e^{i(\vec{k}+\vec{K}) \cdot \vec{r}} g_{\alpha \vec{K}}(\vec{k})\right] \\
& =\hbar \sum_{\vec{K}}(\vec{k}+\vec{K}) g_{\alpha \vec{K}}(\vec{k}) e^{i(\vec{k}+\vec{K}) \cdot \vec{r}}
\end{aligned}
$$




$$
\begin{aligned}
\vec{p} \cdot\left[\vec{P}^{\alpha^{\prime} \alpha}(\vec{r}) f_{\alpha \vec{k}}(\vec{r})\right] & =-i \hbar \vec{\nabla}\left[\sum_{\overrightarrow{K^{\prime}}} e^{i \overrightarrow{K^{\prime}} \cdot \vec{r}} \vec{P}_{\vec{K}^{\prime}}^{\alpha^{\prime} \alpha} \sum_{\vec{K}} e^{i(\vec{k}+\vec{K}) \cdot \vec{r}} g_{\alpha \vec{K}}(\vec{k})\right] \\
& =\hbar \sum_{\vec{K}} \sum_{\vec{K}^{\prime}}\left[\left(\vec{k}+\vec{K}+\overrightarrow{K^{\prime}}\right) \cdot \vec{P}_{\vec{K}^{\prime}}^{\alpha^{\prime} \alpha}\right] g_{\alpha \vec{K}}(\vec{k}) e^{i\left(\vec{k}+\vec{K}+\vec{K}^{\prime}\right) \cdot \vec{r}}
\end{aligned}
$$

$$
\begin{aligned}
{\left[p_{l} \gamma_{l m}^{\alpha^{\prime} \alpha}(\vec{r}) p_{m}\right] f_{\alpha \vec{k}}(\vec{r}) } & =\left\{p_{l}\left[\sum_{\overrightarrow{K^{\prime}}} e^{i \overrightarrow{K^{\prime} \cdot \vec{r}}} \gamma_{l m, \vec{K}^{\prime}}^{\alpha^{\prime} \alpha}\right] p_{m}\right\}\left[\sum_{\vec{K}} e^{i(\vec{k}+\vec{K}) \cdot \vec{r}} g_{\alpha \vec{K}}(\vec{k})\right] \\
& =\hbar^{2} \sum_{\vec{K}} \sum_{\vec{K}^{\prime}}\left(k_{l}+K_{l}+K_{l}^{\prime}\right)\left(k_{m}+K_{m}\right) \gamma_{l m, \vec{K}^{\prime}}^{\alpha^{\prime} \alpha \vec{K}}(\vec{k}) e^{i\left(\vec{k}+\vec{K}+\vec{K}^{\prime}\right) \cdot \vec{r}}
\end{aligned}
$$

portanto

$$
\begin{aligned}
& \sum_{\alpha}^{A}\left\{\frac{1}{2 m_{0}} \hbar \sum_{\overrightarrow{K^{\prime}}}\left[e^{i \overrightarrow{K^{\prime}} \cdot \vec{r}} \vec{P}_{\vec{K}^{\prime}}^{\alpha^{\prime} \alpha}\right] \cdot\left[\sum_{\vec{K}}(\vec{k}+\vec{K}) g_{\alpha \vec{K}}(\vec{k}) e^{i(\vec{k}+\vec{K}) \cdot \vec{r}}\right]\right. \\
& +\quad \frac{1}{2 m_{0}} \hbar \sum_{\vec{K}} \sum_{\vec{K}^{\prime}}\left(\vec{k}+\vec{K}+\overrightarrow{K^{\prime}}\right) \cdot \vec{P}_{\vec{K}^{\prime}}^{\alpha^{\prime} \alpha} g_{\alpha \vec{K}}(\vec{k}) e^{i\left(\vec{k}+\vec{K}+\vec{K}^{\prime}\right) \cdot \vec{r}} \\
& +\quad \hbar^{2} \sum_{l, m} \sum_{\vec{K}} \sum_{K^{\prime}}\left(k_{l}+K_{l}+K_{l}^{\prime}\right)\left(k_{m}+K_{m}\right) \gamma_{l m, \vec{K}^{\prime}}^{\alpha^{\prime} \alpha} g_{\alpha \vec{K}}(\vec{k}) e^{i\left(\vec{k}+\vec{K}+\vec{K}^{\prime}\right) \cdot \vec{r}} \\
& \left.+\quad\left[\sum_{\overrightarrow{K^{\prime}}} e^{i \overrightarrow{K^{\prime}} \cdot \vec{r}} V_{\vec{K}^{\prime}}^{\alpha^{\prime} \alpha}\right]\left[\sum_{\vec{K}} e^{i(\vec{k}+\vec{K}) \cdot \vec{r}} g_{\alpha \vec{K}}(\vec{k})\right]\right\} \\
& =\quad E(\vec{k}) \sum_{\vec{K}} e^{i(\vec{k}+\vec{K}) \cdot \vec{r}} g_{\alpha^{\prime} \vec{K}}(\vec{k})
\end{aligned}
$$

Rearranjando os termos: 


$$
\begin{aligned}
& \sum_{\alpha}^{A} \sum_{\vec{K} \vec{K}^{\prime}} \sum\left\{\vec{P}_{\vec{K}^{\prime}}^{\alpha^{\prime} \alpha} \cdot\left[\frac{(\vec{k}+\vec{K})+\left(\vec{k}+\vec{K}+\vec{K}^{\prime}\right)}{2 m_{0}}\right]\right. \\
& +\quad \hbar^{2} \sum_{l, m}\left(k_{l}+K_{l}+K_{l}^{\prime}\right)\left(k_{m}+K_{m}\right) \gamma_{l m, \vec{K}^{\prime}}^{\alpha^{\prime} \alpha} \\
& \left.+\quad V_{\vec{K}^{\prime}}^{\alpha^{\prime} \alpha}\right\} g_{\alpha \vec{K}}(\vec{k}) e^{i\left(\vec{K}+\vec{K}^{\prime}\right) \cdot \vec{r}} \\
& =\quad E(\vec{k}) \sum_{\vec{K}} g_{\alpha^{\prime} \vec{K}}(\vec{k}) e^{i \vec{K} \cdot \vec{r}}
\end{aligned}
$$

Se definirmos um novo vetor de rede recíproca

$$
\vec{G}=\vec{K}+\overrightarrow{K^{\prime}} \Rightarrow \overrightarrow{K^{\prime}}=\vec{G}-\vec{K}
$$

e novamente rearranjarmos os termos, ficaremos com:

$$
\begin{aligned}
& \sum_{\alpha}^{A} \sum_{\vec{K}}\left\{V_{\vec{G}-\vec{K}}^{\alpha^{\prime} \alpha}+\hbar \vec{P}_{\vec{G}-\vec{K}}^{\alpha^{\prime} \alpha} \cdot\left[\frac{(\vec{k}+\vec{K})+(\vec{k}+\vec{G})}{2 m_{0}}\right]\right. \\
& \left.+\quad \hbar^{2} \sum_{l, m}\left(k_{l}+G_{l}\right)\left(k_{m}+K_{m}\right) \gamma_{l m, \vec{G}-\vec{K}}^{\alpha^{\prime} \alpha}\right\} g_{\alpha \vec{K}}(\vec{k}) \\
& =E(\vec{k}) g_{\alpha^{\prime} \vec{G}}(\vec{k})
\end{aligned}
$$

Como os índices das somatórias são mudos, podemos trocar $\vec{K}$ por $\overrightarrow{K^{\prime}}$ e depois $\vec{G}$ por $\vec{K}$ e definir a quantidade $\Delta \vec{K}=\vec{K}-\vec{K}^{\prime}$. Assim, teremos as expansão final em ondas planas da equação (3.3.5):

$$
\begin{aligned}
& \sum_{\alpha}^{A} \sum_{\vec{K}^{\prime}}\left\{V_{\Delta \vec{K}}^{\alpha^{\prime} \alpha}+\hbar \vec{P}_{\Delta \vec{K}}^{\alpha^{\prime} \alpha} \cdot\left[\frac{\left(\vec{k}+\vec{K}^{\prime}\right)+(\vec{k}+\vec{K})}{2 m_{0}}\right]\right. \\
& \left.+\quad \hbar^{2} \sum_{l, m}\left(k_{l}+K_{l}\right)\left(k_{m}+K_{m}^{\prime}\right) \gamma_{l m, \Delta \vec{K}}^{\alpha^{\prime} \alpha}\right\} g_{\alpha \overrightarrow{K^{\prime}}}(\vec{k}) \\
& =E(\vec{k}) g_{\alpha^{\prime} \vec{K}}(\vec{k})
\end{aligned}
$$

$\operatorname{com} V_{\Delta \vec{K}}^{\alpha^{\prime} \alpha}=\delta_{\alpha^{\prime} \alpha} E_{0, \Delta \vec{K}}^{\alpha}+\delta_{\alpha^{\prime} \alpha} \Phi_{\Delta \vec{K}}^{\alpha}+h_{S O, \Delta \vec{K}}^{\alpha^{\prime} \alpha}$ 
Note que, matricialmente:

$$
\begin{gathered}
\vec{K} \rightarrow|\vec{K}\rangle \rightarrow \text { índice das linhas } \\
\overrightarrow{K^{\prime}} \rightarrow\left\langle\vec{K}^{\prime}\right| \rightarrow \text { índice das colunas }
\end{gathered}
$$

A equação (3.3.13) expressa a forma matricial final do conjunto de equações acopladas para as funções envelopes, no espaço recíproco, que descreverão o comportamento do nosso sistema. 


\section{Propriedades derivadas da estrutura de bandas}

Na presença de luz, sistemas semicondutores apresentam características distintas em seu espectro de luminescência. Éxcitons são criados de acordo com regras de transição específicas que dependem tanto da estrutura eletrônica quanto das funções de ondas do sistema. É de se esperar que o espectro de absorção do material mude com os efeitos de confinamento quântico, já que tanto sua estrutura eletrônica quanto suas funções de onda mudam.

Nesta seção, apresento os passos principais de como se tratar a interação da luz com a matéria e obter uma expressão para o poder de absorção para sistemas semicondutores no formalismo da função envelope $(52,78,79)$. Além disso, como uma forma complementar de entender o espectro de absorção, irei analisar as contribuições que cada termo do Hamiltoniano (3.3.13) tem na energia total (80).

\subsection{Poder de absorção}

Imagine um sistema semicondutor iluminado por um fonte de luz. O Hamiltoniano desse sistema é:

$$
H=H_{0}+H^{\prime}
$$

com $H_{0}$ sendo o Hamiltoniano descrito pela equação (3.3.13) e $H^{\prime}$ a interação da luz com a matéria.

Podemos considerar $H^{\prime}$ como: 


$$
\begin{aligned}
H^{\prime}(\vec{r}, t) & =-\frac{e}{m_{0}} \vec{A}(\vec{r}, t) \cdot \vec{p} \\
& =H^{\prime}(\vec{r}) e^{-i \omega t}+H^{\prime \dagger}(\vec{r}) e^{+i \omega t}
\end{aligned}
$$

com:

$$
H^{\prime}(\vec{r})=-\frac{e A_{0} e^{i \vec{k}_{o p} \cdot \vec{r}}}{2 m_{0}} \hat{e} \cdot \vec{p}
$$

Usando teoria de perturbações dependente do tempo podemos calcular qual a taxa de transição devido a essa interação, $H^{\prime}(\vec{r})$, dada pela regra de ouro de Fermi:

$$
W_{a b s}=\frac{2 \pi}{\hbar}\left|\left\langle a\left|H^{\prime}(\vec{r})\right| b\right\rangle\right|^{2} \delta\left(E_{b}-E_{a}-\hbar \omega\right)
$$

com $E_{b}>E_{a}$ para absorção e, similarmente, para emissão:

$$
W_{e m s}=\frac{2 \pi}{\hbar}\left|\left\langle a\left|H^{\prime}(\vec{r})\right| b\right\rangle\right|^{2} \delta\left(E_{a}-E_{b}+\hbar \omega\right)
$$

A taxa líquida por unidade de volume de haver uma transição por absorção é dada por:

$$
R=\frac{1}{V} \sum_{\vec{k}_{a}} \sum_{\vec{k}_{b}} \frac{2 \pi}{\hbar}\left|H_{a b}^{\prime}\right|^{2} \delta\left(E_{b}-\left[E_{a}+\hbar \omega\right]\right)\left(f_{a}-f_{b}\right)
$$

os fatores $f_{a}$ e $f_{b}$ são as distribuições de Fermi-Dirac:

$$
f=\frac{1}{1+e^{\left(E-E_{F}\right) / k_{B} T}}
$$

e levam em conta se o estado $a$ está ocupado e o $b$ desocupado, e as energias $E_{a}=E_{a}\left(\vec{k}_{a}\right)$ e $E_{b}=E_{b}\left(\vec{k}_{b}\right)$.

O coeficiente de absorção, ou poder de absorção, é dado por:

$$
\alpha(\hbar \omega)=\frac{\pi e^{2}}{n_{r} c \varepsilon_{0} m_{0}^{2} \omega} \frac{1}{V} \sum_{a, b} \sum_{\vec{k}}\left|\hat{e} \cdot \vec{p}_{a b}\right|^{2} \delta\left(E_{b}(\vec{k})-\left[E_{a}(\vec{k})+\hbar \omega\right]\right)\left(f_{a}-f_{b}\right)
$$


na aproximação de dipolo:

$$
A_{0} e^{i \vec{k}_{o p} \cdot \vec{r}} \approx A_{0}
$$

com

$$
\vec{p}_{a b}=\langle a|\vec{P}| b\rangle
$$

Quando levamos em conta a incerteza da transição para um determinado ponto $k$ ocorrerá uma suavização no espectro de absorção, essa suavização pode ser interpretada como a substituição da delta de Dirac por uma lorentziana:

$$
\frac{\Gamma^{2}}{4\left(E_{b}-E_{a}-\hbar \omega\right)^{2}+\Gamma^{2}}
$$

com $\Gamma$ a largura a meia altura.

\subsubsection{Força de oscilador}

Estamos interessados em calcular as transições entre as bandas de valência e condução do semicondutor. Para isso teremos que calcular o elemento de matriz (4.1.10) no formalismo da função envelope desenvolvido no capítulo 3.

A função de onda total será:

$$
\psi_{n \vec{k}}(\vec{r})=e^{i \vec{k} \cdot \vec{r}}\left[\sum_{v=1}^{6} g_{n, \vec{k}, v}(\vec{r}) u_{v}(\vec{r})+\sum_{c=1}^{2} g_{n, \vec{k}, c}(\vec{r}) u_{c}(\vec{r})\right]
$$

onde $g_{n, \vec{k}, v(c)}(\vec{r})$ são as funções envelope para um estado de base pertencente a $n$-ésima subbanda de valência (condução) do ponto $\vec{k}$ e $u_{v(c)}(\vec{r})$ é o fator de Bloch associado ao estado de base da banda de valência (condução).

Na notação de Dirac:

$$
\langle\vec{r} \mid n \vec{k}\rangle=\psi_{n \vec{k}}(\vec{r})
$$


$\operatorname{com} \psi_{n \vec{k}}$ dado pela equação (4.1.12). Não confundir este ket que representa a função de onda total no formalismo da função envelope, com o ket (2.1.12) que representa função de onda para o caso bulk.

Reescrevendo o elemento de matriz (4.1.10), teremos:

$$
\begin{aligned}
\langle m \vec{k}|\vec{P}| n \vec{k}\rangle= & \int \mathrm{d}^{3} r e^{-i \vec{k} \cdot \vec{r}}\left[\sum_{\tilde{v}=1}^{6} g_{m, \vec{k}, \tilde{v}}^{*}(\vec{r}) u_{\tilde{v}}^{*}(\vec{r})+\sum_{\tilde{c}=1}^{2} g_{m, \vec{k}, \tilde{c}}^{*}(\vec{r}) u_{\tilde{c}}^{*}(\vec{r})\right] \\
& \times \vec{p} \cdot e^{i \vec{k} \cdot \vec{r}}\left[\sum_{v=1}^{6} g_{n, \vec{k}, v}(\vec{r}) u_{v}(\vec{r})+\sum_{c=1}^{2} g_{n, \vec{k}, c}(\vec{r}) u_{c}(\vec{r})\right]
\end{aligned}
$$

Calculando separadamente cada contribuição:

$$
\begin{aligned}
p_{\alpha} \psi_{n \vec{k}}(\vec{r})= & p_{\alpha}\left\{e^{i \vec{k} \cdot \vec{r}}\left[\sum_{v=1}^{6} g_{n, \vec{k}, v}(\vec{r}) u_{v}(\vec{r})+\sum_{c=1}^{2} g_{n, \vec{k}, c}(\vec{r}) u_{c}(\vec{r})\right]\right\} \\
= & {\left[p_{\alpha} e^{i \vec{k} \cdot \vec{r}}\right]\left[\sum_{v=1}^{6} g_{n, \vec{k}, v}(\vec{r}) u_{v}(\vec{r})+\sum_{c=1}^{2} g_{n, \vec{k}, c}(\vec{r}) u_{c}(\vec{r})\right] } \\
& +e^{i \vec{k} \cdot \vec{r}}\left\{p_{\alpha}\left[\sum_{v=1}^{6} g_{n, \vec{k}, v}(\vec{r}) u_{v}(\vec{r})+\sum_{c=1}^{2} g_{n, \vec{k}, c}(\vec{r}) u_{c}(\vec{r})\right]\right\} \\
= & e^{i \vec{k} \cdot \vec{r}}\left\{\hbar k_{\alpha}\left[\sum_{v=1}^{6} g_{n, \vec{k}, v}(\vec{r}) u_{v}(\vec{r})+\sum_{c=1}^{2} g_{n, \vec{k}, c}(\vec{r}) u_{c}(\vec{r})\right]\right. \\
& +\sum_{v=1}^{6}\left[p_{\alpha} g_{n, \vec{k}, v}(\vec{r})\right] u_{v}(\vec{r})+\sum_{v=1}^{6} g_{n, \vec{k}, v}(\vec{r})\left[p_{\alpha} u_{v}(\vec{r})\right] \\
& \left.+\sum_{c=1}^{2}\left[p_{\alpha} g_{n, \vec{k}, c}(\vec{r})\right] u_{c}(\vec{r})+\sum_{c=1}^{2} g_{n, \vec{k}, c}(\vec{r})\left[p_{\alpha} u_{c}(\vec{r})\right]\right\}
\end{aligned}
$$

$\operatorname{com} \alpha=x, y, z$

Portanto: 


$$
\begin{aligned}
\langle m \vec{k}|\vec{P}| n \vec{k}\rangle= & \int \mathrm{d}^{3} r\left\{\sum_{\tilde{v}=1}^{6} \sum_{v=1}^{6} g_{m, \vec{k}, \tilde{v}}^{*}(\vec{r}) u_{\tilde{v}}^{*}(\vec{r}) g_{n, \vec{k}, v}(\vec{r})\left[p_{\alpha} u_{v}(\vec{r})\right]\right. \\
& +\sum_{\tilde{c}=1}^{2} \sum_{c=1}^{2} g_{m, \vec{k}, \tilde{c}}^{*}(\vec{r}) u_{\tilde{c}}^{*}(\vec{r}) g_{n, \vec{k}, c}(\vec{r})\left[p_{\alpha} u_{c}(\vec{r})\right] \\
& +\sum_{\tilde{v}=1}^{6} \sum_{v=1}^{6} g_{m, \vec{k}, \tilde{v}}^{*}(\vec{r}) u_{\tilde{v}}^{*}(\vec{r})\left[p_{\alpha} g_{n, \vec{k}, v}(\vec{r})\right] u_{v}(\vec{r}) \\
& \left.+\sum_{\tilde{c}=1}^{2} \sum_{c=1}^{2} g_{m, \vec{k}, \tilde{c}}^{*}(\vec{r}) u_{\tilde{c}}^{*}(\vec{r})\left[p_{\alpha} g_{n, \vec{k}, c}(\vec{r})\right] u_{c}(\vec{r})\right\} \\
= & \sum_{l, \tilde{l}=1}^{8}\left\{\int_{\Omega} \mathrm{d}^{3} r g_{m, \vec{k}, \tilde{l}}^{*}(\vec{r}) g_{n, \vec{k}, l}(\vec{r}) P_{\alpha}^{\tilde{l} l}(\vec{r})\right\}
\end{aligned}
$$

com $P_{\alpha}^{\tilde{l l}}$ dado por (3.2.3).

Para chegarmos na equação (4.1.16), usamos a relação de ortogonalidade dada pela equação (B.0.14). Esta relação separa a contribuição do fator de Bloch da contribuição da função envelope, visto que esta varia mais lentamente.

Note, também que os índices que percorriam as funções envelopes separadamente $(c$ e $v$, $\tilde{c}$ e $\tilde{v}$ ) foram agrupados em dois novos índices, $l$ e $\tilde{l}$. Assim, quando calcularmos o elemento de matriz é só ter em mente que estamos interessados entre transições das bandas de valência com as bandas de condução.

Em uma forma mais sucinta, desprezando a variação de $P_{\alpha}^{\tilde{l} l}$ :

$$
\left\langle n_{c} \vec{k}|\vec{P}| n_{v} \vec{k}\right\rangle=\sum_{i j=1}^{8} M_{c, v, \vec{k}}^{i j} P_{\alpha}^{i j}
$$

com

$$
M_{c, v, \vec{k}}^{i j}=\int \mathrm{d}^{3} r g_{c, \vec{k}, i}^{*}(\vec{r}) g_{v, \vec{k}, j}(\vec{r})
$$

Assim, a força de oscilador será:

$$
f_{c, v}^{\alpha}(\vec{k}) \propto\left|\left\langle n_{c} \vec{k}|\vec{P}| n_{v} \vec{k}\right\rangle\right|^{2}
$$

Resolvendo para transições mediadas por $p_{x}, p_{y}$ e $p_{z}$ na base (2.2.5) para o Hamiltoniano (2.2.6), obteremos: 


$$
\begin{gathered}
f_{c, v}^{x}(\vec{k}) \propto\left|M_{\vec{k}}^{71}-M_{\vec{k}}^{72}-M_{\vec{k}}^{84}+M_{\vec{k}}^{85}\right|^{2} \\
f_{c, v}^{y}(\vec{k}) \propto\left|i\left(M_{\vec{k}}^{71}+M_{\vec{k}}^{72}+M_{\vec{k}}^{84}+M_{\vec{k}}^{85}\right)\right| \\
f_{c, v}^{z}(\vec{k}) \propto\left|M_{\vec{k}}^{73}+M_{\vec{k}}^{86}\right|^{2}
\end{gathered}
$$

De tal forma que o poder de absorção dado pela equação (4.1.8) pode ser reescrito como:

$$
\alpha(\hbar \omega)=\frac{C_{0}}{\omega} \sum_{i, j=1}^{8} \sum_{\vec{k}}\left|\hat{e} \cdot M_{c, v, \vec{k}}^{i, j}\right|^{2} \frac{\Gamma^{2}}{4\left(E_{c}-E_{v}-\hbar \omega\right)^{2}+\Gamma^{2}}
$$

com $i, j$ percorrendo os 8 estados de base (2.2.2) da nossa formulação, $E_{c}, E_{v}$ as energias da banda de condução e valência no determinado ponto $\vec{k}$, o versor $\hat{e}$ especificará a direção da polarização e $C_{0}$ agrupará todas as constantes da formulação.

\subsubsection{Grau de polarização linear}

Podemos definir o grau de polarização linear como:

$$
\rho=\frac{\alpha^{\|}-\alpha^{\perp}}{\alpha^{\|}+\alpha^{\perp}}
$$

e $\alpha$ é o coeficiente de absorção. Por simplicidade, iremos assumir que a radiação incidente se propaga com $\vec{k} \perp \hat{z}$ e as polarizações paralela e perpendicular serão em $\hat{z}$ e $\hat{x}$ (ou $\hat{y}$ ), respectivamente.

Assumindo que as amplitudes do campo elétrico da radiação incidente sejam iguais para as duas polarizações, $\vec{E}_{\infty}^{\|}=\vec{E}_{\infty}^{\perp}$, queremos calcular qual a intensidade desse campo elétrico dentro do material. Como o semicondutor é um material dielétrico, o campo elétrico com polarização perpendicular sofrerá uma redução em seu valor dada por $(57,58)$ :

$$
\delta=\frac{2 \varepsilon_{0}}{\varepsilon_{0}+\varepsilon}
$$


com $\varepsilon$ a constante dielétrica do semicondutor e $\varepsilon_{0}$ a do meio que o cerca.

Resumindo, o campo elétrico dentro do material será:

$$
\begin{aligned}
\vec{E}_{i n}^{\|} & =\vec{E}_{\infty}^{\|} \\
\vec{E}_{i n}^{\perp} & =\delta \vec{E}_{\infty}^{\perp}
\end{aligned}
$$

esse é o efeito do confinamento ótico.

Dessa maneira, como o coeficiente de absorção depende da intensidade do campo elétrico, teremos:

$$
\rho=\frac{\alpha^{\|}-\delta^{2} \alpha^{\perp}}{\alpha^{\|}+\delta^{2} \alpha^{\perp}}
$$

A equação (4.1.28) leva em conta os efeitos de confinamento quântico e ótico.

\subsection{Contribuições de energia}

Estamos interessados em analisar quais estados de base contribuem mais para a formação das bandas de valência no ponto $\Gamma$ de um fio quântico em WZ. Para tal, vamos calcular o seguinte elemento de matriz:

$$
\langle n \vec{k}|H| n \vec{k}\rangle=\sum_{l=1}^{6} \sum_{m=1}^{6}\left\langle F_{l}, c_{l}\left|H_{l, m}\right| F_{m}, c_{m}\right\rangle
$$

com $H_{l, m}$ sendo os elementos do Hamiltoniano parametrizado da equação (3.3.13) expandida em ondas planas no plano de confinamento $x y$ : 


$$
\left(\begin{array}{cccccc}
\tilde{F}+V_{\text {het }} & -\tilde{K}^{\dagger} & 0 & 0 & 0 & 0 \\
-\tilde{K} & \tilde{G}+V_{h e t} & 0 & 0 & 0 & \Delta \\
0 & 0 & \tilde{\lambda}+V_{\text {het }} & 0 & \Delta & 0 \\
0 & 0 & 0 & \tilde{F}+V_{\text {het }} & -\tilde{K} & 0 \\
0 & 0 & \Delta & -\tilde{K}^{\dagger} & \tilde{G}+V_{\text {het }} & 0 \\
0 & \Delta & 0 & 0 & 0 & \tilde{\lambda}+V_{\text {het }}
\end{array}\right)
$$

com

$$
\begin{aligned}
\tilde{F} & =\Delta_{1}(x, y)+\Delta_{2}(x, y)+\tilde{\lambda}+\tilde{\theta} \\
\tilde{G} & =\Delta_{1}(x, y)-\Delta_{2}(x, y)+\tilde{\lambda}+\tilde{\theta} \\
\tilde{\lambda} & =A_{2}(x, y)\left(k_{x}^{2}+k_{y}^{2}\right) \\
\tilde{\theta} & =A_{4}(x, y)\left(k_{x}^{2}+k_{y}^{2}\right) \\
\tilde{K} & =A_{5} k_{+}^{2} \\
\Delta & =\sqrt{2} \Delta_{3}(x, y)
\end{aligned}
$$

Fazendo $V_{\text {het }} \rightarrow V_{\text {het }}(x, y)$, potencial da heteroestrutura, e mudando a ordem dos elementos de base de (2.2.5) para $\left|c_{1}\right\rangle,\left|c_{2}\right\rangle,\left|c_{6}\right\rangle,\left|c_{4}\right\rangle,\left|c_{5}\right\rangle,\left|c_{3}\right\rangle$, teremos a seguinte matriz:

$$
\left(\begin{array}{cccccc}
\tilde{F}+V_{\text {het }} & -\tilde{K}^{\dagger} & 0 & 0 & 0 & 0 \\
-\tilde{K} & \tilde{G}+V_{\text {het }} & \Delta & 0 & 0 & 0 \\
0 & \Delta & \tilde{\lambda}+V_{\text {het }} & 0 & 0 & 0 \\
0 & 0 & 0 & \tilde{F}+V_{\text {het }} & -\tilde{K} & 0 \\
0 & 0 & 0 & -\tilde{K}^{\dagger} & \tilde{G}+V_{\text {het }} & \Delta \\
0 & 0 & 0 & 0 & \Delta & \tilde{\lambda}+V_{\text {het }}
\end{array}\right)
$$

portanto, restringimos as interações entre os elementos de base.

Como os estados são bi-degenerados em spin e $H_{l, m}=H_{m, l}^{\dagger}$, as contribuições fora da diagonal serão da forma $2 R e\left(\left\langle F_{l}, l\left|H_{l m}\right| F_{m}, m\right\rangle\right)$. Então: 


$$
\begin{aligned}
\langle n \vec{k}|H| n \vec{k}\rangle= & \left\langle F_{1}, c_{1}\left|H_{11}\right| F_{1}, c_{1}\right\rangle+2 \operatorname{Re}\left(\left\langle F_{1}, c_{1}\left|H_{12}\right| F_{2}, c_{2}\right\rangle\right) \\
& +\left\langle F_{2}, c_{2}\left|H_{22}\right| F_{2}, c_{2}\right\rangle+2 \operatorname{Re}\left(\left\langle F_{2}, c_{2}\left|H_{26}\right| F_{6}, c_{6}\right\rangle\right) \\
& +\left\langle F_{6}, c_{6}\left|H_{66}\right| F_{6}, c_{6}\right\rangle \\
& +\left\langle F_{4}, c_{4}\left|H_{44}\right| F_{4}, c_{4}\right\rangle+2 \operatorname{Re}\left(\left\langle F_{4}, c_{4}\left|H_{45}\right| F_{5}, c_{5}\right\rangle\right) \\
& +\left\langle F_{5}, c_{5}\left|H_{55}\right| F_{5}, c_{5}\right\rangle+2 \operatorname{Re}\left(\left\langle F_{5}, c_{3}\left|H_{53}\right| F_{3}, c_{3}\right\rangle\right) \\
& +\left\langle F_{3}, c_{3}\left|H_{33}\right| F_{3}, c_{3}\right\rangle
\end{aligned}
$$

ou

$$
\begin{aligned}
\langle n \vec{k}|H| n \vec{k}\rangle= & \left\langle F_{1}\left|\tilde{F}+V_{\text {het }}\right| F_{1}\right\rangle+2 \operatorname{Re}\left(\left\langle F_{1}\left|-\tilde{K}^{\dagger}\right| F_{2}\right\rangle\right) \\
& +\left\langle F_{2}\left|\tilde{G}+V_{\text {het }}\right| F_{2}\right\rangle+2 \operatorname{Re}\left(\left\langle F_{2}|\Delta| F_{6}\right\rangle\right) \\
& +\left\langle F_{6}\left|\tilde{\lambda}+V_{\text {het }}\right| F_{6}\right\rangle \\
& +\left\langle F_{4}\left|\tilde{F}+V_{\text {het }}\right| F_{4}\right\rangle+2 \operatorname{Re}\left(\left\langle F_{4}|-\tilde{K}| F_{5}\right\rangle\right) \\
& +\left\langle F_{5}\left|\tilde{G}+V_{\text {het }}\right| F_{5}\right\rangle+2 \operatorname{Re}\left(\left\langle F_{5}|\Delta| F_{3}\right\rangle\right) \\
& +\left\langle F_{3}\left|\tilde{\lambda}+V_{\text {het }}\right| F_{3}\right\rangle
\end{aligned}
$$




\section{Uma abordagem paralela}

O uso de placas gráficas, em aplicações científicas que exigem alto desempenho, está em ascensão. Um dos primeiros exemplos de uso de computação de propósito geral em placas gráficas (GPGPU, do inglês General-purpose graphics processing unit) remonta ao final da década de 80 (81).

Em 2006 a NVIDIA, fabricante de placas gráficas, introduziu a CUDA ${ }^{T M}$, do inglês Compute Unified Device Architecture, uma plataforma e modelo de programação paralela implementada em suas GPUs. Apesar de recente, ela já está bem estabelecida, contando com implementações de várias bibliotecas computacionais amplamente usadas no meio científico (82).

Essa tecnologia foi introduzida no mercado por dois novos produtos: o chip G80 e a CUDA. O G80 foi o primeiro chip gráfico com suporte a programação de propósito geral em C, através do modelo de programação introduzido pela CUDA. Além disso, foi introduzido o modelo de execução SIMT (do inglês Single-instruction Multiple-Thread).

Neste capítulo introduzo conceitos úteis para o entendimento básico da arquitetura e do modelo de programação das GPUs da NVIDIA.

\subsection{Arquitetura das placas gráficas}

A arquitetura das placas gráficas vem evoluindo à passos largos. Impulsionada pelo mercado de jogos eletrônicos, cada vez mais realistas, as placas gráficas se tornaram peças fundamentais no processamento paralelo de alto desempenho.

Uma medida do poder de processamento é o flop/s (do inglês, Floating-Point operations per second), que mede quantas operações de ponto flutuante são realizadas por segundo. As placas gráficas atuais alcançam picos de execução de 3 Tflop/s (teraflops) contra 500 Gflop/s (gigaflops) que um único processador alcança (83).

Essa discrepância é devida à razão entre transistores dedicados ao processamento e à 

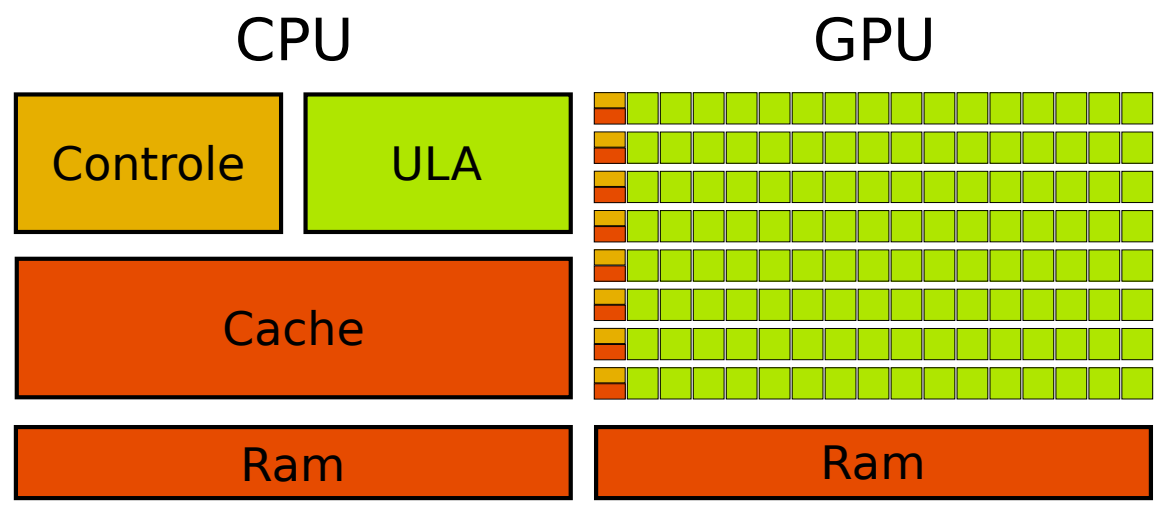

Figura 5.1 - Distribuição de transistores nas CPUs e GPUs. Vemos, a esquerda, o esquema básico de uma CPU: praticamente metade dos transistores são dedicados à memória (cache) e o restante dividido entre controle e processamento; já as GPUs, a direita, possuem praticamente todos os transistores voltados para processamento (83).

memória. Uma visão esquemática da distribuição de transistores em uma GPU e em uma CPU (do inglês, Central processing unit) é mostrada na figura 5.1. Deixando claro o motivo das GPUs serem usadas para processamento maciçamente paralelo.

Tendo em mente o desenvolvimento rápido que a arquitetura das placas gráficas vêm sofrendo, eu me focarei, especialmente, na arquitetura denominada FERMI ${ }^{T M}$.

\subsubsection{FERMI}

As GPUs da família FERMI possuem até 512 CUDA cores (unidade básica de processamento da placa gráfica), organizados em até 16 SMs (do inglês, Stream Multiprocessor) com 32 CUDA cores cada.

A figura 5.2 mostra em detalhes a disposição dos componentes em um chip FERMI. Os SMs são a peça fundamental das GPUs. Eles possuem um escalonador que distribui a carga de serviço para as unidades de processamento adequadas: os cores para processamento geral, as unidades Load/Store para cálculo de endereçamento e as unidades de funções especiais para cálculo de funções transcendentais como, por exemplo, senos e cossenos.

Além das unidades de processamento listadas acima, os SMs contam com um espaço de memória local, configurável e de $64 \mathrm{~KB}$. Esse espaço pode ser separado em 48 KB para memória compartilhada e $16 \mathrm{~KB}$ de cache L1 ou vice-versa. O seu uso correto é decisivo para a obtenção de um bom desempenho. 


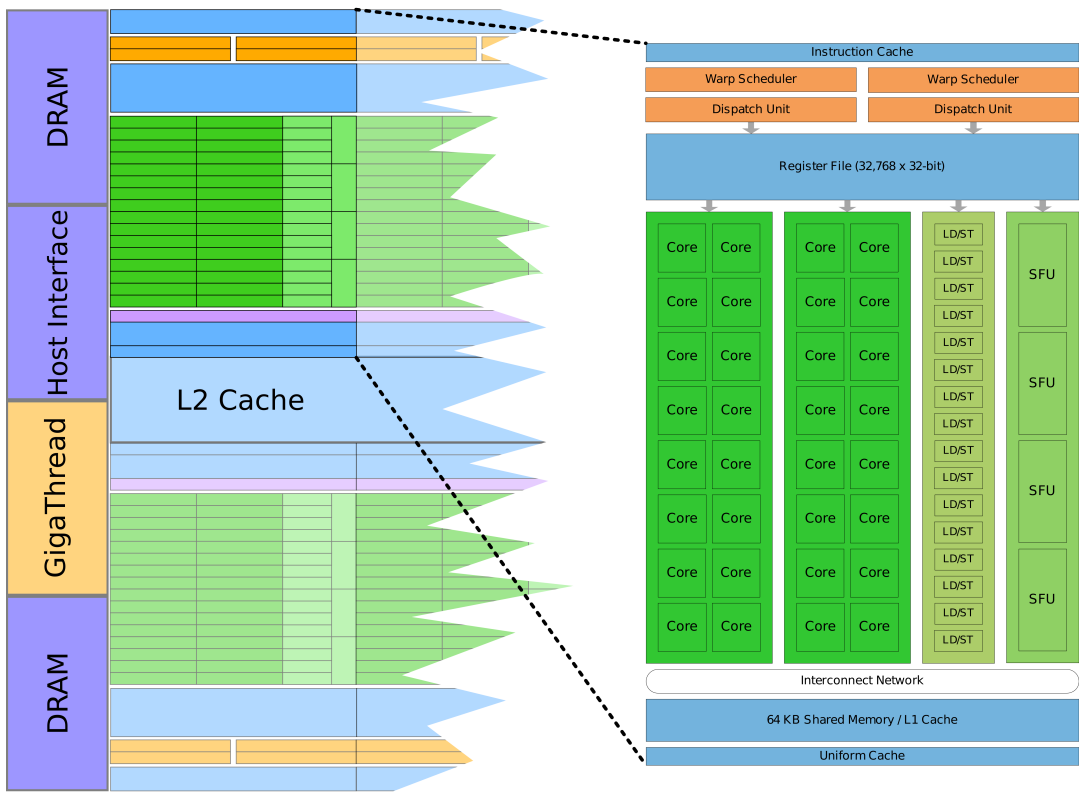

Figura 5.2 - Arquitetura dos chips FERMI. Cada faixa contem: porção verde que represente as unidades de processamento, porção laranja representando o escalonador local e uma porção azul clara representando os registradores e o cache L1. A parte laranja lateral é o escalonador global que distribuirá a execução entre os multiprocessadores. Em destaque está um esquema detalhado de um SM, mostrando todas as suas unidades fundamentais (84).

\subsection{Modelo de programação}

Para ser um modelo de programação escalável, a CUDA se baseia em três abstrações básicas: hierarquia de memória, hierarquia de threads e barreiras de sincronização.

Em termos de granularidade, ou seja, se o problema pode, ou não, ser sub-dividido em pequenas partes, independentes e de execução rápida, essas três abstrações são ideais para contemplar todos os tipos de problemas.

As diretivas de programação em CUDA levam o programador a seguir as abstrações. Primeiramente um problema alvo é sub-divido em partes de granularidade grossa que serão tratados pelos blocos de threads e, por sua vez, esses blocos são sub-divididos em problemas com granularidade fina que serão tratados pelas threads de um bloco, então, a hierarquia de threads, figura 5.3(a), é satisfeita.

A hierarquia de memória segue esse mesmo padrão, possuindo espaços de memórias acessíveis somente para as threads de um mesmo bloco e espaços gerais para os blocos de threads, como visto na figura $5.3(\mathrm{~b})$.

As sincronizações ocorrem tanto entre threads de um mesmo bloco, evitando problemas 
de escrita/leitura fora de ordem, quanto entre blocos de threads evitando que cálculos subsequentes prossigam antes do previsto.

Portanto, uma vez feita a modelagem do problema em seus sub-problemas, os blocos de threads podem ser executados em qualquer ordem e por qualquer SM disponível em uma dada placa, como visto na figura 5.3(c); tornando, assim, o modelo de programação realmente escalável. 


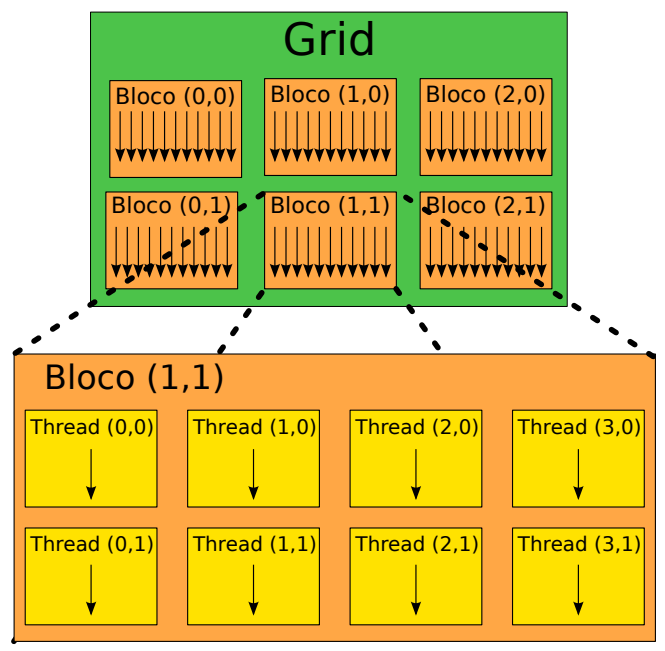

(a) Hierarquia de threads .

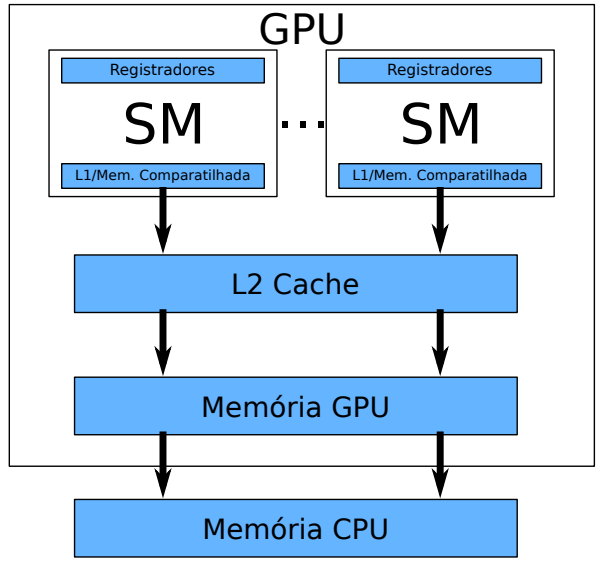

(b) Hierarquia de memória nas GPUs.

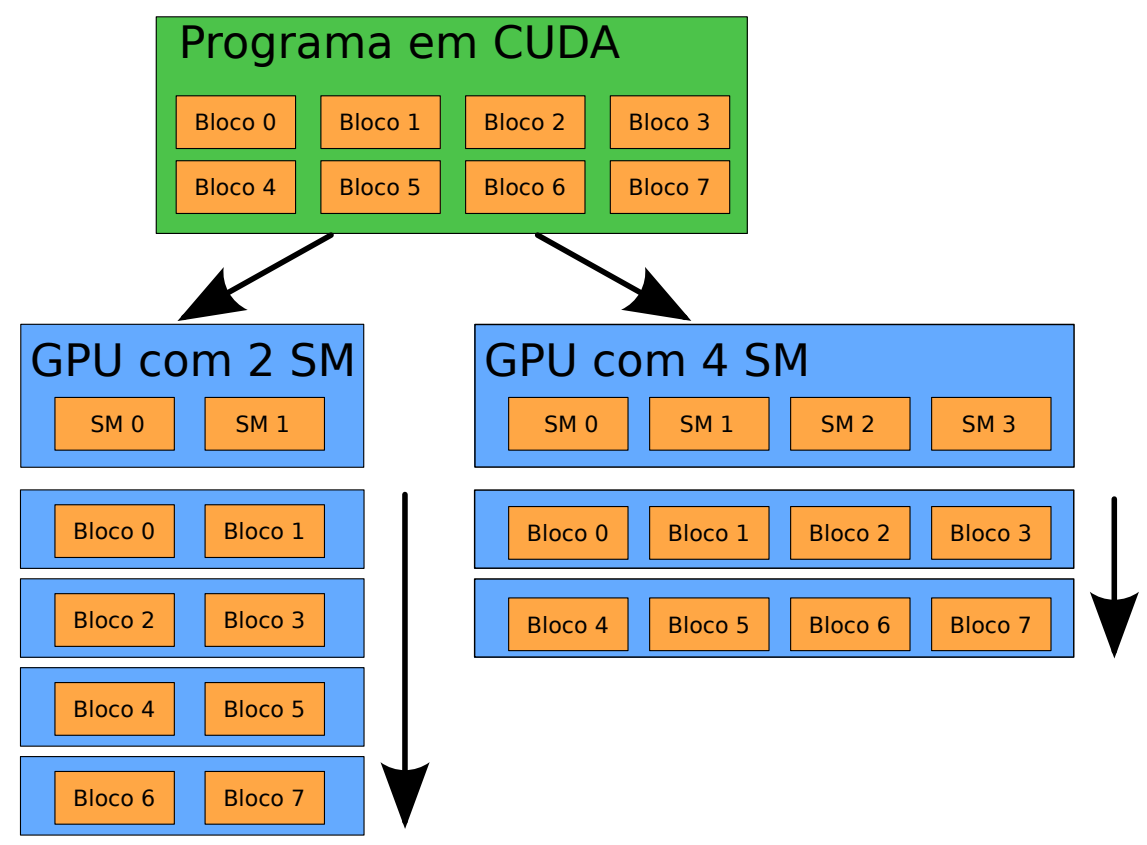

(c) Escalabilidade.

Figura 5.3 - As abstrações do modelo de programação. a) cada programa possui uma sub-divisão em blocos threads que por sua vez são sub-divididos em threads que cooperam na execução; b) Os espaços dentro de um SM são reservados para acessos das threads de um bloco. Já os espaços fora de um SM são para acessos globais; c) a GPU organiza a execução dos blocos de threads automaticamente, distribuindo a carga de trabalho entre os SMs. 


\section{O método de minimização}

Sistemas lineares de equações diferenciais aparecem frequentemente em modelos físicos, e nem sempre possuem soluções analíticas. Para resolvermos o problema numericamente é comum transformarmos estes sistemas em um problema de autovalores e autovetores. Assim podemos obter a solução diagonalizando a matriz formada pelos coeficientes das equações.

Existem diversos métodos, tanto diretos quanto iterativos, na literatura que lidam com a resolução desses sistemas, veja por exemplo Axelsson (85). Dentre eles o que nós escolhemos é uma adaptação do famoso método iterativo do Gradiente Conjugado (86) (CG, do inglês conjugate gradient) chamado LOBPCG (87) (do inglês Locally Optimal Block Preconditioned Conjugate Gradient).

Este capítulo se concentra na apresentação do método de minimização LOBPCG. Veremos como um problema de autovalores e autovetores se relaciona com um sistema linear, e viceversa. Apresentarei uma solução iterativa para sistemas lineares através de minimizações consecutivas seguindo direções específicas. Por fim sua generalização em um método robusto de cálculos de auto pares será apresentada.

\subsection{Sistemas lineares como um problema de diagona- lização}

Imagine que uma modelagem de seu sistema físico resultou em um sistema da forma:

$$
A x_{i}=\lambda_{i} x_{i}
$$

com $A$ uma matriz de dimensão $n \times n, x_{i}$ seus autovetores, $\lambda_{i}$ seus autovalores e $i=1 \cdots n$.

Suponha que exista uma matriz $T$ de tal forma que: 


$$
\begin{aligned}
T^{-1} A T & =\lambda_{i} I_{n} \\
A T & =T\left(\lambda_{i} I_{n}\right) \\
A & =T\left(\lambda_{i} I_{n}\right) T^{-1}
\end{aligned}
$$

com $I_{n}$ uma matriz identidade $n \times n$, e $T$ é formada pelos autovetores, $x_{i}$, de $A$. Assim, decompomos a matriz $A$ em sua forma canônica.

Queremos mostrar que 6.1.1 é equivalente ao sistema abaixo

$$
A y_{i}=b_{i}
$$

com $A$ uma matriz, de dimensão $n \times n$, cujas entradas são conhecidas, $y_{i}$ um vetor desconhecido e $b_{i}$ um vetor conhecido.

Portanto, basta reescrever a equação (6.1.5) usando (6.1.4) da seguinte maneira:

$$
\begin{array}{r}
T\left(\lambda_{i} I_{n}\right) T^{-1} y_{i}=b_{i} \\
\left(\lambda_{i} I_{n}\right) T^{-1} y_{i}=T^{-1} b_{i} \\
\left(\lambda_{i} I_{n}\right) \tilde{y}_{i}=\tilde{b}_{i}
\end{array}
$$

Como a mesma transformação linear, $T^{-1}$, está sendo aplicada em $y_{i}$ e $b_{i}$, resolver o sistema (6.1.5) é equivalente a resolver o sistema (6.1.8). Note que o fato de diagonalizarmos a matriz $A$, nos deixa com um sistema resolvido visto que $\lambda_{i} I_{n}$ é diagonal.

\subsection{Resolução iterativa}

Como vimos na seção anterior, se quisermos resolver uma sistema linear basta diagonalizar a matriz dos coeficientes, e vice-versa. Assim, nossos esforços se voltam para o estudo de métodos eficientes de resolução de sistemas lineares.

A família mais proeminente de métodos é a do Gradiente Conjugado, ideal para a solução 
de sistemas lineares do tipo:

$$
A x-b=0
$$

com $x$ um vetor desconhecido, $b$ um vetor conhecido e $A$ uma matriz conhecida com algumas especificações.

\subsubsection{Preliminares}

Para sabermos que restrições devem ser impostas à matriz $A$, considere: i) o CG é um método de minimização e, assim sendo, ele procurará pela solução do sistema (6.2.1) que mais se aproxima da solução real; ii) portanto, o sistema necessita, obrigatoriamente, de possuir um mínimo. Para isso, considere a seguinte forma quadrática:

$$
f(x)=\frac{1}{2} x^{T} A x-b^{T} x+c
$$

onde $A$ é uma matriz, e $x$ e $b$ são vetores e $c$ uma constante escalar.

Assuma que

$$
\min _{x \in \mathbb{R}^{n}} f(x)=f\left(x^{*}\right)
$$

nos leva ao sistema $A x^{*}=b$.

Então, para $\forall h \in \mathbb{R}^{n}$ :

$$
\begin{aligned}
f(x+h)-f(x) & =\frac{1}{2}(x+h)^{T} A(x+h)-b^{T}(x+h)-\frac{1}{2} x^{T} A x+b^{T} x \\
& =\frac{1}{2} h^{T} A h+\frac{1}{2} x^{T} A h+\frac{1}{2} h^{T} A x-b^{T} h
\end{aligned}
$$

Se $A$ for simétrica

$$
f(x+h)-f(x)=\frac{1}{2} h^{T} A h+h^{T}(A x-b)
$$

Se $x=x^{*}$ e $A$, além de simétrica, positiva definida; ou seja, $x^{T} A x \geq 0 \forall x \in \mathbb{R}^{n}$, teremos: 


$$
f\left(x^{*}+h\right)-f\left(x^{*}\right)=\frac{1}{2} h^{T} A h>0 \text { se } h \neq 0
$$

ou em outras palavras, minimizado a forma quadrática (6.2.2) e resolvido o sistema (6.2.1).

Resumindo, $A$ precisa ser

- quadrada;

- simétrica;

- positiva definida.

\subsubsection{Minimizando iterativamente}

Suponha que exista um conjunto

$$
\mathbb{S}=\left\{s_{1}, s_{2}, \cdots, s_{k}, \cdots\right\}
$$

de direções disponíveis e linearmente independentes e um ponto inicial $x_{0}$.

Para cada iteração queremos o $\alpha$ que minimize $x_{k}=x_{k-1}+\alpha s_{k}$, ou seja, que nos leve a um vetor mais próximo do mínimo de (6.2.2). Então, seguindo os passos da seção (6.2.1) e definindo o vetor resíduo $r_{j}=b-A x_{j}$, teremos:

$$
f\left(x_{k}\right)-f\left(x_{k-1}\right)=\frac{\alpha^{2}}{2} s_{k}^{T} A s_{k}-\alpha s_{k}^{T} r_{k-1}
$$

Minimizando $\alpha$, ou seja, tomando a derivada com relação a $\alpha$ da lado direito da equação e igualando a zero, teremos:

$$
\begin{aligned}
\frac{d}{d \alpha}\left(\frac{\alpha^{2}}{2} s_{k}^{T} A s_{k}-\alpha s_{k}^{T} r_{k-1}\right) & =0 \\
\alpha & =\frac{s_{k}^{T} r_{k-1}}{s_{k}^{T} A s_{k}}
\end{aligned}
$$

Assim a equação (6.2.9) se torna:

$$
f\left(x_{k}\right)=f\left(x_{k-1}\right)-\frac{\alpha}{2} s_{k}^{T} A s_{k}
$$




\subsubsection{Steepest descent}

Uma das possíveis escolhas de direções que formarão o conjunto (6.2.8) são as formadas pela negação do gradiente da forma quadrática (6.2.2):

$$
s=-\nabla f(x)=b-A x
$$

Portanto, escolhendo $s_{k}=b-A x_{k-1}=r_{k-1}$ recuperaremos o algoritmo do Steepest descent (descida mais acentuada):

- Entre com $x_{0}, r_{0}=b-A x_{0}$ e $s_{1}=r_{0}$

- $s_{k}=r_{k-1}=b-A x_{k-1}$

- $\alpha=\frac{r_{k-1 k}^{T} r_{k-1}}{r_{k-1}^{T} A r_{k-1}}$

- $x_{k}=x_{k-1}+\alpha_{k} s_{k}$

\subsubsection{Gradiente Conjugado}

Um dos problemas com o método descrito acima é que várias vezes ele acabada tomando uma direção de busca que já foi usada anteriormente. Isso torna o método difícil de convergir para a solução global. Para resolver este problema considere as seguintes etapas (uma demostração mais completa do método pode ser encontrada na Ref. (86)):

Começando do vetor $x_{0}$ e tomando $k-1$ passos teremos:

$$
\begin{aligned}
x_{k-1} & =x_{0}+\sum_{i=1}^{k-1} \alpha_{i} s_{i} \\
& =x_{0}+\bar{x}
\end{aligned}
$$

Substituindo (6.2.15) em (6.2.12) teremos:

$$
\begin{aligned}
f\left(x_{k}\right) & =f\left(x_{k-1}\right)+\frac{\alpha^{2}}{2} s_{k}^{T} A s_{k}-\alpha s_{k}^{T} r_{k-1} \\
& =f\left(x_{0}+\bar{x}\right)+\frac{\alpha^{2}}{2} s_{k}^{T} A s_{k}-\alpha s_{k}^{T} r_{k-1} \\
& =f\left(x_{0}+\bar{x}\right)+\frac{\alpha^{2}}{2} s_{k}^{T} A s_{k}-\alpha s_{k}^{T} r_{0}+\alpha s_{k}^{T} A \bar{x}
\end{aligned}
$$


Portanto vemos que surge um termo a mais, $\alpha s_{k}^{T} A \bar{x}$, que mistura a nova direção de minimização com as anteriores. A grande ideia por traz do método é fazer esse termo desaparecer, ou seja, tornar as direções $A$-ortogonais ou $A$-conjugadas:

$$
s_{k}^{T} A \bar{x}=0
$$

A construção da nova direção de busca é, usualmente, escrita como:

$$
s_{k}=r_{k-1}+\beta_{k} s_{k-1}
$$

com

$$
\beta_{k}=-\frac{s_{k-1}^{T} A r_{k-1}}{s_{k-1}^{T} A s_{k-1}}
$$

Existe mais de uma forma de se construir as novas direções de minimização e os autovetores deste algoritmo, porém todas se baseiam na $A$-conjugação das direções.

Vale notar que se as direções de minimização forem formadas pelos resíduos, este algoritmo se torna o steepest descent.

\subsubsection{Pré-Condicionador}

O sucesso de qualquer método de solução iterativo está nas propriedades da matriz de coeficientes, principalmente na distribuição de seus autovalores. Se a matriz possuir um espectro espalhado, ou seja, não estiver concentrado em torno de algum valor específico, a taxa de convergência do método será ruim.

Será que existe algum meio de concentrar os autovalores da matriz em torno de algum ponto específico?

A resposta é sim, existe tal meio. Através do uso de pré-condicionadores.

Imagine agora um novo sistema linear:

$$
M^{-1}(A x-b)=0
$$

que possui a mesma solução do sistema original (6.2.1) mas com a característica favorável de possuir um espectro concentrado em torno de um ponto específico. Tal sistema será muito 
mais fácil de ser resolvido pelos métodos iterativos.

Assim, definimos o pré-condicionador $M$ cujas características básicas são:

- ser próximo, em alguma métrica, da matriz $A$;

- e mais fácil de inverter.

Existe uma ampla literatura sobre pré-condicionadores, que discutem quais são os meIhores para os diversos sistemas lineares, os custos computacionais de obtê-los, as taxas de convergências, etc (85-90). Devemos notar que o uso deles é indispensável, para se obter ótimas taxas de convergência, e que sua escolha é intrínseca ao problema.

Nesta dissertação usaremos o pré-condicionador de Jacobi, ou seja,

$$
M_{i, j}= \begin{cases}A_{i, j} & \text { se } i=j \\ 0 & \text { se } i \neq \mathbf{j}\end{cases}
$$

que é um ótima escolha se a matriz, $A$, for diagonal dominante.

\subsection{LOBPCG}

Existem várias maneiras de se formular o método CG, como dito em 6.2.2.2. Uma delas é usando a formulação proposta pro Knyazev em (91).

Nesta formulação a recorrência para a construção dos autovetores é formada por três termos:

$$
\begin{aligned}
x_{k+1} & =w_{k}+\tau_{k} x_{k}+\gamma_{k} x_{k-1} \\
w_{k} & =M^{-1}\left(x_{k}-\alpha_{k} A x_{k}\right) \\
\alpha_{k} & =\frac{x_{k}^{T} x_{k}}{x_{k}^{T} A x_{k}}
\end{aligned}
$$

e os parâmetros $\tau_{k}$ e $\gamma_{k}$ são escolhidos de tal forma a maximizar, no subespaço $\operatorname{span}\left\{w, x_{k}, x_{k-1}\right\}$, o quociente de Rayleigh (6.3.3) usando o método variacional de Rayleigh-Ritz (92).

Por escolher o próximo autovetor em um subespaço formado pela aproximação atual, a anterior e o resíduo pré-conjugado, este método é dito ser local. Note que conforme as 
aproximações dos autovetores tendem à convergência, os vetores que formam o subespaço $\operatorname{span}\left\{w, x_{k}, x_{k-1}\right\}$ se tornam linearmente dependentes. Essa dependência torna o método instável.

A generalização do método acima é o famoso método LOBPCG (87). Além de calcular múltiplos auto pares de uma só vez, ele resolve o problema da instabilidade. A diferença entre as aproximações dos auto estados é usada no lugar da aproximação anterior. 


\section{O programa de cálculo}

Para a realização das simulações de nanoestruturas semicondutores de interesse do Laboratório de Física Computacional (LFC) situado no Instituto de Física de São Carlos (IFSC/USP) nós utilizamos um programa de cálculo baseado no programa que começou a ser desenvolvido em meados da década de 1990 pelo Prof. Dr. Guilherme Matos Sipahi durante seu doutorado no Laboratório de Novos Materiais Semicondutores (IF-USP).

Em sua primeira versão, apensas materiais ZB podiam ser simulados $(93,94)$. Recentemente, no LFC, o programa foi modularizado e houve a inclusão dos módulos de simulação para estruturas semicondutoras de simetria WZ (95). Nos anos de 2011 e 2012, o então aluno de mestrado Paulo Eduardo, incluiu a possibilidade de simularmos nanoestruturas politípicas, variando a fase cristalina entre ZB e WZ em uma mesma estrutura $(17,67)$.

\subsection{Modelo out-of-core}

De posse de todos os parâmetros necessários para a simulação, o programa de cálculo constrói os perfis dos potencias e os termos do Hamiltoniano. Como a nossa formulação é feita no espaço recíproco (vide equação (3.3.13)), calculamos todas as transformadas de Fourier necessárias.

A diagonalização do Hamiltoniano final é feita por duas rotinas distintas: i) a implementada na CPU, usando o CHEEVX do LAPACK, que usa o Hamiltoniano inteiro para efetuar a diagonalização ou ii) o método do LOBPCG implementado tanto na CPU quanto na GPU, que usa a formulação out-of-core.

Em qualquer um dos casos acima, o Hamiltoniano é construído fixando-se o vetor de base e o valor de $K$ e variando os valores de $K^{\prime}$ (como visto na figura 7.1). Essa forma de construção é favorável à paralelização pois, como a construção desses termos é baseada na diferença entre os valores de $K$ e $K^{\prime}$, podemos construir simultaneamente as mesmas colunas dos vários elementos que compõem o Hamiltoniano. 


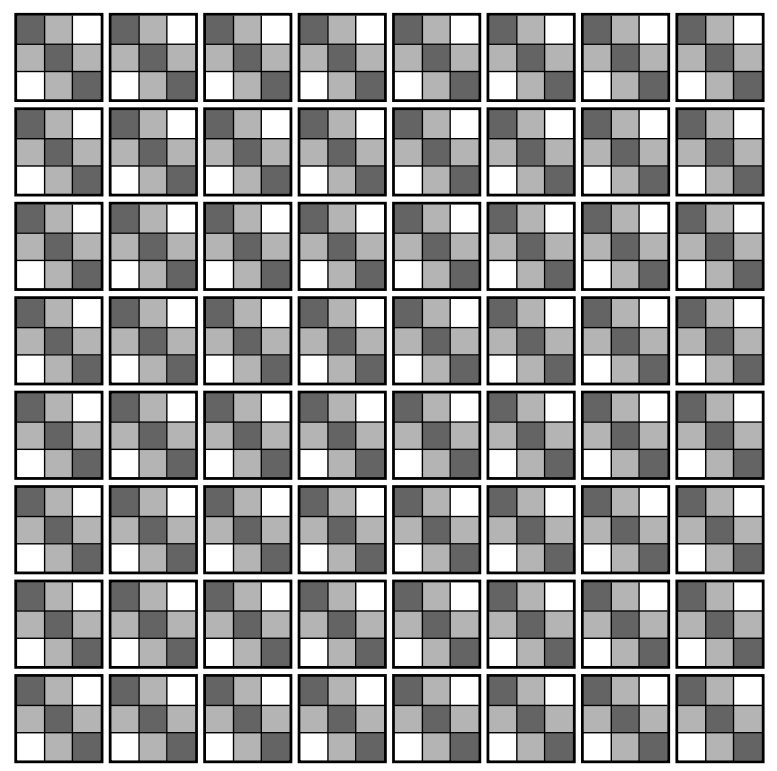

$|\Delta K|=0 \quad|\Delta K|=1 \quad|\Delta K|=2$

Figura 7.1 - Hamiltoniano expandido em 1 onda plana $(K=-1,0,1)$ para confinamento 1D. Nesta representação fixa-se o vetor de base e o valor de $K$ e varia-se os valores de $|\Delta K|$. As cores iguais não representam valores iguais, e sim o mesmo valor de $\Delta K$.

Para a rotina de diagonalização baseada no CHEEVX funcionar, precisamos passar o Hamiltoniano inteiro a ela. Já o LOBPCG somente necessita do Hamiltoniano multiplicado pelos autovetores estimados; assim ele irá calcular o resíduo dessa matriz resultante e comparar com o resíduo da iteração anterior, e continuará até o critério de convergência ser atingido.

O modelo out-of-core se baseia na construção iterativa do Hamiltoniano e na sua prémultiplicação pelo vetor de auto estados. Assim, a cada passo do loop que varre os valores de $K^{\prime}$, iremos construir uma linha para cada elemento do Hamiltoniano. Essa matriz composta pelas linhas referentes à um $K^{\prime}$ é multiplicada pelo vetor dos auto estados e com isso, passo a passo, construiremos o próximo vetor. A figura 7.2 exemplifica este conceito.

As figuras 7.1 e 7.2 exemplificam o processo para confinamento em 1D, ou seja, poços quânticos. Para confinamentos em mais de uma dimensão o processo é o mesmo só trocando $K^{\prime}$ por $\vec{K}^{\prime}$ e $K$ por $\vec{K}$.

Durante a primeira parte do meu mestrado eu me foquei na generalização do programa para cálculos com confinamento em mais de uma dimensão, na validação do método LOBPCG e na sua implementação na placa de vídeo. Apesar de ter generalizado a formulação para confinamentos em mais de uma dimensão, implementado o LOBPCG, tanto na CPU quanto na GPU, e validado o LOBPCG para confinamentos em uma dimensão, não obtive sucesso na sua convergência para confinamentos em mais de uma dimensão. 


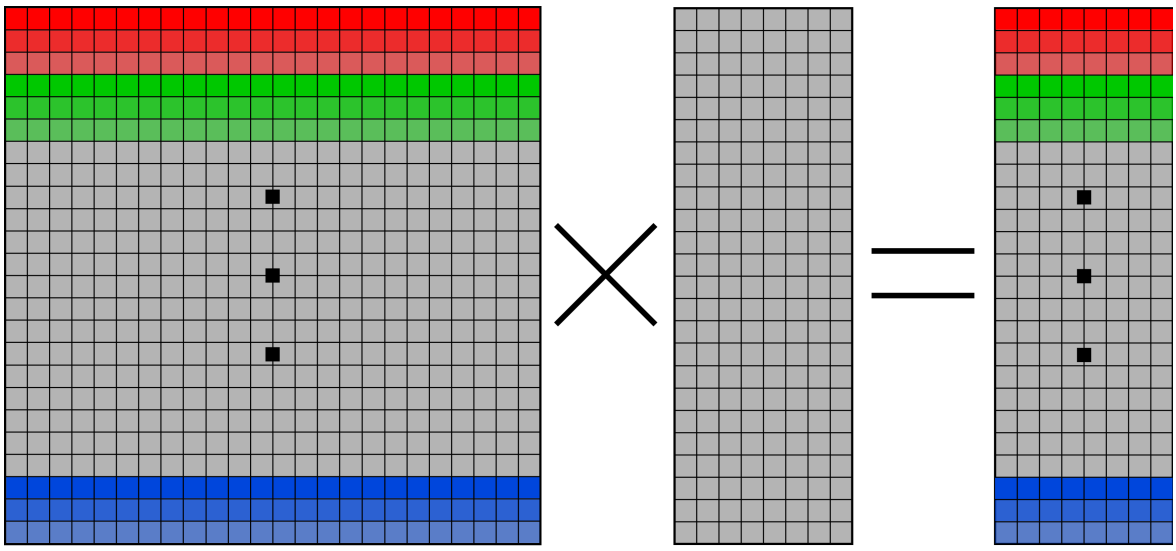

Figura 7.2 - Modelo out-of-core para um Hamiltoniano expandido em uma onda plana com confinamento 1D. O Hamiltoniano é construído linha a linha e multiplicado pelo vetor tentativa de auto estados. Cada cor representa um termo do Hamiltoniano total e a variação de um cor específica representa a variação do valor de $K^{\prime}$.

A dificuldade na convergência destes sistemas cujo confinamento é em mais de uma dimensão, se justifica pelo fato do Hamiltoniano não ser mais diagonal dominante, ou seja, existem elementos fora da diagonal que possuem magnitudes comparáveis aos da diagonal. Dessa maneira, o LOBPCG com o pré-condicionar de Jacobi falha ao convergir vários auto-pares de uma só vez.

A segunda parte do meu mestrado foi focada na simulação de sistemas semicondutores com confinamento em duas dimensões e na obtenção de suas propriedades óticas. 
CAPÍtulo 8

\section{Resultados}

Neste capítulo, apresento dois resultados principais: i) a aceleração da resolução da equação (3.3.13) através do método LOBPCG apresentado no capítulo 6 e ii) os resultados obtidos através da aplicação da teoria desenvolvida do capítulo 4 para NWs de $\ln P$

\subsection{Com o LOBPCG}

O método k.p é o menos custoso computacionalmente entre os método existentes para lidar com sistemas confinados. Apesar disso, quando necessitamos discretizar o espaço com um número grande de pontos, ou quando estamos lidando com confinamentos em mais de uma dimensão, o Hamiltoniano que descreve o sistema atinge tamanhos em que os métodos de diagonalização direta não são mais adequados. Para lidar com esse problema, o aconselhável é usar métodos de minimização iterativos como o LOBPCG.

Esses métodos de minimização possuem uma estrutura altamente paralelizável baseada na multiplicação, por etapas, de matrizes por vetores. Além de implementarmos uma rotina de minimização na CPU nós também a implementamos na GPU, para explorar o alto poder de processamento paralelo disponível nos computadores comuns de mesa.

Nesta seção, discuto os limites em que o uso do LOBPCG é favorável se comparado com o método de diagonalização direta. Além disso, comparo os tempos de execução das rotinas implementadas na CPU e na GPU.

As simulações foram realizadas em uma heteroestrutura com confinamento em uma dimensão, visto que o LOBPCG aliado ao pré-condicionador de Jacobi atinge melhores taxas de convergência nesses sistemas. 


\subsubsection{Poço quântico}

O tempo de execução do programa de cálculo depende do número de ondas planas (NOP) que se deseja discretizar o sistema simulado. Para fins de teste, escolherei um sistema formado por múltiplos poços quânticos de tal forma que será necessário um grande NOP para descrevermos bem o sistema. A amostra consiste de uma matriz de $\mathrm{Al}_{0.35} \mathrm{Ga}_{0.65} \mathrm{As}$ de $180 \mathrm{~nm}$ com 8 poços de GaAs de $10 \mathrm{~nm}$ cada. O perfil de potencial para os elétrons é apresentado na figura 8.1. Os parâmetros utilizados na simulação se encontram na tabela 8.1.

Tabela 8.1 - Parâmetros k.p para GaAs e $\mathrm{Al}_{0.35} \mathrm{Ga}_{0.65} \mathrm{As}$ (96).

\begin{tabular}{ccc}
\hline Parâmetro & $\mathrm{GaAs}$ & $\mathrm{Al}_{0.35} \mathrm{Ga}_{0.65} \mathrm{As}$ \\
\hline Parâmetro de rede $(\mathrm{nm})$ & & \\
$a$ & 0.56532 & 0.5656 \\
Parâmetros de energia $(\mathrm{meV})$ & & \\
$E_{g}$ & 1.519 & 2.073 \\
$\Delta_{S O}$ & 0.341 & 0.32 \\
Parâmetros de massa efetiva $\left(\hbar^{2} / 2 m_{0}\right)$ & & \\
$\gamma_{1}$ & 6.98 & 5.853 \\
$\gamma_{2}$ & 2.06 & 1.626 \\
$\gamma_{3}$ & 2.93 & 2.402 \\
$A$ & 14.9254 & 10.4167 \\
\hline
\end{tabular}

São vastas as aplicações tecnológicas de heterojunções em uma dimensão, e especialmente os poços quânticos (ou múltiplos poços quânticos) de GaAs/AIGaAs. Como o GaAs possui um acoplamento spin-órbita fraco, ele é amplamente usado em dispositivos baseados em spintrônica, laser de cascata, etc. (97-100)

Se quisermos descrever esse perfil de potencial com um ponto a cada $0.2 \mathrm{~nm}$ necessitaremos de aproximadamente 200 OP. A tabela 8.2 traz uma comparação entre alguns NOP's em 1D e seus equivalentes, de tal forma a manter o mesmo tamanho de matriz, para 2D e 3D. Nota-se claramente que se tivermos um confinamento em mais de uma dimensão e quisermos manter a mesma discretização, teremos que aumentar o NOP e com isso o tamanho do $\mathrm{Ha}$ miltoniano final. Relacionamos o NOP em 1D com seus equivalentes em 2D e 3D usando a relação abaixo:

$$
2 \times N O P_{1 D}=\left(2 \times N O P_{q D}+1\right)^{q}
$$




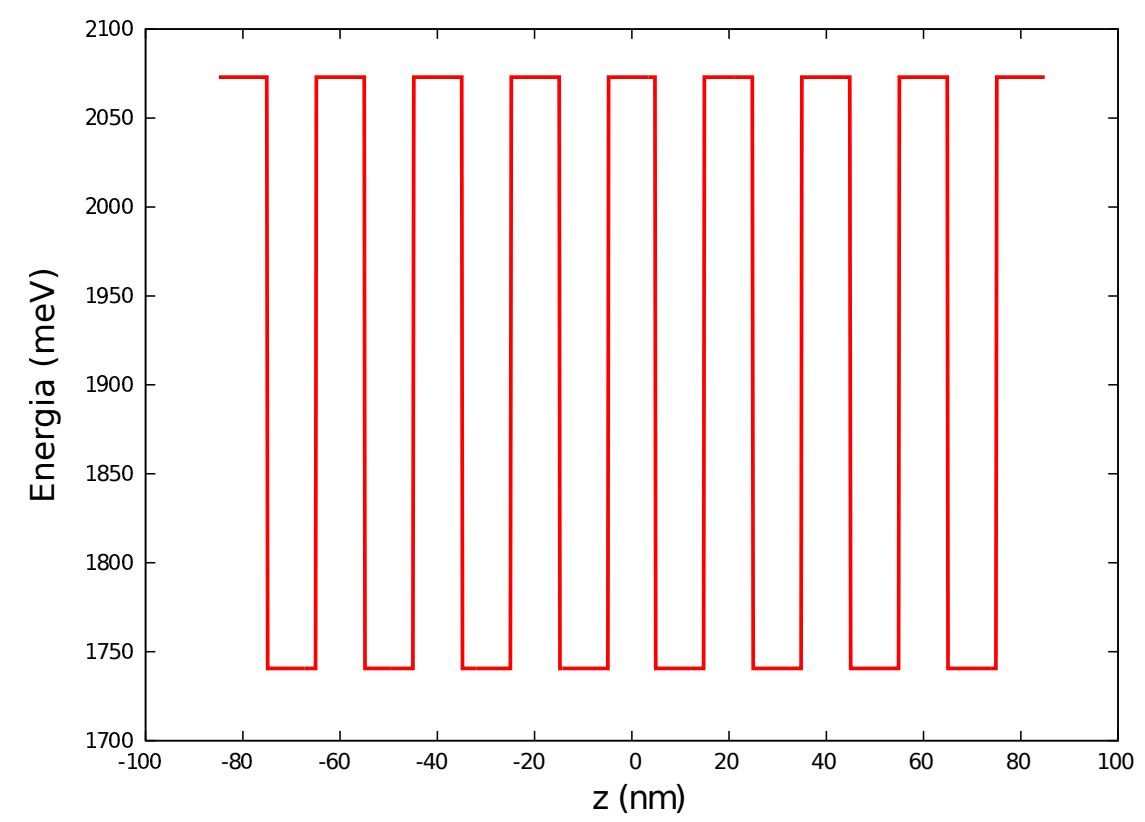

Figura 8.1 - Perfil de confinamento para os elétrons em uma heteroestrutura de $\mathrm{GaAs} / \mathrm{Al}_{0.35} \mathrm{Ga}_{0.65} \mathrm{As}$. Este perfil será usado para testar os tempos de execução do programa de cálculo usando os métodos de diagonalização na CPU e os de minimização, tanto na CPU quanto na GPU.

$\operatorname{com} q=2,3$.

Tabela 8.2 - Relação entre o número de ondas planas em 1D e seus equivalentes em 2D e 3D

\begin{tabular}{|c|c|c|c|c|}
\hline Confinamento & \multicolumn{4}{|c|}{ NOP } \\
\hline \hline 1D & 50 & 100 & 200 & 300 \\
\hline 2D & 4,53 & 6,59 & 9,51 & 11.76 \\
\hline 3D & 1,83 & 2,43 & 3.19 & 3.72 \\
\hline
\end{tabular}

Na notação Big $O$, ou seja, na notação que descreve o comportamento assintótico de uma função no limite que seu argumento tende ao infinito, temos que o tempo de execução para as funções de diagonalização direta (métodos exatos, não de minimização) vai com $n^{3}$, onde $n$ é a dimensão da matriz. Já para os métodos de minimização, o limite é menor que $n^{2}$. Assim, teoricamente, a utilização do LOBPCG é justificável.

Vamos comparar o tempo de execução dos métodos e analisar como eles se comportam. O gráfico 8.2 apresenta essa comparação para o LOBPCG tanto na CPU quanto na GPU. Por ser um método iterativo de minimização, nem todo ponto converge com o mesmo número de iterações. Assim os tempos coletados referem-se a uma média entre o tempo total de convergência e número de iterações levadas.

As operações de multiplicação são implementadas usando precisão dupla no LOBPCG. A 

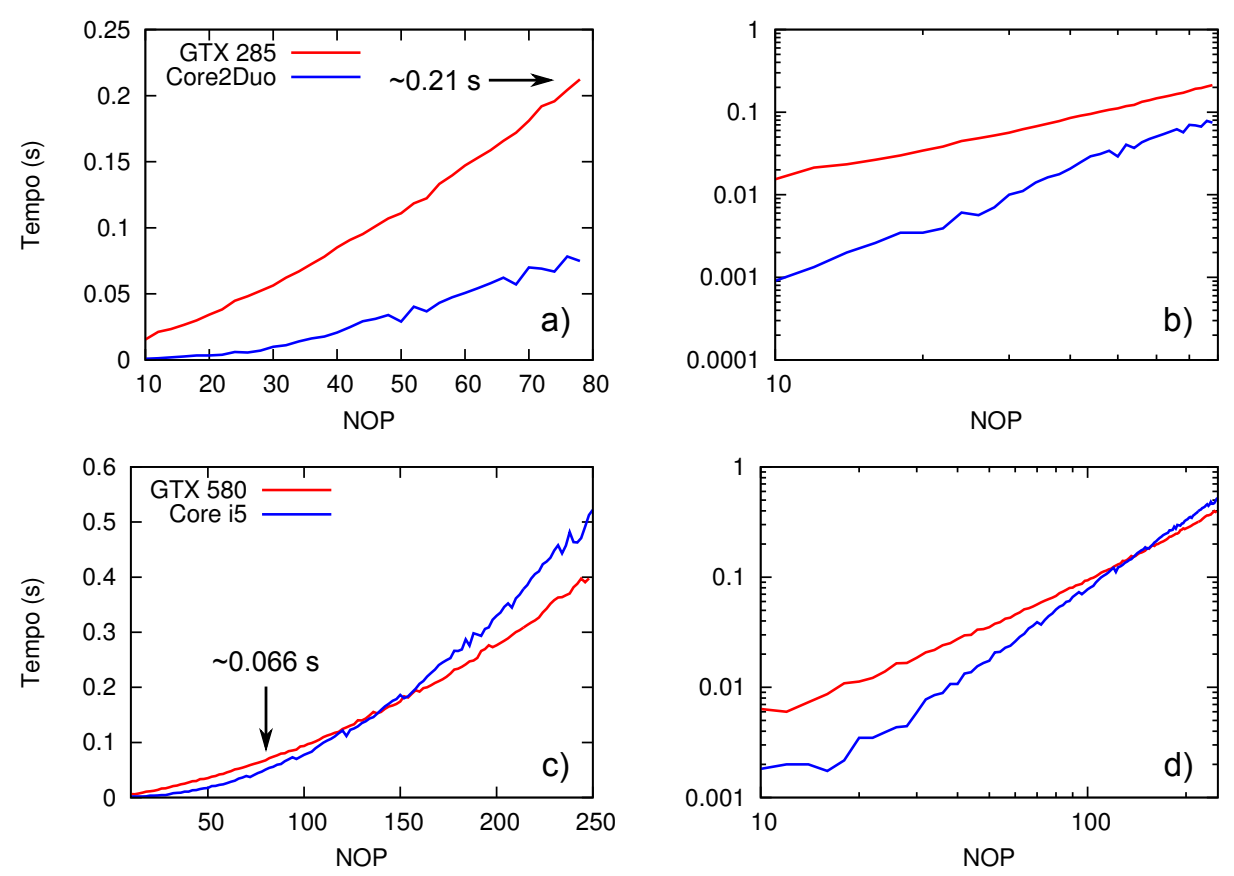

Figura 8.2 - Comparação entre os tempos de execução de uma iteração do LOBPCG na CPU e na GPU. As linhas vermelhas representam a execução nas GPU, e as azuis na CPU. Os gráficos b) e d) estão em escala logarítmica para compararmos visualmente a inclinação das curvas. O programa foi executado em duas placas de vídeo distintas: uma com menos recursos, GTX 285 e outra com mais recursos, GTX 580; e em dois processadores distintos: um com menos recursos, Core2Duo e outro com mais recursos, Core i5.

GPU GTX 285 não possui suporte nativo à precisão dupla. Dessa maneira um número em precisão dupla é emulado por dois em precisão simples, aumentando em 4 vezes o tempo necessário para uma multiplicação, como mostrado na figura 8.2(a) e 8.2(c). A execução é levemente mais lenta na CPU Core2Duo do que na Core i5 simplesmente pelo fato da última ser mais rápida que a primeira.

Outra característica interessante de se notar é que nos dois casos a execução com um número menor de ondas planas favorece a CPU. Isso acontece porque existe uma latência maior entre a comunicação da memória RAM com a GPU do que com a CPU. Após um certo tamanho de matriz o tempo de execução na GPU supera essa latência é preferível executar na GPU.

Agora que sabemos que a partir de uma certo número de ondas planas é preferível usar a implementação do LOBPCG na GPU contra a da CPU, vamos ver se é preferível usar o LOBPCG ao invés do CHEEVX.

Em média, usando o pré-condicionador de Jacobi, cada ponto levou 20 iterações para convergir com uma precisão de 6 casas depois da vírgula. Então, no gráfico 8.3, irei comparar a execução do CHEEVX com 20 iterações do LOBPCG na GPU e na CPU mais rápidas. 

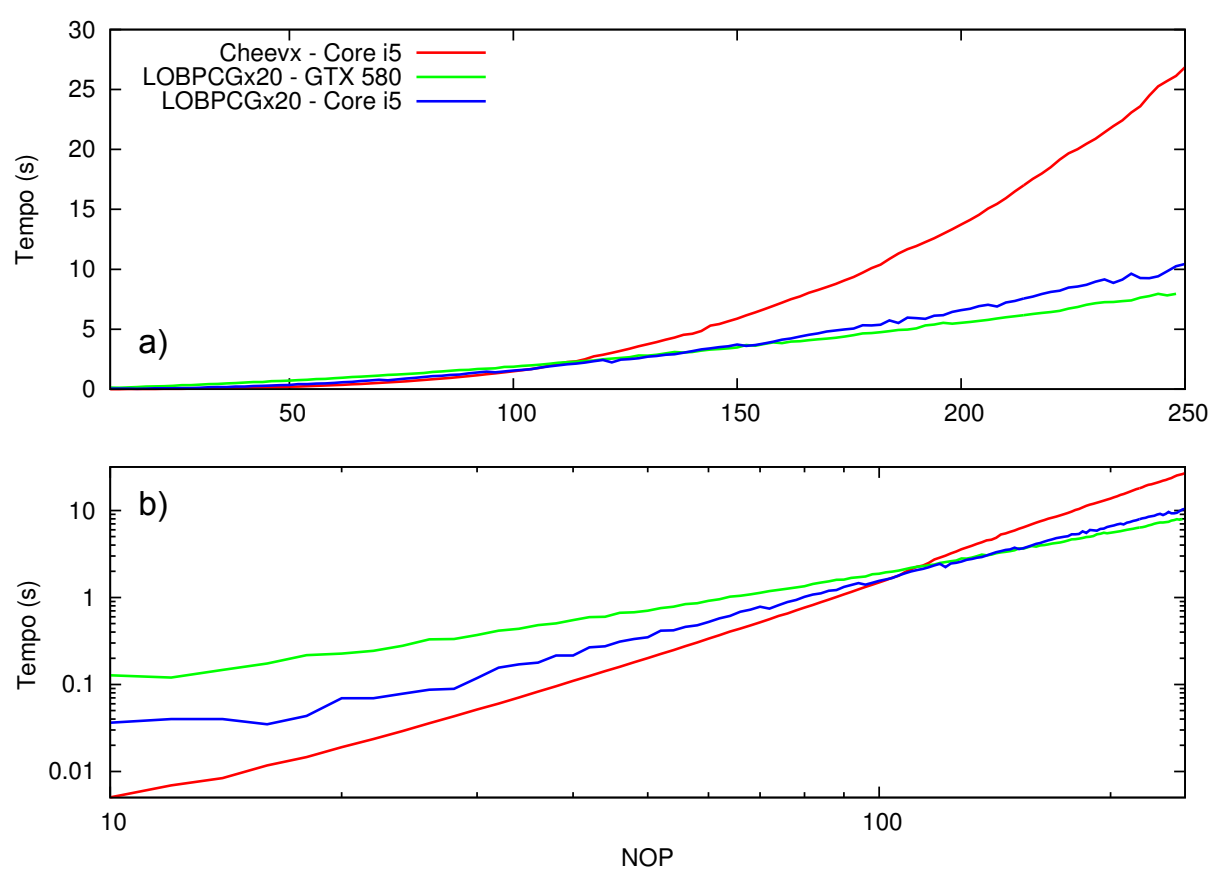

Figura 8.3 - Comparação entre os tempos de execução do CHEEVX e do LOBPCG. A linha vermelha corresponde à execução do CHEEVX na CPU, a azul de 20 iterações do LOBPCG na mesma CPU e a verde de 20 iterações do LOBPCG na GPU mais rápida. Em b) temos os tempos de execução em escala logarítmica para compararmos visualmente a inclinação das curvas.

Podemos observar que a partir de 150 OP a execução do LOBPCG na GPU é mais rápida que a execução na CPU, e ambas execuções são mais rápidas que a CPU para sistemas com mais de 100 OP em uma dimensão. Portanto, é possível simular sistemas mais complexos, utilizando o LOBPCG, em um computador de mesa, explorando o alto poder de processamento que as placas gráficas atuais fornecem.

\subsection{Coeficiente de absorção}

Quando se cresce NWs de InP a fase cristalina predominante é a WZ, ao contrário do bulk que é ZB $(13,32)$. Com o seu gap de cerca de $1.4 \mathrm{eV}$ (em ambas as fases cristalinas), ele se torna ideal para o uso em telecomunicações e na fabricação de células solares, pois atua na faixa do infra-vermelho ao ultra violeta; além de ser um ótimo composto para aplicações de lógica ultra rápida $(28,40)$.

Para melhor entender as características que fazem dos NWs promissores a aplicações tecnológicas de ponta, é necessário um entendimento teórico sobre suas propriedades óticas, assim como o efeito que o confinamento quântico exerce sobre ela. Para isso, aplico o formalismo 
desenvolvido nos capítulos 2 e 3 para obter a estrutura de bandas de um NW de InP.

A partir da estrutura de bandas, calcularemos o poder (ou coeficiente) de absorção e o grau de polarização linear (GPL), dados pelas equações (4.1.23) e (4.1.28) respectivamente. Dessa forma poderemos estudar as diferenças entre as duas fases cristalinas, WZ e ZB, em que tais NWs são encontrados.

\subsubsection{InP bulk}

Antes de apresentar os resultados para os NWs analisaremos o comportamento da absorção no bulk, cujos resultados servirão de validação para o nosso modelo. Os parâmetros usados para as simulações se encontram na tabela 8.3 e estes serão usados de agora em diante.

Tabela 8.3 - Parâmetros k.p para InP ZB e WZ. Os parâmetros para o ZB foram derivados usando as relações (2.2.9).

\begin{tabular}{ccc}
\hline Parâmetro & ZB [111] (96) & WZ [0001] (17) \\
\hline Parâmetro de rede $(\mathrm{nm})$ & 0.41505 & 0.41505 \\
$c$ & 1.01666 & 0.67777 \\
$c$ & & \\
Parâmetros de energia $(\mathrm{meV})$ & 1.4236 & 1.474 \\
$E_{g}$ & 0 & 0.303 \\
$\Delta_{1}$ & 0.036 & 0.036 \\
$\Delta_{2}=\Delta_{3}$ & & \\
Parâmetros de massa efetiva $\left(\hbar^{2} / 2 m_{0}\right)$ & -13.48 & -10.7176 \\
$A_{1}$ & -0.88 & -0.8299 \\
$A_{2}$ & 12.6 & 9.9301 \\
$A_{3}$ & -6.3 & -5.2933 \\
$A_{4}$ & -5.8 & 5.0 \\
$A_{5}$ & -7.4953 & 1.5 \\
$A_{6}$ & -0.5 & 0 \\
$A_{z}$ & 12.5786 & 9.5238 \\
$e_{1}$ & 12.5786 & 11.3636 \\
$e_{2}$ & &
\end{tabular}

As estruturas da banda de valência para o bulk de InP em ZB[111] e WZ[0001] estão apresentadas na figura 8.4 .

O ZB, por possuir simetria cúbica, não apresenta anisotropias no seu espetro de absorção em relação às direções [001], [010] e [100], como visto na figura 8.4(a). Sua banda de valência é formada por seis estados que, de acordo com a denominação usual no ponto $\Gamma$, são: $H H$ 
(heavy hole), LL (light hole) e SO (split-off hole). Os HHs e LHs são quadri-degenerados em spin (dois a dois); e os SOs, bi-degenerados em spin, estão distanciados dos HHs e LHs pelo $\Delta_{S O}$ do material.
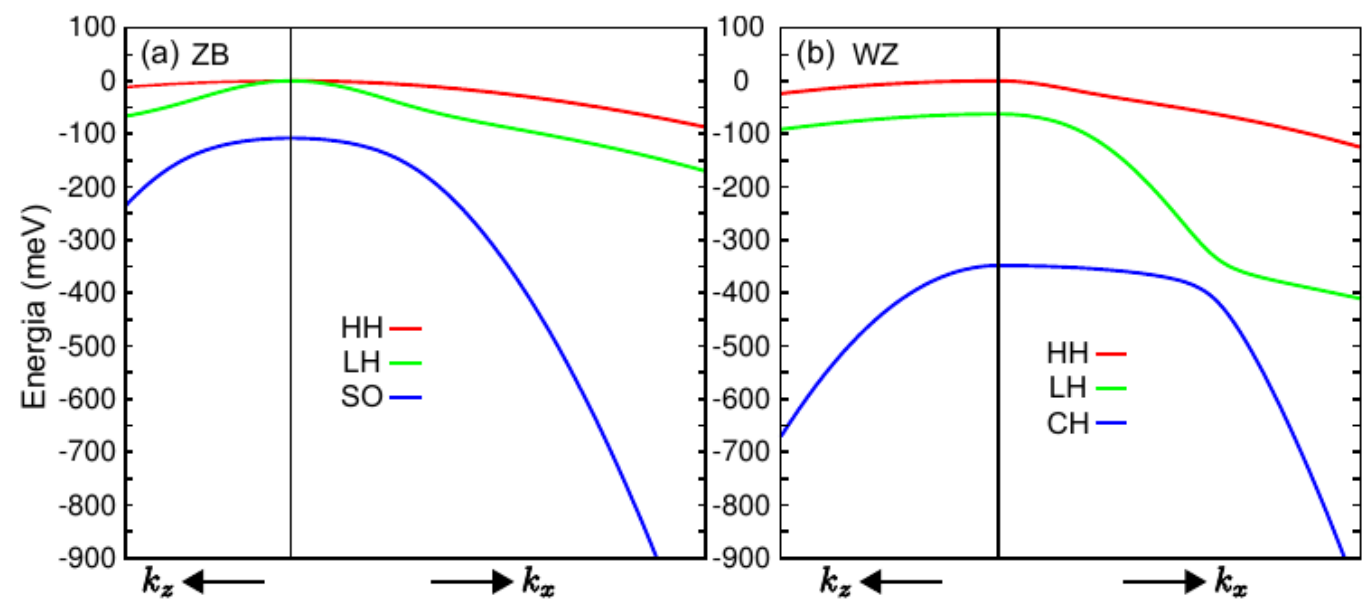

Figura 8.4 - Estrutura da banda de valência para o bulk de InP em ZB[111](a) e WZ[0001](b) (67).

Seu espectro de absorção será caracterizado por duas regiões em energia. A primeira, variando do gap do material até o valor de seu $\Delta_{S O}$, com transições dos HHs e LHs; e a segunda, variando do $\Delta_{S O}$ em diante, com transições de todos os buracos. Considerando a isotropia de suas bandas de valência e que seus estados degenerados possuem a mesma contribuição dos kets $|X\rangle,|Y\rangle$ e $|Z\rangle$ (vide equação 2.2.2), o espectro de absorção do ZB deverá ser igual para qualquer polarização, como mostra a figura 8.5.

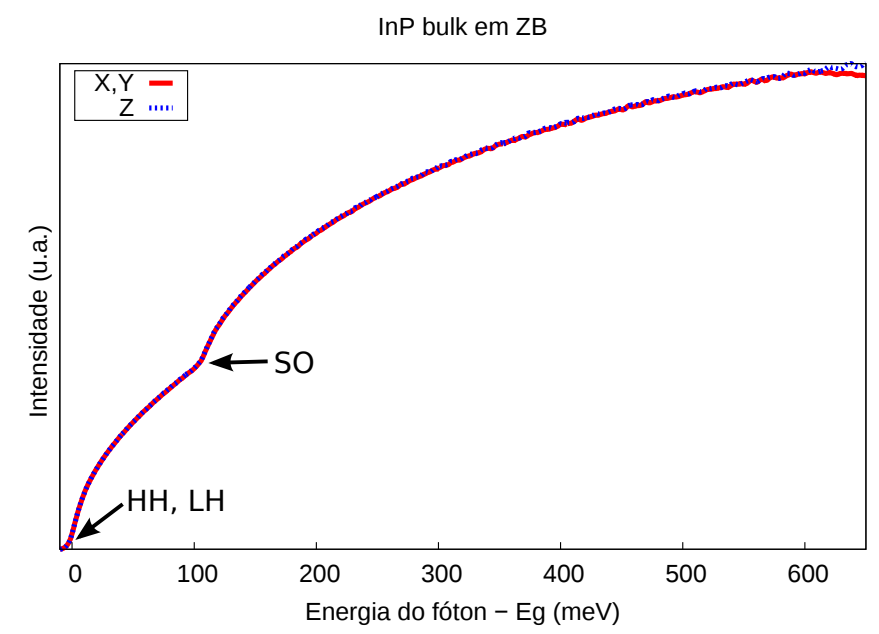

Figura 8.5 - Coeficiente de absorção para um bulk de InP ZB. A curva em vermelho denota o poder de absorção para luz com polarização em $\hat{x}$ ou $\hat{y}$; já a curva em azul, o poder de absorção para luz polarizada em $\hat{z}$. As setas no gráfico indicam as transições, no ponto $\Gamma$, de cada banda de valência para a banda de condução

A WZ, por ser hexagonal, não possui as mesmas características que o ZB. Todas as bandas são bi-degeneradas e possuem a seguinte denominação, no ponto $\Gamma$ : $H H_{s}$ são compostos por 
$\left|c_{1}\right\rangle$ e $\left|c_{4}\right\rangle$, LHs são compostos principalmente por $\left|c_{2}\right\rangle$ e $\left|c_{5}\right\rangle$ e $\mathrm{CH}$ (crystal field split-off hole) principalmente por $\left|c_{3}\right\rangle$ e $\left|c_{6}\right\rangle$. Assim, seu espectro de absorção será composto por três regiões: a primeira com transições dos $\mathrm{HHs}$, a segunda com transições dos $\mathrm{HHs}$ e LHs e a terceira com todas as transições. Podemos observar essa característica diretamente na estrutura de suas bandas de valência, figura $8.4(\mathrm{~b})$.

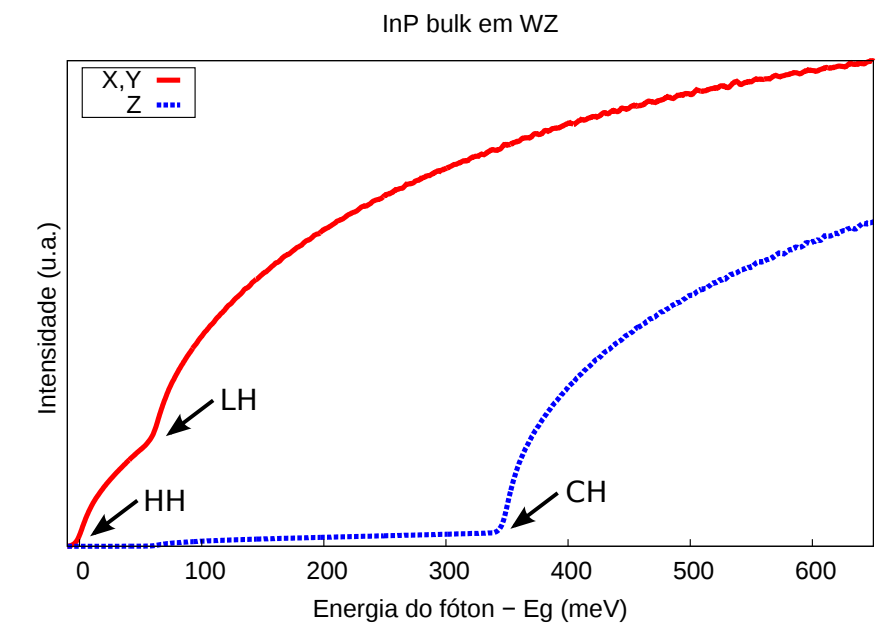

Figura 8.6 - Coeficiente de absorção para um bulk de $\operatorname{lnP}$ em WZ. A curva em vermelho denota o poder de absorção para luz com polarização em $\hat{x}$ ou $\hat{y}$; já a curva em azul, o poder de absorção para luz polarizada em $\hat{z}$. As setas no gráfico indicam as transições, no ponto $\Gamma$, de cada banda de valência para a banda de condução

Como seus estados, já no ponto $\Gamma$, não possuem contribuições iguais dos kets $|X\rangle,|Y\rangle$ e $|Z\rangle$, vide Ref. (72), espera-se que o espectro de absorção seja anisotrópico em relação às transições com diferentes polarizações. De fato é isso que observamos na figura 8.6: claramente há uma preferência às transições com polarização em $\hat{x}$ ou $\hat{y}$; na segunda região vemos um aumento gradual da contribuição com polarização $\hat{z}$ devido à natureza multi-banda do método que acopla os estados de base fora do ponto $\Gamma$; e na terceira região vemos um salto na contribuição com polarização em $\hat{z}$ dada pela inclusão dos estados com grandes porcentagens do ket $|Z\rangle$ na sua composição.

\subsubsection{Free-standing nanowires de $\ln \mathrm{P}$}

NWs possuem características óticas distintas das observadas no bulk, primordialmente devido aos efeitos que o confinamento quântico gera em sua estrutura de bandas; e, também, por possuir uma grande diferença entre sua área e volume, gerando efeitos de confinamento ótico. Recentemente, com o avanço nas técnicas de crescimento, NWs com uma única fase cristalina estão sendo reportados (9). O interesse no estudo das propriedades óticas desses 
sistemas aumentou quando Wang et al (60) reportou uma anisotropia gigante no espectro de luminescência de um NW cilíndrico de InP em ZB.

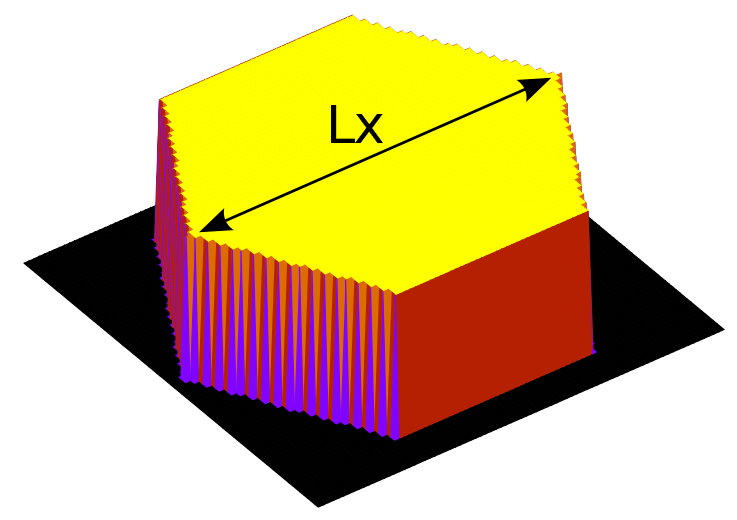

Figura 8.7 - Seção transversal do NWs. Os NWs que serão analisados possuem seção transversal hexagonal.

Apesar da fase cristalina predominante nesses NWs ser a WZ, os únicos estudos teóricos são para NWs em ZB $(61,62)$, e somente as transições inter-bandas mediadas por dipolo não explicaram a grande anisotropia observada por Wang. Nesses NWs, cuja diferença entre a constante dielétrica do material e do meio que o cerca é grande, os efeitos de CO têm uma influência grande nessa anisotropia (54). Posteriormente, cálculos mais acurados, levando em conta os efeitos de CO e de CQ para o ZB, mostraram grande concordância entre os resultados experimentais e os teóricos $(57,59)$.

Para a WZ, somente trabalhos experimentais relatam a existência de uma anisotropia para os NWs. Esses NWs possuem diâmetros onde o $C Q$ não exerce mais efeito, e suas características podem ser explicadas pelo comportamento do bulk $(9,40,42)$.

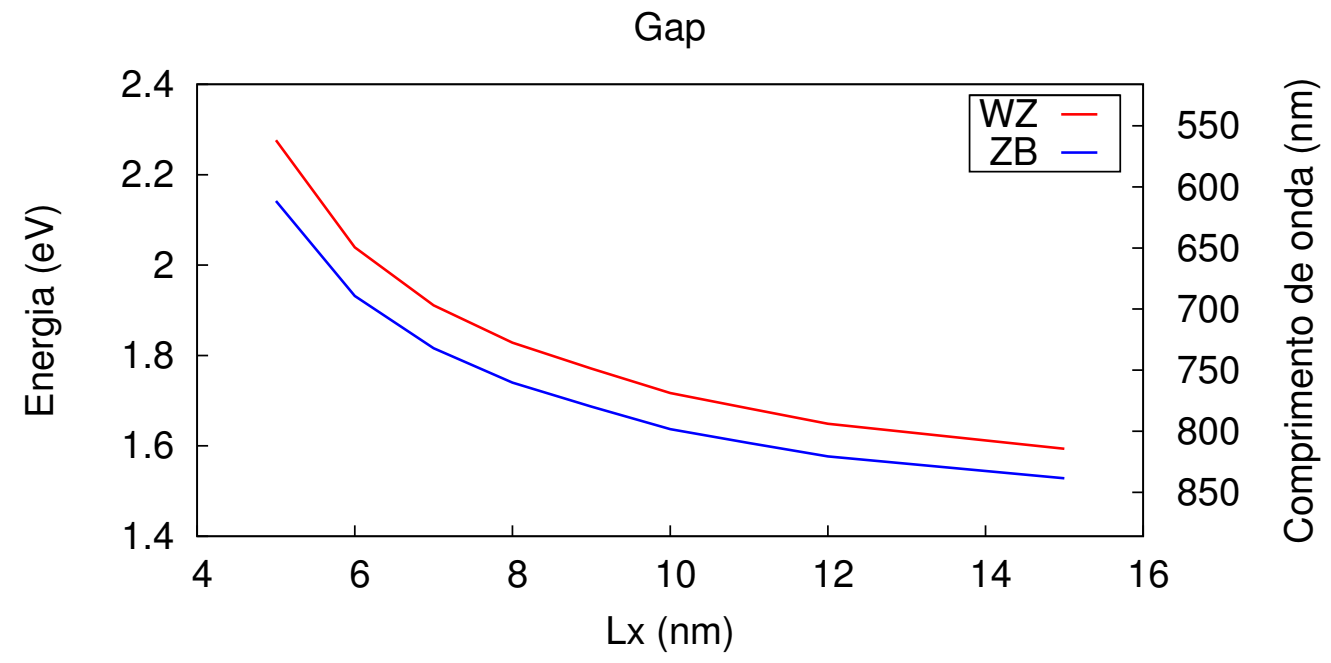

Figura 8.8 - Gaps calculados para os NWs. A escala da esquerda representa os valores do gap em $\mathrm{eV}$ e a da direita os respectivos comprimentos de onda associados aos valores valores do gap. 
Visto que existe um gap entre o estudo da WZ e do ZB, o nosso intuito é fazer uma análise teórica, baseada no método k.p e na função envelope, para NWs com diâmetros pequenos. Irei calcular o poder de absorção bem como o grau de polarização linear, levando em conta os efeitos de CO, e analisar qual o efeito do CQ exerce sobre as características óticas dos NWs.
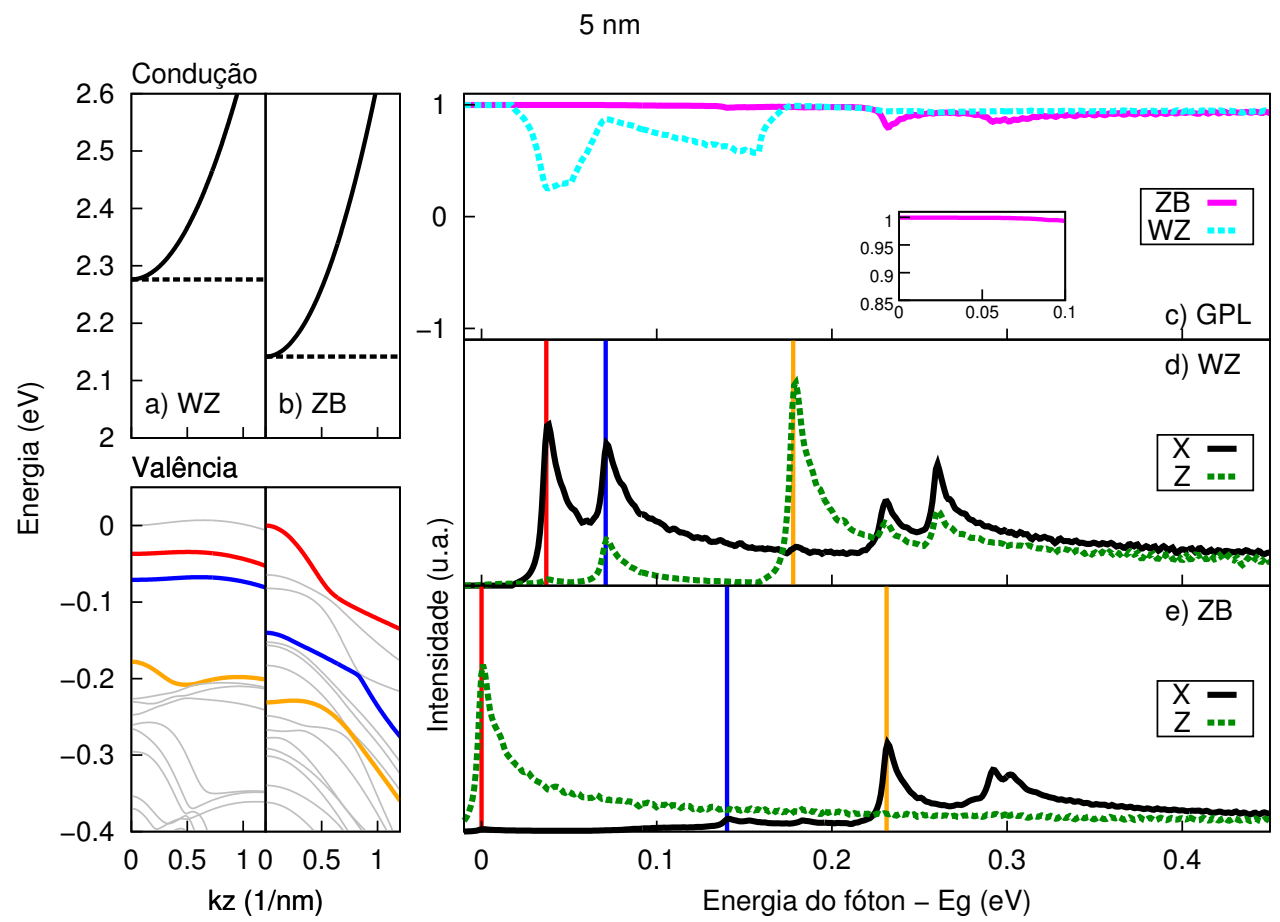

Figura 8.9 - Absorção para um fio com $L_{x}=5 \mathrm{~nm}$. A estrutura de bandas estão gráficadas em a) para os NWs em WZ e em b) para ZB, o grau de polarização linear com efeitos de CO e CQ está representado em c), e o coeficiente de absorção para NWs de InP em WZ e em ZB está representado em d) e e) respectivamente. O inset mostra um zoom em torno do valor de energia do gap para o GPL do NW em ZB.

Os NWs de InP analisados terão seção transversal hexagonal, como mostrado na figura 8.7 e sua escolha é justificada pelos trabalhos na literatura que mostram que tanto os NWs em ZB quanto os em WZ possuem essa seção transversal $(9,13,15,70,101)$. Seu tamanho será definido pelo comprimento $L_{x}$ e o comprimento perpendicular, $L_{y}$, definido como $L_{y}=\frac{L_{x} \sqrt{3}}{2}$.

Após o cálculo da estrutura de bandas dos NWs é possível calcular o gap efetivo do sistema, que é definido como: a diferença de energia, no ponto $\Gamma$, entre a primeira banda de condução e a primeira de valência. Os gaps calculados são mostrados na figura 8.8. Nota-se que eles são maiores que os reportados na literatura. Pode-se atribuir esse efeito à seção transversal de nossos NWs que, por ser hexagonal, confina mais que os cilíndricos (59, 102). Observa-se também que quanto maior $L_{x}$, mais o gap se aproxima do seu valor no bulk, ou seja, com o aumento da seção lateral, o CQ vai perdendo importância, como esperado.

As figuras 8.9-8.12 apresentam a estrutura de bandas, o poder de absorção e o grau de 
polarização linear dos NWs simulados. As linhas coloridas verticais representam transições, no ponto $\Gamma$, das bandas de valência, com a mesma cor, para a(s) banda(s) de condução. A linha horizontal tracejada na banda de condução representa o gap do NW. O inset é um zoom no grau de polarização linear do NW em ZB em torno do gap.

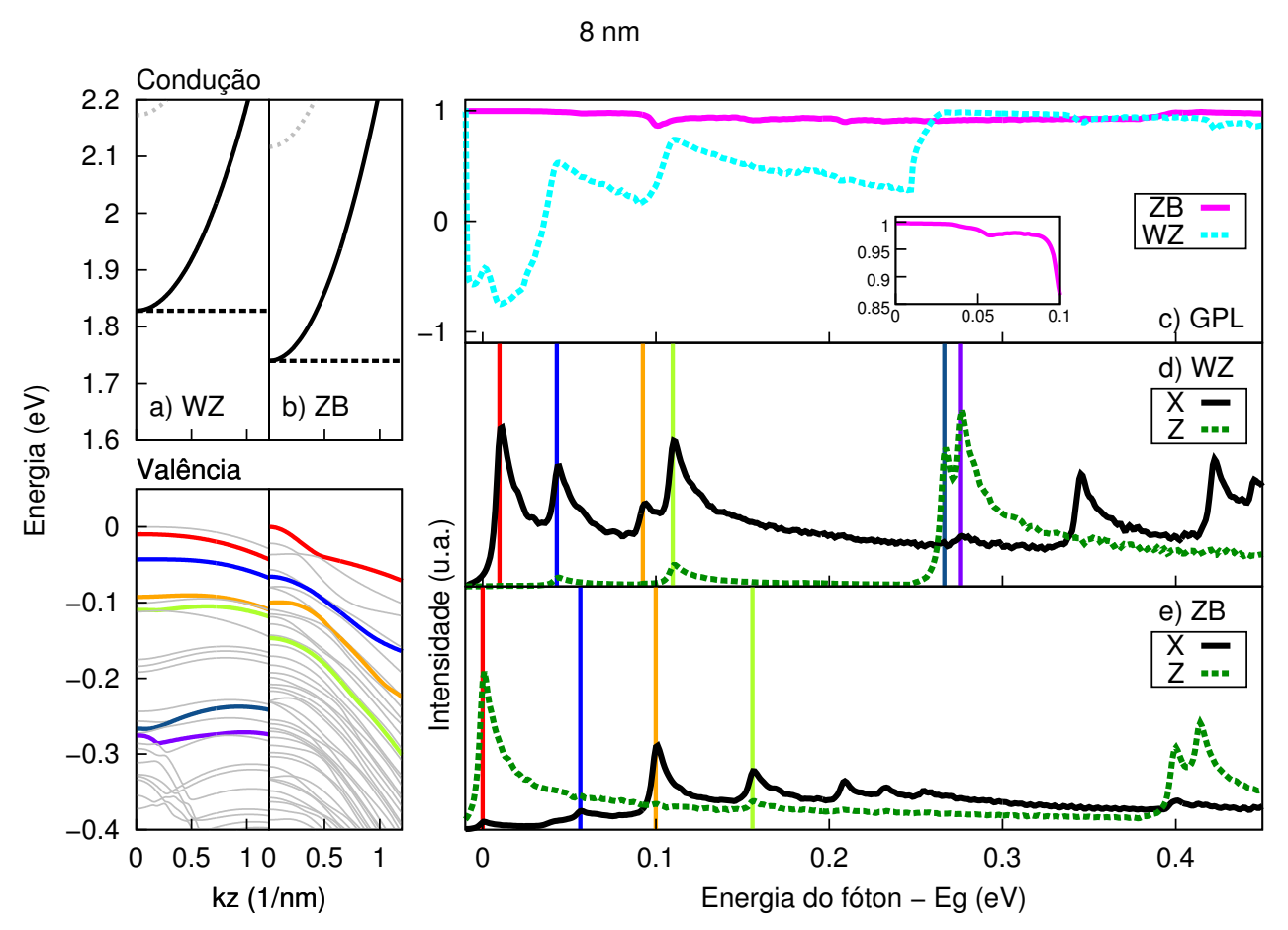

Figura 8.10 - Absorção para um fio com $L_{x}=8 \mathrm{~nm}$. A estrutura de bandas estão gráficadas em a) para os NWs em WZ e em b) para ZB, o grau de polarização linear com efeitos de CO e CQ está representado em c), e o coeficiente de absorção para NWs de InP em WZ e em ZB está representado em d) e e) respectivamente. O inset mostra um zoom em torno do valor de energia do gap para o GPL do NW em ZB.

O grau de polarização linear possui valor 1 se a luz absorvida for totalmente polarizada paralela ao eixo do NW (no nosso caso $\hat{z}$ ) , -1 para se for totalmente polarizada perpendicular ao eixo do NW (no nosso caso $\hat{x}$ ) e 0 para luz despolarizada. O valor da constante dielétrica do $\ln P$ foi retirada do artigo de Wang et al (60), e vale 12,4.

Nota-se que para NWs em ZB a absorção ocorre primeiramente para polarização paralela ao eixo do fio $(\hat{z})$, enquanto que para a WZ a polarização preferencial é a perpendicular $(\hat{x})$. Isso ocorre devido às diferentes combinações dos estados de base que cada material possui, resultando em diferentes contribuições para as transições por dipolo que compõe o coeficiente de absorção. Como explicado para o bulk, na seção 8.2.1.

Para NWs em WZ com $L_{x}=5 \mathrm{~nm}$, figura $8.9(\mathrm{~d})$, notamos que a absorção para luz polarizada em $\hat{z}$ começa em valores de energia menores se comparado com o bulk, figura 8.6. De fato, observamos que já no primeiro pico, linha vertical vermelha, existe uma pequena 


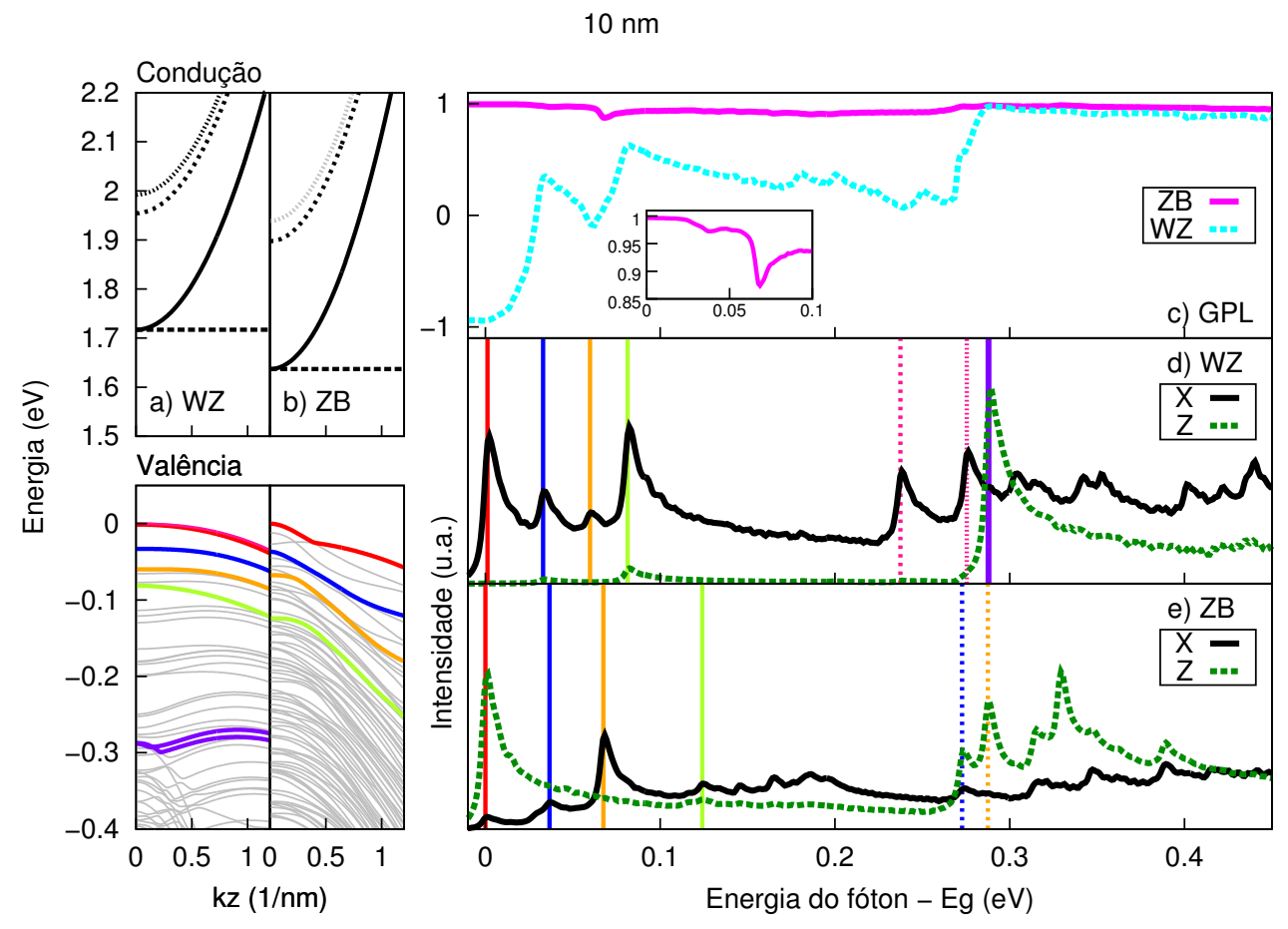

Figura 8.11 - Absorção para um fio com $L_{x}=10 \mathrm{~nm}$. A estrutura de bandas estão gráficadas em a) para os NWs em WZ e em b) para ZB, o grau de polarização linear com efeitos de $\mathrm{CO}$ e $(\mathrm{C}$ está representado em c), e o coeficiente de absorção para NWs de $\ln P$ em WZ e em ZB está representado em d) e e) respectivamente. O inset mostra um zoom em torno do valor de energia do gap para o GPL do NW em ZB.

contribuição da luz polarizada em $\hat{z}$. Podemos interpretar esse fato como a junção de dois efeitos: o espaçamento dos níveis de energia, dado pelo CQ, e a projeção das bandas de energia, como se faz no esquema de representação de zona reduzida (veja, por exemplo, capítulo 10 da Ref. (66)).

Dada a natureza multi-banda do método k.p, aplicado na obtenção da estrutura de bandas, um ponto $k$ distante do ponto $\Gamma$ possuirá contribuições de todos os kets da base (veja figura 8.13). Sendo assim, esse efeito de zone folding criará bandas de energia com contribuições consideráveis do ket $|Z\rangle$ no ponto $\Gamma$, contribuindo para a absorção de luz polarizada paralela ao eixo do fio.

O efeito observado na absorção do ZB é o contrário: no bulk vemos que as direções de polarização são isotrópicas, enquanto que no NW há um favorecimento da direção paralela ao eixo do fio. Vemos que o crescimento na direção [111] e o CQ favorece estados com bastante composição do ket $|Z\rangle$.

Outro fato notável é que para NWs em WZ com diâmetro menor que cerca de $L_{x}=$ $11 \mathrm{~nm}$ a primeira banda de valência não possui transição por dipolo para a primeira banda 


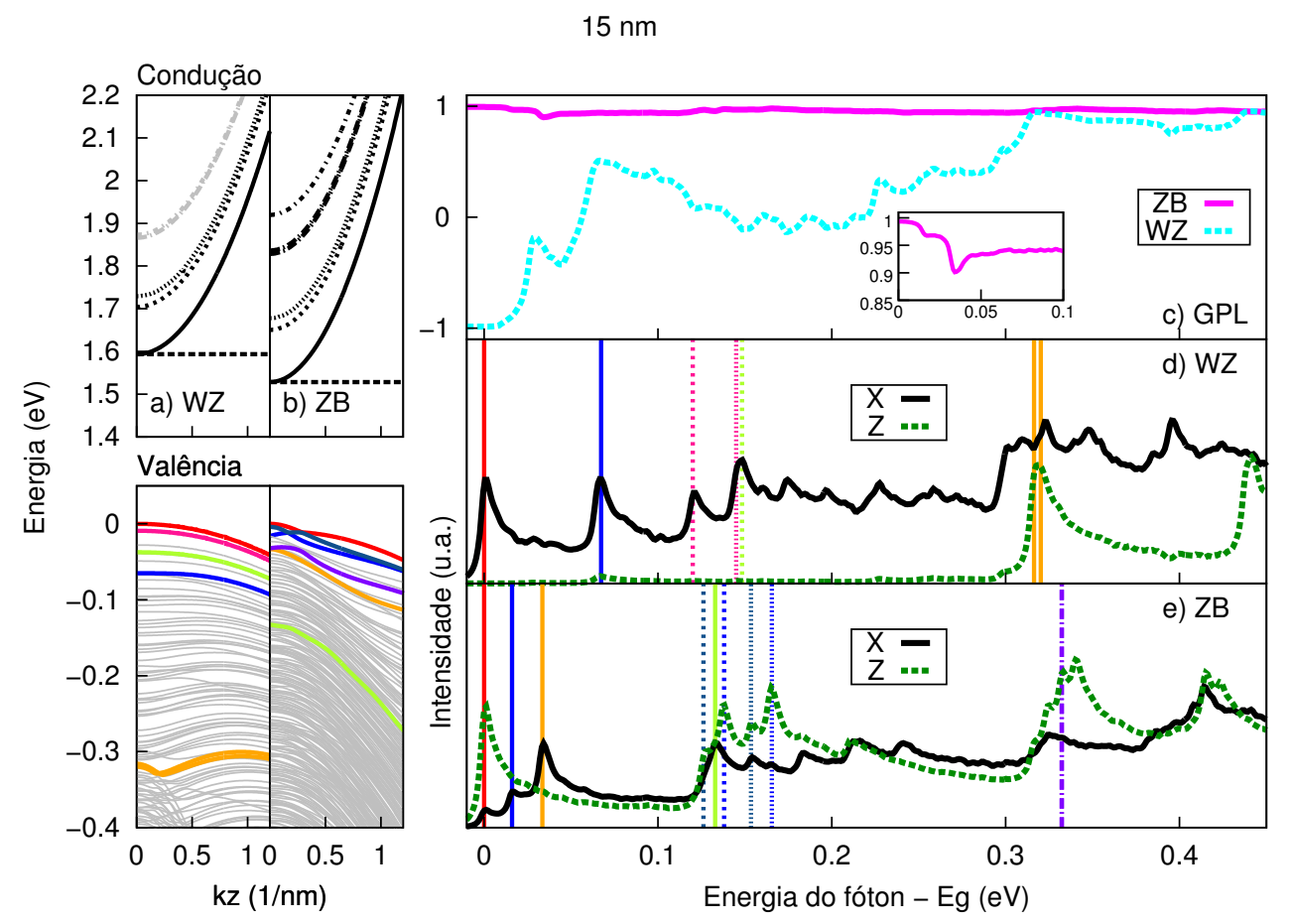

Figura 8.12 - Absorção para um fio com $L_{x}=15 \mathrm{~nm}$. A estrutura de bandas estão gráficadas em a) para os NWs em WZ e em b) para ZB, o grau de polarização linear com efeitos de $\mathrm{CO}$ e $\mathrm{CQ}$ está representado em c), e o coeficiente de absorção para NWs de $\ln P$ em WZ e em ZB está representado em d) e e) respectivamente. O inset mostra um zoom em torno do valor de energia do gap, para o GPL do NW em ZB, que está de acordo com o observado por Wang et al (60) para a mesma espessura de NW.

de condução, figuras $8.9(\mathrm{~d})-8 \cdot 11(\mathrm{~d})$. Esse estado da banda de valência é chamado de estado escuro, ou estado oticamente proibido.

Conforme aumentamos o tamanho $L_{x}$ do NW os picos de absorção, tanto em WZ quanto em ZB, tendem aos valores do bulk indicando que o efeito de $C Q$ está enfraquecendo. Com isso a absorção tende a ficar polarizada perpendicularmente ao eixo, na WZ, e totalmente isotrópica no ZB. Analisando as figuras 8.9(d,e)-8.11(d,e), observamos esse efeito em NWs em WZ pelo deslocamento do primeiro pico de absorção: à esquerda para luz polarizada em $\hat{x}$ e à direita para luz polarizada em $\hat{z}$; já nos NWs em ZB pelo o deslocamento à esquerda dos picos de absorção para luz polarizada em $\hat{x}$.

De acordo com Wang et al (60) os NW em ZB, com seção transversal circular, apresentaram uma anisotropia maior que $90 \%$, favorecendo luz com polarização paralela ao eixo do fio. Os nossos cálculos validam essa afirmação, mesmo para NWs em ZB com seção transversal hexagonal, veja insets na figuras $8.9(\mathrm{c})-8.12(\mathrm{c})$.

Para a WZ, os experimentos realizados em NWs com diâmetros grandes, mostram que 


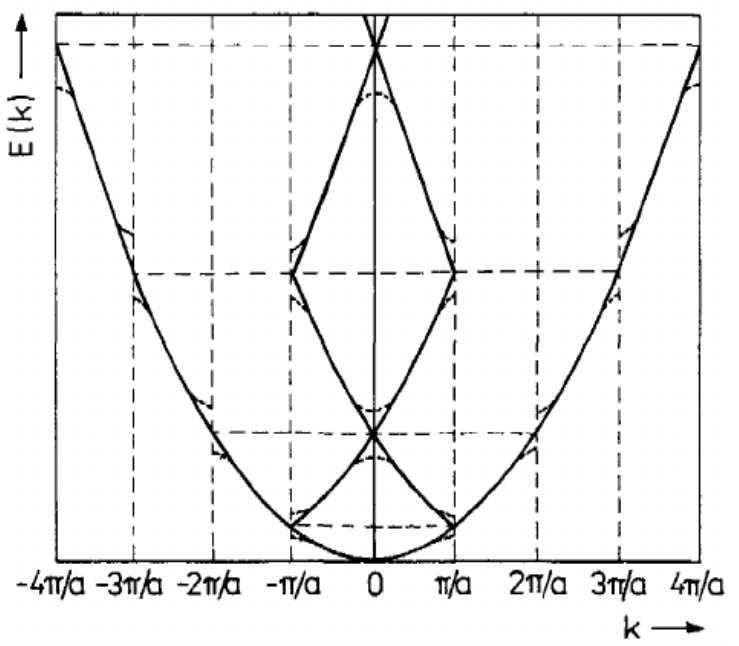

Figura 8.13 - Redução da banda de energia para a primeira zona de Brillouin de uma rede unidimensional. Um efeito semelhante acontece na presença do CQ. O sistema confinado possui uma nova zona de Brillouin menor que a zona do material bulk. Na figura, a é o vetor de base da rede de Bravais no espaço real (65).

a absorção é totalmente polarizada perpendicularmente ao eixo do fio $(32,64)$. Os nossos cálculos mostram exatamente o mesmo comportamento, quando aumentamos o tamanho do NW. Contudo, para NWs com $L_{x}$ pequeno, observamos que essa polarização não existe. Nota-se que em torno da energia do gap, no caso de $L_{x}=5 \mathrm{~nm}$, o GPL vale 1 , com uma diminuição logo após, tendendo a 0 e posteriormente voltando à 1, veja figura 8.9(c). Quando aumentamos o valor de $L_{x}$ para $8 \mathrm{~nm}$, a anisotropia (favorecendo a polarização perpendicular ao eixo do fio) já aumenta, tendendo ao seu valor máximo em torno do gap, veja figura 8.10(c). Quando aumentamos mais ainda o valor de $L_{x}$, esse comportamento é acentuado e os NWs em WZ passam a ter o GLP, em torno do gap, valendo -1, veja figuras 8.11(c) e 8.12(c), como reportam os experimentais.

\subsubsection{Cruzamento das bandas de energia}

Como observado na seção anterior, os NWs em WZ com diâmetros pequenos não possuem a anisotropia favorecendo a luz com polarização perpendicular ao eixo do fio. Para diâmetros pequenos não há transição devido à simetria da primeira banda de valência. Conforme aumentamos o valor de $L_{x}$, há uma mudança da simetria da função de onda do topo da banda de valência permitindo, agora, uma transição, como visto na figura 8.14. Como, no nosso modelo, as bandas de energia são sempre degeneradas em spin, refiro-me a elas sem levar em conta essa degenerescência. 


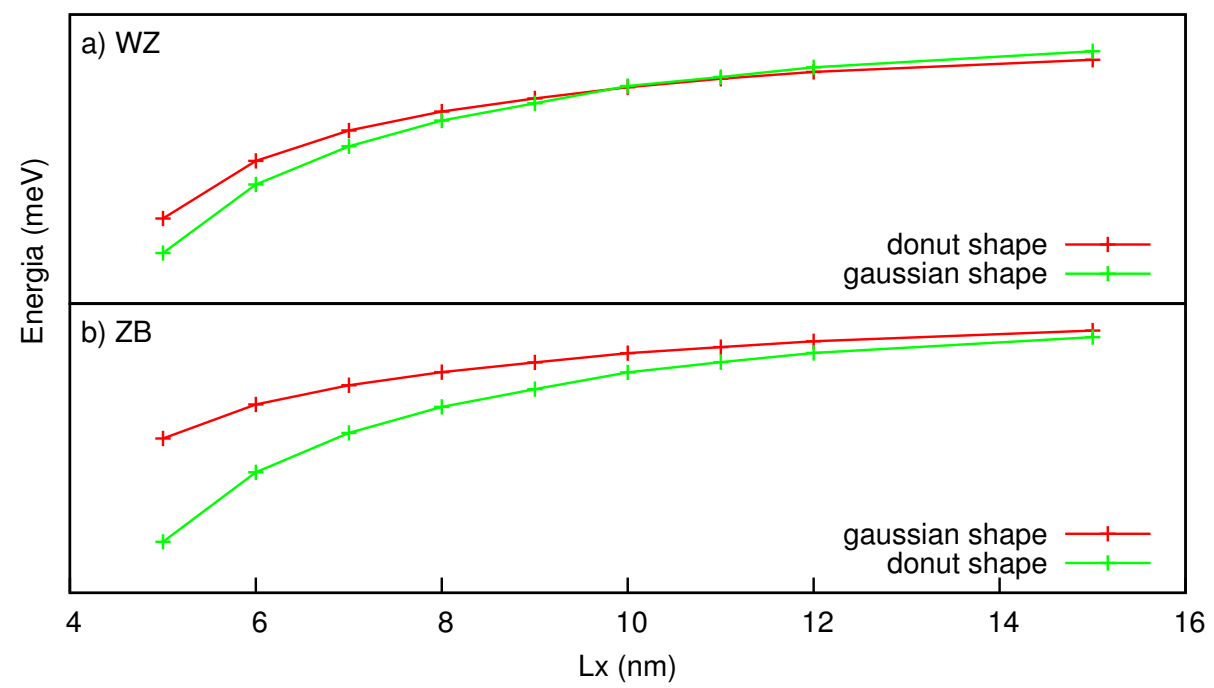

Figura 8.14 - Energia do topo das duas primeiras bandas de valência em função do tamanho, $L_{x}$, do NW em a) WZ e em b) ZB. Note que para a WZ há um cruzamento entre as bandas de energia entre os valores $L_{x}=10 \mathrm{~nm}$ e $L_{x}=11 \mathrm{~nm}$ que não ocorre para o ZB. Doughnut shape e gaussian shape se referem à forma da função de onda no ponto $\Gamma$, veja figura 8.17 .

Para entender melhor esse cruzamento, vamos fazer um paralelo com o problema quântico de uma partícula na caixa. Quando resolvemos o problema de uma partícula na caixa unidimensional, obtemos níveis de energias discretos e funções de onda que obedecem a seguinte relação:

$$
\psi_{n}=\sqrt{\frac{2}{L}} \sin \left(\frac{n \pi}{L} x\right)
$$

com $L$ o tamanho da caixa e $n=1,2,3 \cdots$. Como a função de onda é proporcional ao seno, elas possuirão $p$ nós, com $p=n-1$. Define-se como nó, um cruzamento por zero. As funções de ondas e suas densidades de probabilidades estão representadas na figura 8.15(a).

No nosso modelo, a banda de condução se comporta como uma partícula na caixa, ou segundo o modelo de tight-binding, uma banda s. Assim, suas funções de onda deverão se assemelhar às de um poço quântico bi-dimensional. As densidades de probabilidade, para os dois primeiros estados da banda de condução no ponto $\Gamma$, realmente se comportam como o previsto e estão apresentados nas figuras 8.15 (b) e 8.15(c). Pela nossa seção transversal ser hexagonal o segundo estado, figura 8.15 (c), é levemente alongado em direção às faces do hexágono. 


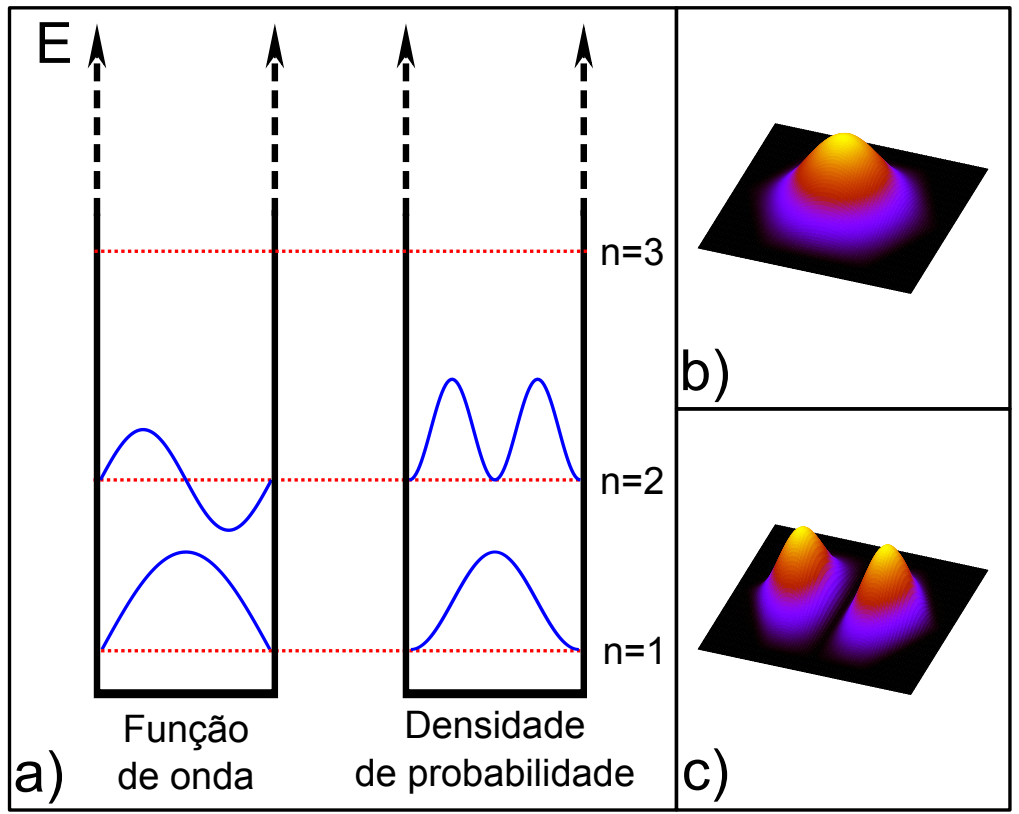

Figura 8.15 - Níveis de energia de um poço quântico, suas funções de ondas e densidades de probabilidade. a) Poço quântico uni-dimensional: estado fundamental não possui nó; estado excitado possui. A banda de condução, no nosso modelo, se comporta como uma partícula na caixa. b) Densidade de probabilidade, no ponto $\Gamma$, para o primeiro estado da banda de condução de um NW na fase WZ, se assemelha a uma gaussiana. c) Densidade de probabilidade, no ponto $\Gamma$, para o segundo estado da banda de condução de um NW na fase WZ, possui um nó.

E as bandas de valência, devem se comportar como o modelo de uma partícula na caixa? A resposta é não. Do ponto de vista atômico, as bandas de energia são formadas a partir das hibridizações dos orbitais atômicos. Quando os átomos estão próximos uns dos outros seu potencial é modificado, com isso os orbitais se superpõem e geram as bandas de energia. A figura 8.16(a) exemplifica esse princípio. A figura da esquerda mostra o potencial atômico e seus níveis de energia, a da direita mostra a representação do surgimento das bandas de energia. Quanto mais perto os átomos estão, mais seus níveis se superpõem e as bandas se alargam. A figura 8.16(b) mostra a estrutura de bandas do InP bulk calculada por A. De e Craig E. Pryor (103). Vemos que o topo da banda de valência não é o estado fundamental do sistema, dessa maneira não podemos dizer que ela segue o modelo de uma partícula na caixa.

Assim, não existe nenhum impedimento para a troca de simetria nas primeiras bandas de valência de um sistema confinado, visto que elas não são o estado fundamental. $O C Q$ age modificando os níveis de energia das hibridizações dos orbitais do sistema e provocando a troca das bandas de energia.

Uma das características interessantes é a forma que a densidade de probabilidade assume, no ponto $\Gamma$. Para NWs em WZ com $L_{x}<11 \mathrm{~nm}$ a densidade de probabilidade para o primeiro estado se assemelha à uma rosquinha (ou em inglês donut), como se observa na 

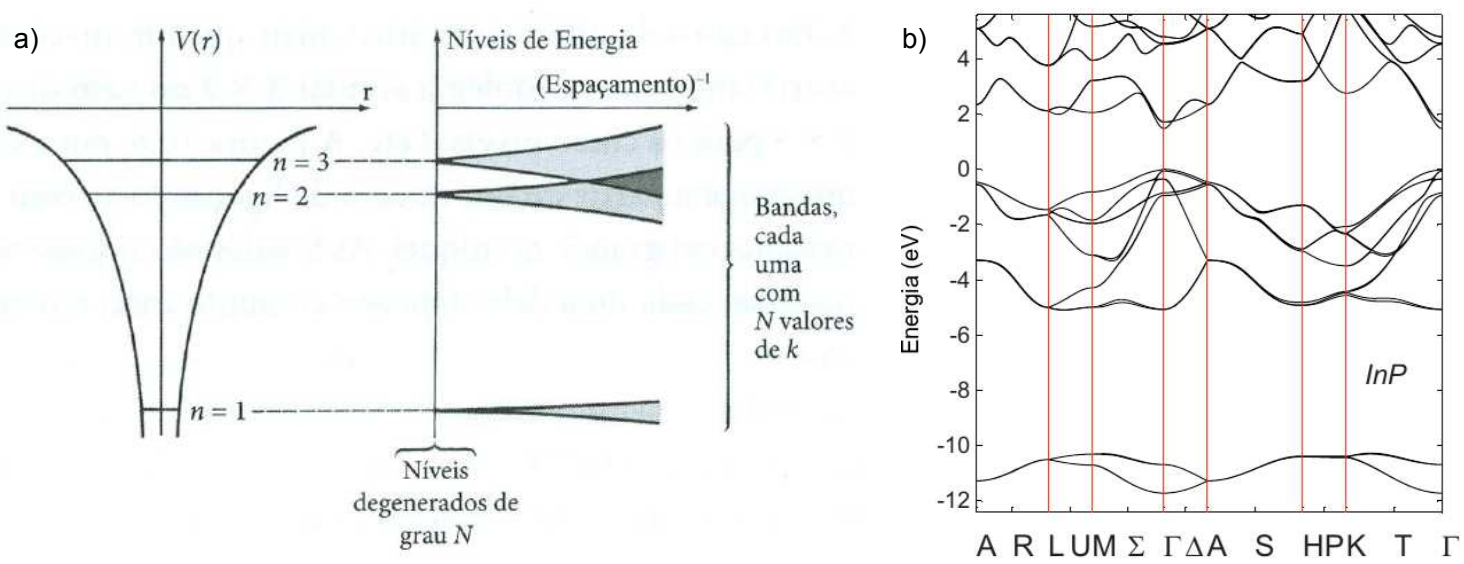

Figura 8.16 - Bandas de energia de um cristal. A figura a) exemplifica o surgimento das bandas de energia a partir da superposição dos orbitais atômicos (66). A figura b) mostra a estrutura de bandas do $\operatorname{lnP}$ bulk (103). Note que o topo da banda de valência não é o estado fundamental do sistema.

figura 8.17(a), com seu valor máximo espalhado circularmente pela seção transversal; e a do segundo estado se assemelha à uma gaussiana, como se observa na figura 8.17(b), com seu máximo concentrado no meio da seção transversal. O outro efeito é o cruzamento em energia dessas duas densidades de probabilidade.

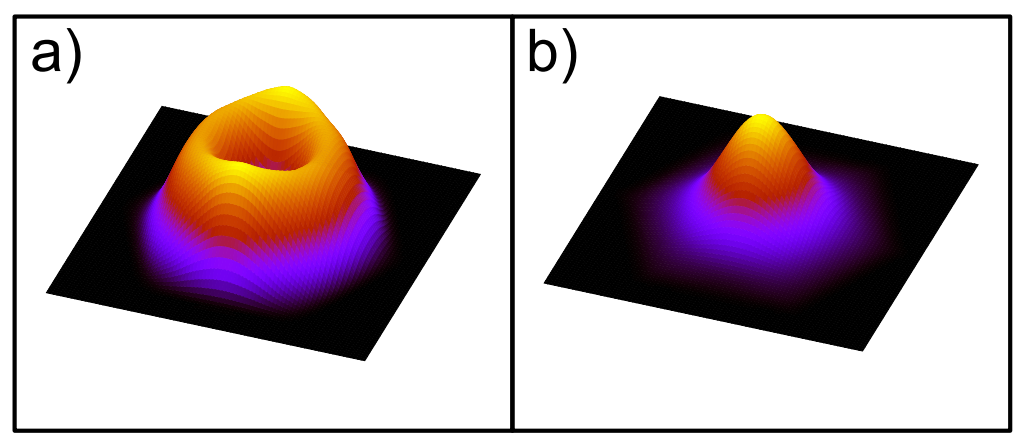

Figura 8.17 - Densidade de probabilidade, no ponto $\Gamma$, para um NW na fase WZ com $L_{x}=8 \mathrm{~nm}$. Nesta figura estão presentes os dois primeiros estados da banda de valência. a) Densidade de probabilidade do primeiro estado da banda de valência. b) Densidade de probabilidade do segundo estado da banda de valência. Neste caso, as densidades de probabilidade da banda de valência não seguem o mesmo comportamento da banda de condução.

Como apresentado na seção 8.2.1, a primeira banda de valência, no ponto $\Gamma$ do bulk em WZ, possui somente contribuição do kets $\left|c_{1}\right\rangle$ e $\left|c_{4}\right\rangle$; já no ZB, a composição é uma mistura de todos os kets que formam a base. As figuras 8.18 e 8.19 apresentam essa composição, para os dois primeiros estados da banda de valência, para a WZ e o ZB, respectivamente.

No limite em que o CQ é desprezível, a composição dos estados devem tender ao bulk, assim como a diferença de energia entre eles deve tender a zero. Na figura 8.14 vemos que a diferença de energia tende a zero rapidamente para ambas estruturas. Observamos, também, 

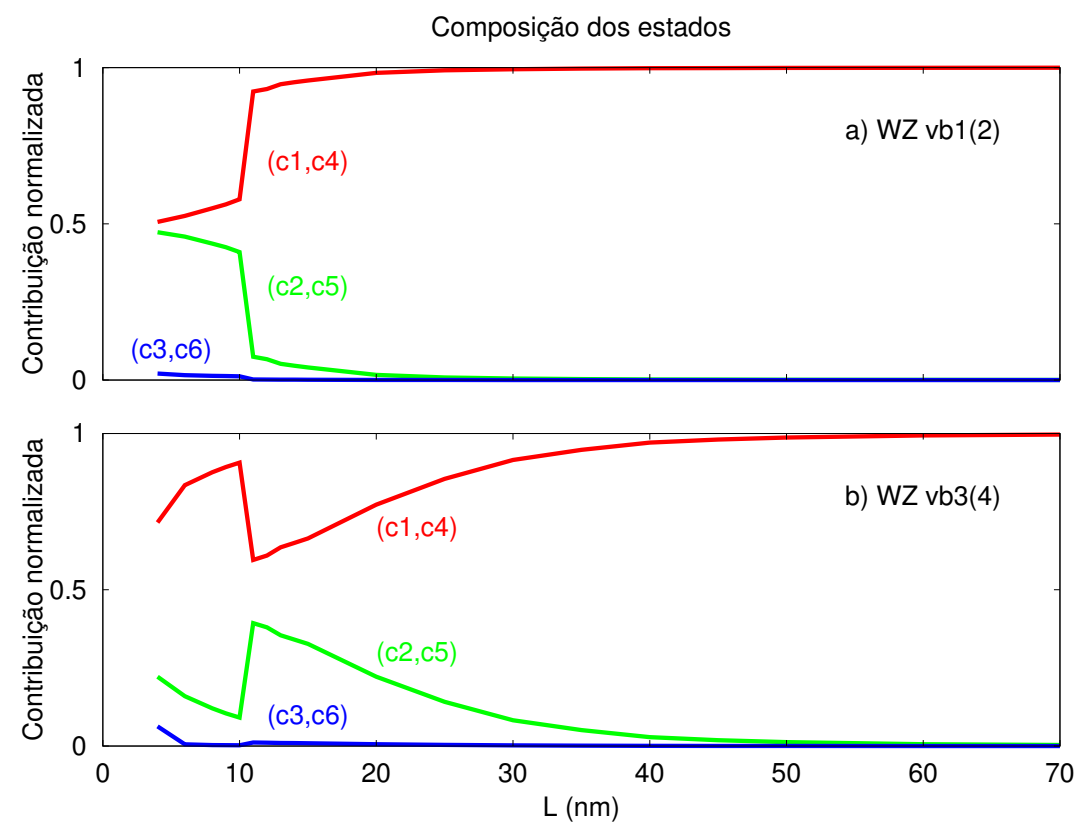

Figura 8.18 - Composição dos dois primeiros estados da banda de valência da WZ como função de $L_{x}$. Há uma mudança brusca na composição dos estados entre $L_{x}=10 \mathrm{~nm}$ e $L_{x}=12 \mathrm{~nm}$. O primeiro estado da banda de valência, vb1(2), até $L_{x}=11 \mathrm{~nm}$ é aquele cujo formato se assemelha à um donut. Em $L_{x}=12 \mathrm{~nm}$ vb1(2) passa a ser o que se assemelha à uma gaussiana. Todos os estados tendem à composição do bulk.

que a composição do estado que se assemelha à gaussiana já é praticamente a composição do bulk por volta de $L_{x}=20 \mathrm{~nm}$, figura 8.18(a), enquanto que o estado donut perdura até praticamente $L_{x}=40 \mathrm{~nm}$. No caso do ZB, por volta de $L_{x}=20 \mathrm{~nm}$ os dois estados já possuem as mesmas contribuições que o bulk, figura 8.19. Assim, concluímos que o estado donut sofre mais o efeito de $\mathrm{CQ}$ na fase $\mathrm{WZ}$ e, portanto, é mais propenso à variar sua energia conforme variamos o $\mathrm{CQ}$.

Para corroborar esse fato, vamos usar a matriz (4.2.4) e a equação (4.2.6) para calcular quais estados de base, ou interações entre eles, contribuem mais para a energia final do estado diagonalizado.

Denotarei por $h 12(45)+h 21(54)$ o valor da interação entre os estados de base $\left|c_{1}\right\rangle$ com $\left|c_{2}\right\rangle$ ou $\left|c_{4}\right\rangle$ com $\left|c_{5}\right\rangle$; e $h 11(44)$ e $h 22(55)$ o valor da diagonal; ou seja:

$$
h 12(45)+h 21(54)=2 \operatorname{Re}\left(\left\langle F_{1}\left|-\tilde{K}^{\dagger}\right| F_{2}\right\rangle\right)+2 R e\left(\left\langle F_{4}|-\tilde{K}| F_{5}\right\rangle\right)
$$



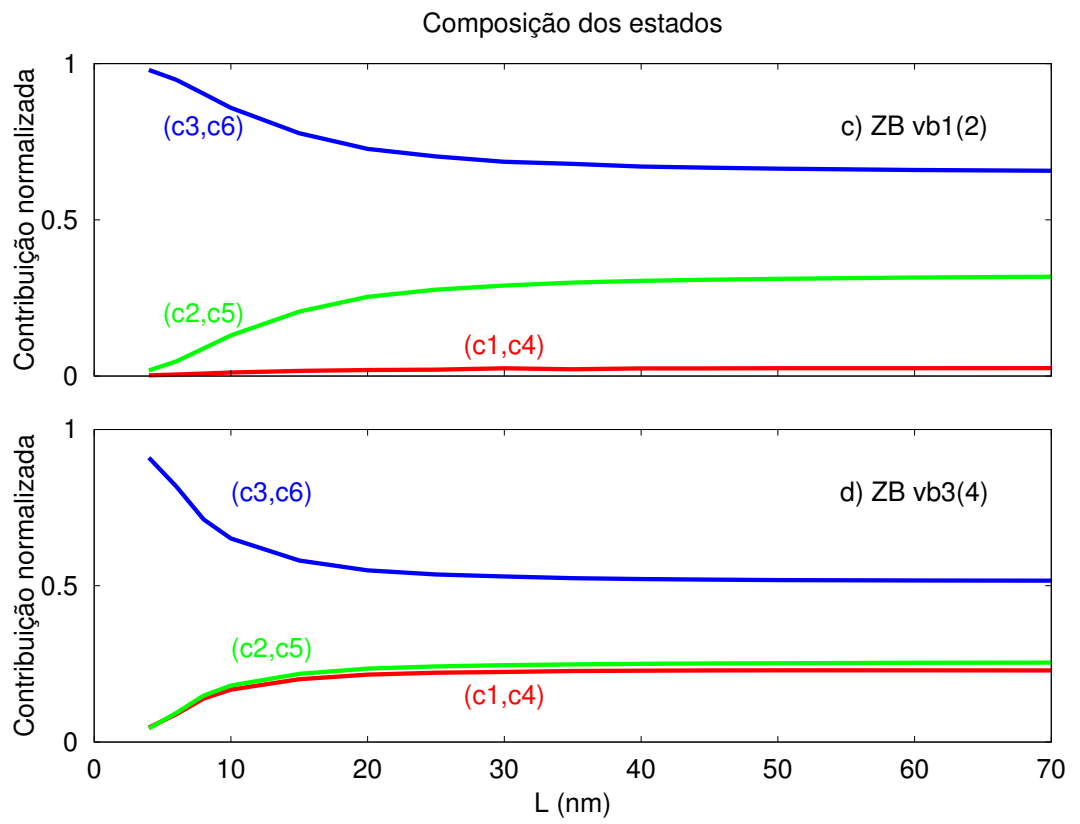

Figura 8.19 - Composição dos dois primeiros estados da banda de valência do ZB como função de $L_{x}$. Não há descontinuidade na composição dos estados, eles tendem suavemente à composição do bulk.

e

$$
\begin{aligned}
h 11 & =\left\langle F_{1}\left|\tilde{F}+V_{\text {het }}\right| F_{1}\right\rangle \\
h 44 & =\left\langle F_{4}\left|\tilde{F}+V_{\text {het }}\right| F_{4}\right\rangle \\
h 22 & =\left\langle F_{2}\left|\tilde{G}+V_{\text {het }}\right| F_{2}\right\rangle \\
h 55 & =\left\langle F_{5}\left|\tilde{G}+V_{\text {het }}\right| F_{5}\right\rangle
\end{aligned}
$$

com $F_{i}$ as funções envelopes associadas aos estados de base $\left|c_{i}\right\rangle$.

A figura 8.20 sumariza as contribuições de energia, do NW em WZ, em função do tamanho $L_{x}$. A contribuição de energia da interação tende a zero, conforme diminuímos o $C Q$, para os dois estados. Entretanto, a contribuição relativa da interação com a diagonal tende a zero de maneira diferente. No donut, as contribuições andam juntas; já no gaussiano, as contribuições são diferentes.

O termo fora da diagonal, dado por $\tilde{K}$, representa a interação que o CQ induz aos estados de base $\left|c_{1(4)}\right\rangle$ e $\left|c_{2(5)}\right\rangle$. Para o estado donut, no regime de CQ grande, a contribuição de energia da interação é comparável à contribuição de energia da diagonal. Assim, o CQ induzirá um mixing maior dos estados de base na função de onda final, veja figuras 8.20(a) e 8.20(c). A contribuição de energia da interação para o estado gaussiano é sempre menor 

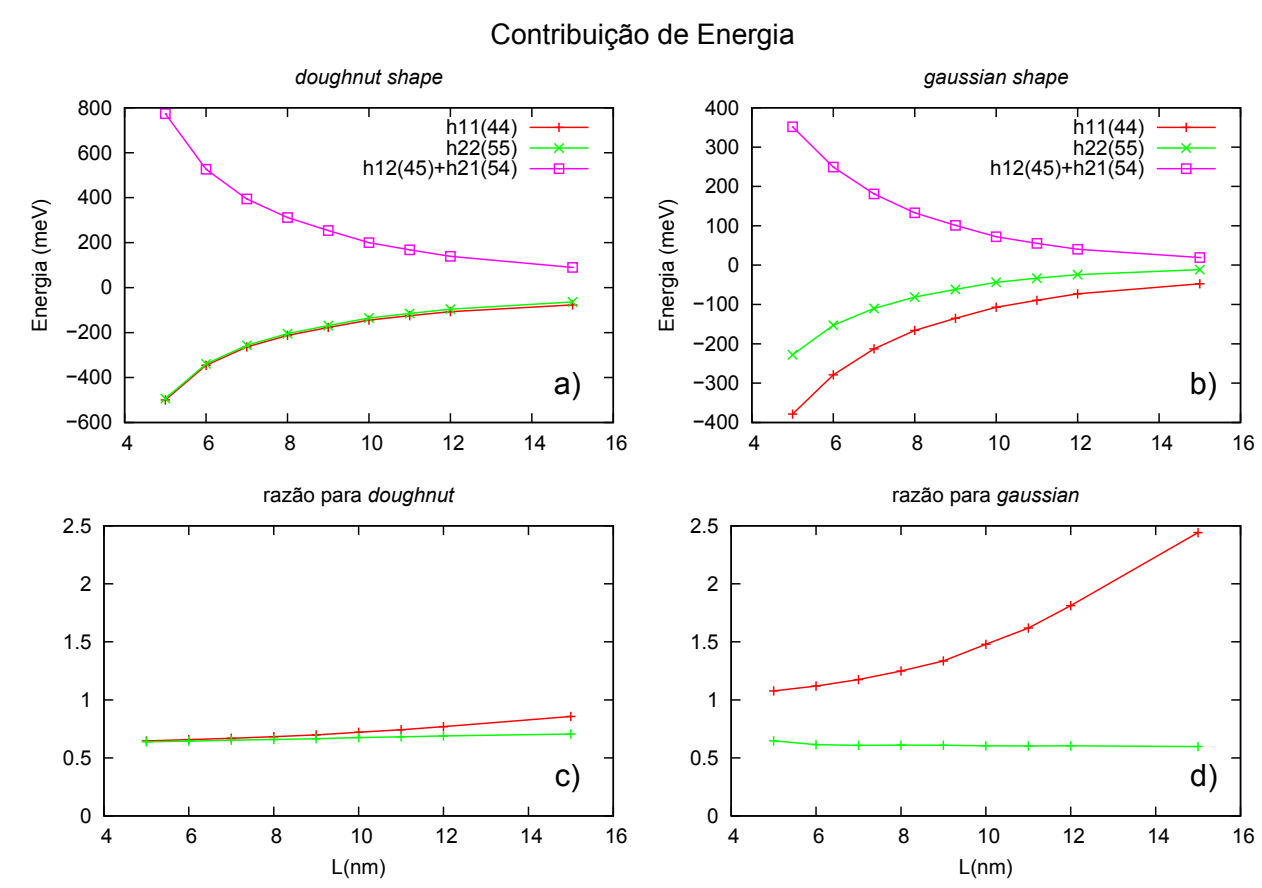

Figura 8.20 - Contribuição de energia em função do tamanho $L_{x}$ do NW. As linhas em vermelho e verde representam as contribuições dos elementos da diagonal e a linha em magenta representa a contribuição do termo de interação. Em a) e b) temos as contribuições de energia dos três termos, em c) e d) temos o valor absoluto da razão entre o valor da diagonal com a interação. Note que para o estado donut as contribuições da diagonal são próximas, já o gaussiano possui o termo $h 11(44)$ sempre maior que a interação. A contribuição do termo $h 22(55)$ possui o mesmo comportamento nos dois estados.

que a contribuição da diagonal, e o mixing dos estados perde força rapidamente, veja figuras 8.20 (b) e 8.20 (d). Portanto, vemos que os efeitos induzidos pelo CQ são mais fortes no estado donut.

Esses estados escuros foram primeiramente observados em pontos quânticos de CdS e CdSe na fase WZ. Sua natureza foi amplamente estudada teoricamente, tanto pelo método k.p quanto por métodos ab initio, e confirmada experimentalmente (104-110). Até o presente momento fui capaz de encontrar somente um trabalho (111) onde esse estado que se assemelha à um donut foi reportado, em NWs em ZB de InAs. A realização experimental de NWs com diâmetros nessa faixa não está longe de ser alcançada e com isso uma gama de aplicações, que antes eram restritas aos pontos quânticos, poderão ser exploradas com esses fios quânticos. 


\section{Conclusões}

Observamos que houve um ganho de desempenho na utilização do método de minimização, LOBPCG, comparado com a execução utilizando a rotina de diagonalização direta, CHEEVX. Esse ganho no desempenho é atribuído a dois fatores: i) os métodos de minimização, em geral, possuem um comportamento assintótico limitado superiormente pelo tamanho da matriz ao quadrado; e os métodos de diagonalização direta, pelo tamanho da matriz ao cubo. ii) As placas gráficas possuem um alto poder de processamento disponível para problemas que são maciçamente paralelos.

Por se basear em multiplicações de matrizes, a implementação do LOBPCG utiliza-se do poder máximo de processamento que as GPUs oferecem. Isso, aliado ao seu comportamento assintótico, o torna adequado para ser usado quando a matriz que descreve nosso sistema ultrapassa 5,5 giga elementos.

Além de implementar esse código na GPU, estudei a interação da radiação com os NWs. Para isso, generalizamos a aproximação da função envelope e o formalismo da expansão em ondas planas para confinamentos em mais de uma dimensão. A partir desse ponto, pudemos

calcular a estrutura de bandas para NWs e analisar como as transições eletrônicas (criação de pares elétron-buraco) desses sistemas influenciam seu poder de absorção.

De acordo com a literatura, os NWs de ZB exibem um GPL maior que 0,9 em seu poder de absorção. Somente a criação de pares elétron-buraco não explica seu espectro de absorção e a inclusão do CO, através do amortecimento da componente perpendicular do campo elétrico incidente, se fez necessária. Assim, para NWs de ZB com diâmetro reduzido, as simulações realizadas com o método k.p 6x6 reproduziu fielmente essa anisotropia observada experimentalmente.

Para a WZ, os resultados experimentais contemplam somente NWs com diâmetros grandes. Nesses NWs, é observada uma anisotropia contrária à do ZB, ou seja, favorecendo a radiação com polarização paralela ao eixo do NW.

Além de reproduzir esses resultados com o modelo proposto, observamos que para NWs em WZ, com diâmetro reduzido, há o surgimento de um estado proibido. Esse estado modifica 
a anisotropia dos NWs de WZ. Quando o CQ é grande, a anisotropia em torno do gap é parecida com a do ZB visto que não existe transições permitidas nessa faixa de energia. Conforme diminuímos o $C Q$, há um cruzamento de energia entre o estado proibido e o estado acessível, e com isso GPL dos NWs em WZ tendem aos valores observados experimentalmente.

Em conclusão, o método de cálculo usado no LFC foi generalizado e portado para a GPU. Observamos um ganho no desempenho do programa, com a possibilidade de aumentálo ainda mais. Ao que tange as características óticas dos NWs, consolidei o método usado confrontando-o com os resultados experimentais presentes na literatura. Para NWs de WZ com diâmetro reduzido, observamos o surgimento de um estado proibido como o observado em pontos quânticos de $\mathrm{CdS}$ e $\mathrm{CdSe}$. 


\section{Trabalhos futuros}

Para acelerar mais ainda o método de minimização, devemos considerar as características inerentes ao sistema de equações que resolvemos. Dessa maneira, ao invés de utilizarmos pré-condicionadores gerais nós podemos nos focar naqueles específicos à forma do nosso $\mathrm{Ha}$ miltoniano. O sistema que resolvemos, descrito pela equação 3.3.13, pertence à uma classe especial de sistemas lineares chamado de block Toeplitz systems. Os pré-condicionares indicados à esse tipo de sistema são as matrizes circulantes. Usando essa classe de pré-condicionadores um sistema Toeplitz $n \times n$ pode ser resolvido com uma complexidade $O(n \log n)$ (112). Por falta de tempo hábil, durante a realização do presente estudo, não implementei essa classe de pré-condicionadores. Contudo, pretendo implementá-lo e testá-lo no meu doutorado. Com a possibilidade de alcançar uma taxa de convergência maior no método de minimização, poderemos simular fios ou pontos quânticos dopados e/ou core/shell.

Com a inclusão de carga no sistema, temos que realizar um cálculo auto-consistente. Cada interação desse cálculo consiste na diagonalização, para os vários pontos $\vec{k}$ do espaço recíproco, do Hamiltoniano, incluindo os efeitos da interação de Coulomb e de troca-correlação. Já os fios core/shell usam uma discretização maior, aumentando o tamanho do Hamiltoniano. Assim, um método mais eficiente se faz necessário. Esses sistemas são estudados em diversos temas atuais: pólarons magnéticos (113-115), texturas de spin (116-118), absorção óptica com aplicações em materiais fotovoltaicos e dispositivos spintrônicos (119-121), etc. 


\section{REFERÊNCIAS}

1 ESAKI, L.; TSU, R. Superlattice and negative differential conductivity in semiconductors. IBM Journal of Research and Development, v. 14, n. 1, p. 61-65, Jan. 1970.

2 WANG, N.; CAI, Y.; ZHANG, R. Growth of nanowires. Materials Science and Engineering: $R$ : reports, v. 60, n. 1-6, p. 1-51, Mar. 2008.

3 DUBROVSKII, V. G.; CIRLIN, G. E.; USTINOV, V. M. Semiconductor nanowhiskers: synthesis, properties, and applications. Semiconductors, v. 43, n. 12, p. 1539-1584, Dec. 2009.

4 GLAS, F.; PATRIARCHE, G.; HARMAND, J. C. Growth, structure and phase transitions of epitaxial nanowires of III-V semiconductors. Journal of Physics: conference series, v. 209, n. 1, p. 012002, Feb. 2010.

5 DUAN, X.; LIEBER, C. M. General synthesis of compound semiconductor nanowires. Advanced Materials, v. 12, n. 4, p. 298-302, Feb. 2000.

6 GUDIKSEN, M. S.; WANG, J.; LIEBER, C. M. Synthetic control of the diameter and length of single crystal semiconductor nanowires. Journal of Physical Chemistry B, v. 105, n. 19, p. 4062-4064, May 2001.

7 MATTILA, M.; HAKKARAINEN, T.; MULOT, M.; LIPSANEN, H. Crystal-structuredependent photoluminescence from InP nanowires. Nanotechnology, v. 17, n. 6, p. 1580-1583, Mar. 2006.

8 TRAGARDH, J.; PERSSON, A. I.; WAGNER, J. B.; HESSMAN, D.; SAMUELSON, L. Measurements of the band gap of wurtzite inas[sub $1-x] p[$ sub $x]$ nanowires using photocurrent spectroscopy. Journal of Applied Physics, v. 101, n. 12, p. 123701, June 2007.

9 VU, T. T. T.; ZEHENDER, T.; VERHEIJEN, M. A.; PLISSARD, S. R.; IMMINK, G. W. G.; HAVERKORT, J. E. M.; BAKKERS, E. P. A. M. High optical quality single crystal phase wurtzite and zincblende InP nanowires. Nanotechnology, v. 24, n. 11, p. 115705, Mar. 2013.

10 SPIRKOSKA, D. et al. Structural and optical properties of high quality zincblende/wurtzite GaAs nanowire heterostructures. Physical Review B, v. 80, n. 24, p. 1-9, Dec. 2009.

11 PEMASIRI, K.; MONTAZERI, M.; GASS, R.; SMITH, L. M.; JACKSON, H. E.; YARRISON-RICE, J.; PAIMAN, S.; GAO, Q.; TAN, H. H.; JAGADISH, C.; ZHANG, X.; 
ZOU, J. Carrier dynamics and quantum confinement in type II ZB-WZ InP nanowire homostructures. Nano Letters, v. 9, n. 2, p. 648-54, Feb. 2009.

12 JANCU, J.-M.; GAUTHRON, K.; LARGEAU, L.; PATRIARCHE, G.; HARMAND, J.-C.; VOISIN, P. Type II heterostructures formed by zinc-blende inclusions in InP and GaAs wurtzite nanowires. Applied Physics Letters, v. 97, n. 4, p. 041910, July 2010.

13 LI, D.; WANG, Z.; GAO, F. First-principles study of the electronic properties of wurtzite, zinc-blende, and twinned InP nanowires. Nanotechnology, v. 21, n. 50, p. 505709, Dec. 2010.

14 ZHANG, L.; LUO, J.-W.; ZUNGER, A.; AKOPIAN, N.; ZWILLER, V.; HARMAND, J.C. Wide InP nanowires with wurtzite/zincblende superlattice segments are type-II whereas narrower nanowires become type-I: an atomistic pseudopotential calculation. Nano Letters, v. 10, n. 10, p. 4055-60, Oct. 2010.

15 KITAUCHI, Y.; KOBAYASHI, Y.; TOMIOKA, K.; HARA, S.; HIRUMA, K.; FUKUI, T.; MOTOHISA, J. Structural transition in indium phosphide nanowires. Nano Letters, v. 10, n. 5, p. 1699-703, May 2010.

16 PANSE, C.; KRIEGNER, D.; BECHSTEDT, F. Polytypism of GaAs, InP, InAs, and InSb: an ab initio study. Physical Review B, v. 84, n. 7, p. 1-9, Aug. 2011.

17 FARIA JUNIOR, P. E.; SIPAHI, G. M. Band structure calculations of InP wurtzite/zincblende quantum wells. Journal of Applied Physics, v. 112, n. 10, p. 103716, Nov. 2012.

18 DHEERAJ, D. L.; MUNSHI, A. M.; SCHEFFLER, M.; VAN HELVOORT, A. T. J.; WEMAN, H.; FIMLAND, B. O. Controlling crystal phases in GaAs nanowires grown by Au-assisted molecular beam epitaxy. Nanotechnology, v. 24, n. 1, p. 015601, Jan. 2013.

19 CUI, Y.; WEI, Q.; PARK, H.; LIEBER, C. M. Nanowire nanosensors for highly sensitive and selective detection of biological and chemical species. Science, v. 293, n. 5533, p. 1289-92, Aug. 2001.

20 ZHENG, G.; PATOLSKY, F.; CUI, Y.; WANG, W. U.; LIEBER, C. M. Multiplexed electrical detection of cancer markers with nanowire sensor arrays. Nature Biotechnology, v. 23, n. 10, p. 1294-301, Oct. 2005.

21 NA, Y.-R.; KIM, S. Y.; GAUBLOMME, J.; SHALEK, A.; JORGOLLI, M.; PARK, H.; YANG, E. G. Probing enzymatic activity inside living cells using a nanowire-cell "sandwich"assay. Nano Letters, v. 13, n. 1, p. 153-158, Dec. 2012.

22 JEONG, H. E.; KIM, I.; KARAM, P.; CHOI, H.-J.; YANG, P. Bacterial recognition of silicon nanowire arrays. Nano Letters, May 2013. DOI: 10.1021/nl401205b. Disponível em: <http://pubs.acs.org/doi/abs/10.1021/nl401205b>. Acesso em: 11 jun. 2013. 
23 HUANG, Y.; DUAN, X.; LIEBER, C. Nanowires for integrated multicolor nanophotonics. Small, v. 1, n. 1, p. 142-147, Oct. 2005.

24 PETTERSSON, H.; TRäGA RDH, J.; PERSSON, A. I.; LANDIN, L.; HESSMAN, D.; SAMUELSON, L. Infrared photodetectors in heterostructure nanowires. Nano Letters, v. 6 , n. 2, p. 229-32, Feb. 2006.

25 XU, S.; GUO, W.; DU, S.; LOY, M. M. T.; WANG, N. Piezotronic effects on the optical properties of ZnO nanowires. Nano Letters, v. 12, n. 11, p. 5802-7, Nov. 2012.

26 AHTAPODOV, L.; TODOROVIC, J.; OLK, P.; MJÅ LAND, T.; SLA TTNES, P.; DHEERAJ, D. L.; VAN HELVOORT, A. T. J.; FIMLAND, B. R.-O.; WEMAN, H. A story told by a single nanowire: optical properties of wurtzite GaAs. Nano Letters, v. 12, n. 12, p. 6090-5, Dec. 2012.

27 FEEZELL, D.; SHARMA, Y.; KRISHNA, S. Optical properties of nonpolar III-nitrides for intersubband photodetectors. Journal of Applied Physics, v. 113, n. 13, p. 133103, Apr. 2013.

28 DUAN, X.; HUANG, Y.; CUI, Y.; WANG, J.; LIEBER, C. M. Indium phosphide nanowires as building blocks for nanoscale electronic and optoelectronic devices. Nature, v. 409, n. 6816, p. 66-9, Jan. 2001.

29 ASSALI, S.; ZARDO, I.; PLISSARD, S.; KRIEGNER, D.; VERHEIJEN, M. A.; BAUER, G.; MEIJERINK, A.; BELABBES, A.; BECHSTEDT, F.; HAVERKORT, J. E. M.; BAKKERS, E. P. A. M. Direct band gap wurtzite gallium phosphide nanowires. Nano Letters, v. 13, n. 4, p. 1559-1563, Mar. 2013.

30 CUI, Y.; DUAN, X.; HU, J.; LIEBER, C. M. Doping and electrical transport in silicon nanowires. Journal of Physical Chemistry B, v. 104, n. 22, p. 5213-5216, June 2000.

31 ROMEO, L.; COQUILLAT, D.; PEA, M.; ERCOLANI, D.; BELTRAM, F.; SORBA, L.; KNAP, W.; TREDICUCCI, A.; VITIELLO, M. S. Nanowire-based field effect transistors for terahertz detection and imaging systems. Nanotechnology, v. 24, n. 21, p. 214005, May 2013.

32 MISHRA, A.; TITOVA, L. V.; HOANG, T. B.; JACKSON, H. E.; SMITH, L. M.; YARRISON-RICE, J. M.; KIM, Y.; JOYCE, H. J.; GAO, Q.; TAN, H. H.; JAGADISH, C. Polarization and temperature dependence of photoluminescence from zincblende and wurtzite InP nanowires. Applied Physics Letters, v. 91, n. 26, p. 263104, Dec. 2007.

33 CHEN, R.; TRAN, T.-T. D.; NG, K. W.; KO, W. S.; CHUANG, L. C.; SEDGWICK, F. G.; CHANG-HASNAIN, C. Nanolasers grown on silicon. Nature Photonics, v. 5, n. 3, p. 170-175, Feb. 2011.

34 GRZELA, G.; PANIAGUA-DOMÍngUEZ, R.; BARTEN, T.; FONTANA, Y.; SánCHEZGIL, J. A.; GóMEZ RIVAS, J. Nanowire antenna emission. Nano Letters, v. 12, n. 11, p. 5481-6, Nov. 2012. 
35 GARNETT, E.; YANG, P. Light trapping in silicon nanowire solar cells. Nano Letters, v. 10, n. 3, p. 1082-7, Mar. 2010.

36 KAILUWEIT, P.; PETERS, M.; LEENE, J.; MERGENTHALER, K.; DIMROTH, F.; BETT, A. W. Numerical simulations of absorption properties of $\ln P$ nanowires for solar cell applications. Progress in Photovoltaics: research and applications, v. 20, n. 8, p. 945-953, Sept. 2011.

37 MARIANI, G.; ZHOU, Z.; SCOFIELD, A.; HUFFAKER, D. L. Direct-bandgap epitaxial core-multishell nanopillar photovoltaics featuring subwavelength optical concentrators. Nano Letters, v. 13, n. 4, p. 1632-1637, Mar. 2013.

38 LIU, C.; TANG, J.; CHEN, H. M.; LIU, B.; YANG, P. A fully integrated nanosystem of semiconductor nanowires for direct solar water splitting. Nano Letters, May 2013. DOI: 10.1021/nl401615t. Disponível em: <http://pubs.acs.org/doi/abs/10. 1021/nl401615t >. Acesso em: 11 jun. 2013.

39 LIN, X. X.; HUA, X.; HUANG, Z. G.; SHEN, W. Z. Realization of high performance silicon nanowire based solar cells with large size. Nanotechnology, v. 24, n. 23, p. 235402, June 2013.

40 WALLENTIN, J.; ANTTU, N.; ASOLI, D.; HUFFMAN, M.; ABERG, I.; MAGNUSSON, M. H.; SIEFER, G.; FUSS-KAILUWEIT, P.; DIMROTH, F.; WITZIGMANN, B.; XU, H. Q.; SAMUELSON, L.; DEPPERT, K.; BORGSTRöM, M. T. InP nanowire array solar cells achieving $13.8 \%$ efficiency by exceeding the ray optics limit. Science, v. 1057, n. 6123, p. 1057-1060, Jan. 2013.

41 PRIBIAG, V. S.; NADJ-PERGE, S.; FROLOV, S. M.; VAN DEN BERG, J. W. G.; VAN WEPEREN, I.; PLISSARD, S. R.; BAKKERS, E. P. A. M.; KOUWENHOVEN, L. P. Electrical control of single hole spins in nanowire quantum dots. Nature Nanotechnology, v. 8, n. 3, p. 170-174, Feb. 2013.

42 JOYCE, H. J.; DOCHERTY, C. J.; GAO, Q.; TAN, H. H.; JAGADISH, C.; LLOYDHUGHES, J.; HERZ, L. M.; JOHNSTON, M. B. Electronic properties of GaAs, InAs and InP nanowires studied by terahertz spectroscopy. Nanotechnology, v. 24, n. 21, p. 214006, May 2013.

43 DOBROVOLSKY, A.; STEHR, J. E.; CHEN, S. L.; KUANG, Y. J.; SUKRITTANON, S.; TU, C. W.; CHEN, W. M.; BUYANOVA, I. A. Mechanism for radiative recombination and defect properties of GaP/GaNP core/shell nanowires. Applied Physics Letters, v. 101, n. 16, p. 163106, Oct. 2012.

44 CHUANG, S.; GAO, Q.; KAPADIA, R.; FORD, A. C.; GUO, J.; JAVEY, A. Ballistic InAs nanowire transistors. Nano Letters, v. 13, n. 2, p. 555-558, Jan. 2013. 
45 NILSSON, H. A.; THELANDER, C.; FRÖBERG, L. E.; WAGNER, J. B.; SAMUELSON, L. Nanowire-based multiple quantum dot memory. Applied Physics Letters, v. 89, n. 16, p. 163101, Oct. 2006.

46 FRIEDMAN, R. S.; MCALPINE, M. C.; RICKETTS, D. S.; HAM, D.; LIEBER, C. M. Nanotechnology: high-speed integrated nanowire circuits. Nature, v. 434, n. 7037, p. 1085, Apr. 2005.

47 THELANDER, C.; NILSSON, H. A.; JENSEN, L. E.; SAMUELSON, L. Nanowire singleelectron memory. Nano Letters, v. 5, n. 4, p. 635-8, Apr. 2005.

48 HUANG, Y.; DUAN, X.; CUI, Y.; LAUHON, L. J.; KIM, K. H.; LIEBER, C. M. Logic gates and computation from assembled nanowire building blocks. Science, v. 294, n. 5545, p. 1313-7, Nov. 2001.

49 STANESCU, T. D.; TEWARI, S. Majorana fermions in semiconductor nanowires: fundamentals, modeling, and experiment. Journal of Physics: condensed matter, v. 25, n. 23, p. 233201, June 2013.

50 FRANZ, M. Majorana's wires. Nature Nanotechnology, v. 8, n. 3, p. 149-52, Mar. 2013.

51 MOURIK, V.; ZUO, K.; FROLOV, S. M.; PLISSARD, S. R.; BAKKERS, E. P. A. M.; KOUWENHOVEN, L. P. Signatures of Majorana fermions in hybrid superconductorsemiconductor nanowire devices. Science, v. 336, n. 6084, p. 1003-7, May 2012.

52 YU, P. Y.; CARDONA, M. Fundamentals of semiconductors. Berlin, Heidelberg: SpringerVerlag, 2005.

53 RUDA, H.; SHIK, A. Polarization-sensitive optical phenomena in semiconducting and metallic nanowires. Physical Review B, v. 72, n. 11, p. 115308, Sept. 2005.

54 RUDA, H. E.; SHIK, A. Polarization-sensitive optical phenomena in thick semiconducting nanowires. Journal of Applied Physics, v. 100, n. 2, p. 024314, July 2006.

55 CHEN, H.-Y.; YANG, Y.-C.; LIN, H.-W.; CHANG, S.-C.; GWO, S. Polarized photoluminescence from single GaN nanorods: effects of optical confinement. Optics Express, v. 16, n. 17, p. 13465, Aug. 2008.

56 ILS, P.; GRéUS, C.; FORCHEL, A.; KULAKOVSKII, V.; GIPPIUS, N.; TIKHODEEV, S. Linear polarization of photoluminescence emission and absorption in quantum-well wire structures: experiment and theory. Physical Review B, v. 51, n. 7, p. 4272-4277, Feb. 1995.

57 CALIFANO, M.; ZUNGER, A. Anisotropy of interband transitions in inas quantum wires: an atomistic theory. Physical Review B, v. 70, n. 16, p. 165317, Oct. 2004. 
58 PERSSON, M.; XU, H. Giant polarization anisotropy in optical transitions of free-standing InP nanowires. Physical Review B, v. 70, n. 16, p. 161310, Oct. 2004.

59 MASLOV, A.; NING, C. Radius-dependent polarization anisotropy in semiconductor nanowires. Physical Review B, v. 72, n. 16, p. 161310, Oct. 2005.

60 WANG, J.; GUDIKSEN, M. S.; DUAN, X.; CUI, Y.; LIEBER, C. M. Highly polarized photoluminescence and photodetection from single indium phosphide nanowires. Science, v. 293, n. 5534, p. 1455-7, Aug. 2001.

61 SERCEL, P.; VAHALA, K. Polarization dependence of optical absorption and emission in quantum wires. Physical Review B, v. 44, n. 11, p. 5681-5691, Sept. 1991.

62 MCINTYRE, C.; SHAM, L. Theory of luminescence polarization anisotropy in quantum wires. Physical Review B, v. 45, n. 16, p. 9443-9446, Apr. 1992.

63 SHAN, C.; LIU, Z.; HARK, S. Photoluminescence polarization in individual CdSe nanowires. Physical Review B, v. 74, n. 15, p. 153402, Oct. 2006.

64 WILHELM, C.; LARRUE, A.; DAI, X.; MIGAS, D.; SOCI, C. Anisotropic photonic properties of III-V nanowires in the zinc-blende and wurtzite phase. Nanoscale, v. 4, n. 5, p. 1446-54, Mar. 2012.

65 ENDERLEIN, R.; HORING, J. M. N. Fundamentals of semiconductor physics and devices. Singapore: World Scientific, 1997.

66 ASHCROFT, N. W.; MERMIN, N. D. Física do estado sólido. São Paulo: Cengage Learning, 2011.

67 FARIA JUNIOR, P. E. Nanowhiskers politípicos - uma abordagem teórica baseada em teoria de grupos e no método k.p. 2012. p. 138. Dissertação (Mestrado em Ciências) Instituto de Física de São Carlos, Universidade de São Paulo, São Carlos, 2012.

68 LUTTINGER, J.; KOHN, W. Motion of electrons and holes in perturbed periodic fields. Physical Review, v. 97, n. 4, p. 869-883, Feb. 1955.

69 KANE, E. O. Physics of III-V compounds. New York: Academic Press, 1966. v.1.

70 POOLE, P. J.; DALACU, D.; WU, X.; LAPOINTE, J.; MNAYMNEH, K. Interplay between crystal phase purity and radial growth in InP nanowires. Nanotechnology, v. 23, n. 38, p. 385205, Sept. 2012.

71 PARK, S.-H.; CHUANG, S.-L. Comparison of zinc-blende and wurtzite GaN semiconductors with spontaneous polarization and piezoelectric field effects. Journal of Applied Physics, v. 87 , n. 1 , p. 353 , Sept. 2000. 
72 CHUANG, S.; CHANG, C. k.p method for strained wurtzite semiconductors. Physical Review B, v. 54, n. 4, p. 2491-2504, July 1996.

73 BASTARD, G. Wave mechanics applied to semiconductor heterostructure. Les Ulis Cedex, France: Halsted Press, 1988.

74 BARAFF, G.; GERSHONI, D. Eigenfunction-expansion method for solving the quantumwire problem: formulation. Physical Review B, v. 43, n. 5, p. 4011-4022, Feb. 1991.

75 BURT, M. G. The justification for applying the effective-mass approximation to microstructures. Journal of Physics: condensed matter, v. 4, n. 32, p. 6651-6690, Aug. 1992.

76 ZIAIE, B.; BALDI, A.; ATASHBAR, M. Introduction to micro/nanofabrication. In: BHUSHAN, B. (Ed.) Springer handbook of nanotechnology. Berlin: Springer-Verlag, 2007.

77 BAHDER, T. Eight-band k.p model of strained zinc-blende crystals. Physical Review B, v. 41, n. 17, p. 11992-12001, June 1990.

78 CHUANG, S. L. Physics of optoelectronic devices. New York: Wiley, 1995. (Wiley series in pure and applied optics, v.22).

79 REDLlńSKI, P.; PEETERS, F. Optical properties of free-standing GaAs semiconductor nanowires and their dependence on the growth direction. Physical Review B, v. 77, n. 7, p. 075329, Feb. 2008.

80 RAVI KISHORE, V. V.; CUKARIC, N.; PARTOENS, B.; TADIC, M.; PEETERS, F. M. Hole subbands in freestanding nanowires: six-band versus eight-band $k \cdot p$ modelling. Journal of Physics: condensed matter, v. 24, n. 13, p. 135302, Apr. 2012.

81 HULL, G. "life". Amazing Computing, v. 09, n. 91, p. 81-84, 121987.

82 BIBLIOTECAS implementadas em CUDA. Disponível em: <https://developer. nvidia.com/technologies/Libraries >. Acesso em: 07 mar. 2013.

83 CUDA C programming guide. Disponível em: <http://docs.nvidia.com/cuda/ cuda-c-programming-guide/index.html>. Acesso em: 07 mar. 2013.

84 WHITEPAPER CUDA ${ }^{T M}$ Compute Architecture: FERMI ${ }^{T M}$. Disponível em: $<$ http:// www.nvidia.com/content/PDF/fermi_white_papers/NVIDIA_Fermi_Compute_ Architecture_Whitepaper.pdf >. Acesso em: 15 mar. 2013.

85 AXELSSON, O. Iterative solution methods. New York: Cambridge University Press, 1996. 
86 SHEWCHUK, J. R. An introduction to the conjugate gradient method without the agonizing pain. Disponível em: <http://www.cs.cmu.edu/ jrs/jrspapers.html>. Acesso em: 07 mar. 2013.

87 KNYAZEV, A. V. Toward the optimal preconditioned eigensolver: locally optimal block preconditioned conjugate gradient method. SIAM Journal on Scientific Computing, v. 23, n. 2, p. 517-541, Jan. 2001.

88 KNYAZEV, A. V. Preconditioned eigensolvers. Disponível em: <http://math. ucdenver.edu/ aknyazev/research/papers/>. Acesso em: 12 mar. 2013.

89 TREFETHEN, L. N.; BAU, D. Numerical linear algebra. Philadelphia: SIAM: Society for Industrial and Applied Mathematics, 1997.

90 BARRETT, R.; BERRY, M.; CHAN, T. F.; DEMMEL, J.; DONATO, J. M.; DONGARRA, J.; EIJKHOUT, V.; POZO, R.; ROMINE, C. Templates for the solution of linear systems: building blocks for iterative methods. Philadelphia: SIAM: Society for Industrial and Applied Mathematics, 1987.

91 KNYAZEV, A. V. A preconditioned conjugate gradient method for eigenvalue problems and its implementation in a subspace. Disponível em: <http://math.ucdenver.edu/ aknyazev/research/papers/>. Acesso em: 12 mar. 2013.

92 ARFKEN, G.; WEBER, H.; HARRIS, F. Mathematical methods for physicists 6th ed. Waltham, Massachusetts: Elsevier Science, 2005.

93 SIPAHI, G. M.; ENDERLEIN, R.; SCOLFARO, L. M. R.; LEITE, J. R.; DA SILVA, E. C. F.; LEVINE, A. Theory of luminescence spectra from $\delta$-doping structures: application to gaas. Physical Review B, v. 57, n. 15, p. 9168-9178, Apr. 1998.

94 SIPAHI, G. M. Teoria do confinamento de buracos em heteroestruturas semicondutoras do tipo $\delta$-doping. 1997. p. 127. Tese (Doutorado em Física) - Instituto de Física, Universidade de São Paulo, São Paulo, 1997.

95 D'EURYDICE, M. N. Estrutura de bandas de valência em poços quânticos e super-redes de nitretos na fase hexagonal. 2006. p. 73. Dissertação (Mestrado em Ciências) - Instituto de Física de São Carlos, Universidade de São Paulo, São Carlos, 2006.

96 VURGAFTMAN, I.; MEYER, J. R.; RAM-MOHAN, L. R. Band parameters for III-V compound semiconductors and their alloys. Journal of Applied Physics, v. 89, n. 11, p. 5815, Feb. 2001.

97 DOS SANTOS, L. F.; PUSEP, Y. A.; VILLEGAS-LELOVSKY, L.; LOPEZ-RICHARD, V.; MARQUES, G. E.; GUSEV, G. M.; SMIRNOV, D.; BAKAROV, A. K. Quantum oscillations of spin polarization in a GaAs/AIGaAs double quantum well. Physical Review B, v. 86, n. 12, p. 125415, Sept. 2012. 
98 WATSON, J. D.; MONDAL, S.; GARDNER, G.; CSÁTHY, G. A.; MANFRA, M. J. Exploration of the limits to mobility in two-dimensional hole systems in $\mathrm{GaAs} / \mathrm{AIGaAs}$ quantum wells. Physical Review B, v. 85, n. 16, p. 165301, Apr. 2012.

99 TRONC, P. Spin phenomena in asymmetrical [001] GaAs/AlxGa1-xAs quantum wells. Semiconductor Science and Technology, v. 27, n. 5, p. 055016, Apr. 2012.

100 SIRTORI, C.; KRUCK, P.; BARBIERI, S.; COLLOT, P.; NAGLE, J.; BECK, M.; FAIST, J.; OESTERLE, U. GaAs/Al[sub x] Ga[sub 1-x]As quantum cascade lasers. Applied Physics Letters, v. 73, n. 24, p. 3486, Oct. 1998.

101 IKEJIRI, K.; KITAUCHI, Y.; TOMIOKA, K.; MOTOHISA, J.; FUKUI, T. Zinc blende and wurtzite crystal phase mixing and transition in indium phosphide nanowires. Nano Letters, v. 11, n. 10, p. 4314-8, Oct. 2011.

102 YU, H.; LI, J.; LOOMIS, R. A.; WANG, L.-W.; BUHRO, W. E. Two- versus threedimensional quantum confinement in indium phosphide wires and dots. Nature Materials, v. 2, n. 8, p. 517-20, Aug. 2003.

103 DE, A.; PRYOR, C. E. Predicted band structures of III-V semiconductors in the wurtzite phase. Physical Review B, v. 81, n. 15, p. 155210, Apr. 2010.

104 EFROS, A. Luminescence polarization of CdSe microcrystals. Physical Review B, v. 46, n. 12, p. 7448-7458, Sept. 1992.

105 NORRIS, D.; BAWENDI, M. Measurement and assignment of the size-dependent optical spectrum in CdSe quantum dots. Physical Review B, v. 53, n. 24, p. 16338-16346, June 1996.

106 EFROS, A.; ROSEN, M.; KUNO, M.; NIRMAL, M.; NORRIS, D.; BAWENDI, M. Bandedge exciton in quantum dots of semiconductors with a degenerate valence band: dark and bright exciton states. Physical Review B, v. 54, n. 7, p. 4843-4856, Aug. 1996.

107 XIA, J.-B.; LI, J. Electronic structure of quantum spheres with wurtzite structure. Physical Review B, v. 60, n. 16, p. 11540-11544, Oct. 1999.

108 LI, J.; XIA, J.-B. Hole levels and exciton states in CdS nanocrystals. Physical Review B, v. 62, n. 19, p. 12613-12616, Nov. 2000.

109 HU, J.; LI, L.-S.; YANG, W.; ALIVISATOS, A. P. Semiempirical pseudopotential calculation of electronic states of CdSe quantum rods. Journal of Physical Chemistry B, v. 106, n. 10, p. 2447-2452, Mar. 2002.

110 PLANELLES, J.; RAJADELL, F.; CLIMENTE, J. I. Hole band mixing in CdS and CdSe quantum dots and quantum Rods. Journal of Physical Chemistry C, v. 114, n. 18, p. 83378342, May 2010. 
111 PERSSON, M.; XU, H. Electronic structure of [100]-oriented free-standing InAs and InP nanowires with square and rectangular cross sections. Physical Review $B$, v. 73, n. 12, p. 125346, Mar. 2006.

112 CHAN, R. H.-F.; JIN, X.-Q. An introduction to iterative toeplitz solvers. Philadelphia: SIAM: Society for Industrial and Applied Mathematics, 2007.

113 PIENTKA, J. M.; OSZWAŁDOWSKI, R.; PETUKHOV, A. G.; HAN, J. E.; ŽUTIĆ, I. Reentrant formation of magnetic polarons in quantum dots. Physical Review B, v. 86, n. 16, p. 161403, Oct. 2012.

114 VÝBORNÝ, K.; HAN, J. E.; OSZWAŁDOWSKI, R.; ŽUTIĆ, I.; PETUKHOV, A. G. Magnetic anisotropies of quantum dots doped with magnetic ions. Physical Review B, v. 85, n. 15, p. 155312, Apr. 2012.

115 ABOLFATH, R. M.; HAWRYLAK, P.; ŽUTIĆ, I. Tailoring magnetism in quantum dots. Physical Review Letters, v. 98, n. 20, p. 207203, May 2007.

116 HUTASOIT, J. A.; STANESCU, T. D. Induced spin texture in semiconductor/topological insulator heterostructures. Physical Review B, v. 84, n. 8, p. 085103, Aug. 2011.

117 KHOMITSKY, D. V. Manipulating the spin texture in a spin-orbit superlattice by terahertz radiation. Physical Review B, v. 77, n. 11, p. 113313, Mar. 2008.

118 SAN-JOSE, P.; SCHARFENBERGER, B.; SCHÖN, G.; SHNIRMAN, A.; ZARAND, G. Geometric phases in semiconductor spin qubits: manipulations and decoherence. Physical Review B, v. 77, n. 4, p. 045305, Jan. 2008.

119 RODDARO, S.; FUHRER, A.; BRUSHEIM, P.; FASTH, C.; XU, H. Q.; SAMUELSON, L.; XIANG, J.; LIEBER, C. M. Spin states of holes in Ge/Si nanowire quantum dots. Physical Review Letters, v. 101, n. 18, p. 186802, Oct. 2008.

120 ZOU, B.; LIU, R.; WANG, F.; PAN, A.; CAO, L.; WANG, Z. L. Lasing mechanism of $\mathrm{ZnO}$ nanowires/nanobelts at room temperature. Journal of Physical Chemistry B, v. 110, n. 26, p. 12865-12873, June 2006.

121 PEARTON, S.; NORTON, D.; HEO, Y.; TIEN, L.; IVILL, M.; LI, Y.; KANG, B.; REN, F.; KELLY, J.; HEBARD, A. ZnO spintronics and nanowire devices. Journal of Electronic Materials, v. 35, n. 5, p. 862-868, May 2006.

122 COTTLE, R. W. Manifestations of the Schur complement. Linear Algebra and its Applications, v. 8, n. 3, p. 189-211, June 1974.

123 LÖWDIN, P.-O. A note on the quantum-mechanical perturbation theory. Journal of Chemical Physics, New York, v. 19, n. 11, p. 1396, July 1951. 
APENNDICE $A$

\section{Teoria de perturbação}

\section{A.1 O complemento de Schur}

Suponha uma matriz $M$, hermitiana, da seguinte forma:

$$
M=\left(\begin{array}{cc}
A & B \\
B^{*} & C
\end{array}\right)
$$

e o vetor:

$$
\psi=\left(\begin{array}{l}
x \\
y
\end{array}\right)
$$

Então, uma das formas de se resolver o sistema linear $M \psi=E \psi$ é usando o método do complemento de Schur (122), ou seja, dado o sistema:

$$
\begin{aligned}
\tilde{A} x+B y & =0 \\
B^{*} x+\tilde{C} y & =0
\end{aligned}
$$

Podemos usar o complemento de Schur de $\tilde{C}$ em $M,(M / \tilde{C})$, para obter a solução para $x:$

$$
\left(\tilde{A}-B \tilde{C}^{-1} B^{*}\right) x=0
$$

$\operatorname{com} \tilde{A}=A-E$ e $\tilde{C}=C-E$

\section{A.2 Resultados tradicionais da teoria de perturbação}




$$
\begin{aligned}
H \psi_{n} & =E_{n} \psi_{n} \\
H & =H^{(0)}+\lambda H^{\prime}
\end{aligned}
$$

com $\lambda H^{\prime}$ sendo um potencial de perturbação pequeno. E assuma conhecidos os autovetores e autovalores do Hamiltoniano não perturbado, ou seja:

$$
H^{(0)}|n\rangle=E_{n}^{(0)}|n\rangle
$$

Então, para resolver o problema, devemos expandir tanto o auto estado quanto o autovalor em ordens de $\lambda$ :

$$
\begin{aligned}
& E_{n}=E_{n}^{(0)}+\lambda E_{n}^{(1)}+\lambda^{2} E_{n}^{(2)}+\cdots \\
& \psi_{n}=\psi_{n}^{(0)}+\lambda \psi_{n}^{(1)}+\lambda^{2} \psi_{n}^{(2)}+\cdots
\end{aligned}
$$

de tal forma que a equação A.2.1 se torne:

$$
\begin{array}{r}
\left(H^{(0)}+\lambda H^{\prime}\right)\left(\psi_{n}^{(0)}+\lambda \psi_{n}^{(1)}+\lambda^{2} \psi_{n}^{(2)}+\cdots\right)= \\
\left(E_{n}^{(0)}+\lambda E_{n}^{(1)}+\lambda^{2} E_{n}^{2}+\cdots\right)\left(\psi_{n}^{(0)}+\lambda \psi_{n}^{(1)}+\lambda^{2} \psi_{n}^{(2)}+\cdots\right)
\end{array}
$$

Agrupando os termos com a mesma ordem em $\lambda$ podemos achar a solução de A.2.1 até a ordem desejada, ou seja,

$$
\begin{aligned}
H^{(0)} \psi_{n}^{(0)} & =E_{n}^{(0)} \psi_{n}^{(0)} \\
\left(H^{(0)}-E_{n}^{(0)}\right) \psi_{n}^{(1)} & =\left(E_{n}^{(1)}-H^{\prime}\right) \psi_{n}^{(0)} \\
\left(H^{(0)}-E_{n}^{(0)}\right) \psi_{n}^{(2)} & =E_{n}^{(2)} \psi_{n}^{(0)}+\left(H^{\prime}-E_{n}^{(1)}\right) \psi_{n}^{(1)} \\
\cdots & =\cdots
\end{aligned}
$$


Resolvendo para cada ordem, teremos as correções:

$$
E_{n}=E_{n}^{(0)}+\left\langle m\left|H^{\prime}\right| n\right\rangle+\sum_{m \neq n} \frac{\left\langle n\left|H^{\prime}\right| m\right\rangle\left\langle m\left|H^{\prime}\right| n\right\rangle}{E_{n}^{(0)}-E_{m}^{(0)}}
$$

\section{A.3 Löwdin}

O método de perturbação tradicional, desenvolvido na seção anterior, considera a influência de todos os elementos da base para um dado estado.

No método proposto por Löwdin em (123) consideramos duas classes de estados, $A$ e $B$. Assim, calcularemos a influência da classe de estados $B$ sobre $A$. Assumiremos que os estados pertencentes à classe $A$ podem interagir fortemente entre si e fracamente com os estados da classe $B$.

Considere, novamente, o problema:

$$
\begin{aligned}
H\left|\psi_{n}\right\rangle & =E_{n}\left|\psi_{n}\right\rangle \\
\left(H^{(0)}+H^{\prime}\right)\left|\psi_{n}\right\rangle & =E_{n}\left|\psi_{n}\right\rangle
\end{aligned}
$$

Então, seguindo a proposição, escreveremos $\left|\psi_{n}\right\rangle$ da seguinte maneira:

$$
\begin{aligned}
\left|\psi_{n}\right\rangle & =\sum_{\alpha}^{A} a_{\alpha}\left|\phi_{\alpha}^{(0)}\right\rangle+\sum_{\beta}^{B} a_{\beta}\left|\phi_{\beta}^{(0)}\right\rangle \\
\left|\psi_{n}\right\rangle & =|\alpha\rangle+|\beta\rangle
\end{aligned}
$$

Com:

$$
\begin{aligned}
& H_{0}|\alpha\rangle=E_{\alpha}|\alpha\rangle, \\
& H_{0}|\beta\rangle=E_{\beta}|\beta\rangle,
\end{aligned}
$$

Tomando o elemento de matriz, na equação A.3.2, com um estado $\left|\phi_{\alpha^{\prime}}^{(0)}\right\rangle$, teremos: 


$$
\left(E_{n}-E_{\alpha^{\prime}}\right) a_{\alpha^{\prime}}=\sum_{\alpha^{\prime}}^{A} a_{\alpha^{\prime}}\left\langle\phi_{\alpha^{\prime}}^{(0)}\left|H^{\prime}\right| \phi_{\alpha}^{(0)}\right\rangle+\sum_{\beta}^{B} a_{\beta}\left\langle\phi_{\alpha^{\prime}}^{(0)}\left|H^{\prime}\right| \phi_{\beta}^{(0)}\right\rangle
$$

Tomando o elemento de matriz com um estado $\left|\phi_{\beta^{\prime}}^{(0)}\right\rangle$, teremos:

$$
a_{\beta^{\prime}}=\sum_{\alpha}^{A} a_{\alpha} \frac{\left\langle\phi_{\beta^{\prime}}^{(0)}\left|H^{\prime}\right| \phi_{\alpha}^{(0)}\right\rangle}{\left(E_{n}-E_{\beta^{\prime}}\right)}+\sum_{\beta^{\prime}}^{B} a_{\beta^{\prime}} \frac{\left\langle\phi_{\beta^{\prime}}^{(0)}\left|H^{\prime}\right| \phi_{\beta}^{(0)}\right\rangle}{\left(E_{n}-E_{\beta^{\prime}}\right)}
$$

Substituindo (A.3.8) em (A.3.7) e desprezando interações da classe $B$ com ela mesma, teremos:

$$
\begin{aligned}
\left(E_{n}-E_{\alpha^{\prime}}\right) a_{\alpha^{\prime}} & =\sum_{\alpha^{\prime}}^{A} a_{\alpha^{\prime}} H_{\alpha^{\prime} \alpha}^{\prime}+\sum_{\beta}^{B}\left[\sum_{\alpha}^{A} a_{\alpha} \frac{H_{\beta \alpha}^{\prime}}{\left(E_{\alpha}-E_{\beta}\right)}+\sum_{\beta}^{B} a_{\beta} \frac{H_{\beta \beta^{\prime}}^{\prime}}{\left(E_{\alpha}-E_{\beta}\right)}\right] H_{\alpha^{\prime} \beta}^{\prime} \\
& =\sum_{\alpha^{\prime}}^{A} a_{\alpha^{\prime}} H_{\alpha^{\prime} \alpha}^{\prime}+\sum_{\beta}^{B} \sum_{\alpha}^{A} a_{\alpha} \frac{H_{\alpha^{\prime} \beta}^{\prime} H_{\beta \alpha}^{\prime}}{\left(E_{\alpha}-E_{\beta}\right)}
\end{aligned}
$$

com $H_{m n}^{\prime}$ o elemento de matriz $\left\langle m\left|H^{\prime}\right| n\right\rangle$

Portanto:

$$
E_{n}=E_{\alpha}+H_{\alpha \alpha}^{\prime}+\sum_{\beta}^{B} \frac{H_{\alpha \beta}^{\prime} H_{\beta \alpha}^{\prime}}{\left(E_{\alpha}-E_{\beta}\right)}
$$

\section{A.4 Sumarizando}

Vocês, leitores, devem estar se perguntando: Porque um apêndice sobre teoria de perturbação começa com uma seção sobre o complemento de Schur?

Considere que um dado Hamiltoniano expresso em uma dada base possa ser decomposto e representado pela matriz A.1.1. Nesta matriz, os elementos $A, B$ e $C$ são na verdade outras matrizes. Assim, a expressão A.1.5 é interpretada como o efeito de $C$ em $A$.

Então, definiremos:

$$
U=A-B \tilde{C}^{-1} B^{*}
$$


com $U x=E x$ Sendo assim, decompomos a matriz $C$ da seguinte forma:

$$
C=C_{d}+C_{n d}
$$

com $C_{d}$ sendo a diagonal de $C$ e a parte não diagonal representada por $C_{n d}$.

Com isso, se $C$ for diagonal dominante, podemos expandir $C^{-1}$ em série de pontências, utilizando a série de Neumann

$$
C^{-1}=\sum_{n=0}^{\infty}(\mathbb{I}-C)
$$

e obter:

$$
U=A+B \frac{1}{E-C_{d}} B^{*}+B \frac{1}{E-C_{d}} C_{n d} \frac{1}{E-C_{d}} B^{*}+\cdots
$$

Que é a mesma expressão que A.3.9 e nos leva à mesma forma para a correção de energia obtida tanto em A.2 quanto em A.3. Então podemos interpretar a teoria de perturbação, tanto a tradicional quanto a de Löwdin, como o método de Schur para resolução de sistemas lineares. O fato é que se $A$ for apenas um estado (teoria de perturbação tradicional) ou uma classe de estados (Löwdin), a matemática por trás é a mesma. 


\section{Ortogonalidade da função de onda no formalismo da função envelope}

Neste apêndice irei mostrar os passos necessários para se obter a relação de ortogonalidade das funções de onda do sistema no formalismo da função envelope. Essa discussão foi apresentada primeiramente por Faria Junior (67) e eu estou resumindo aqui por completeza.

Considere a seguinte notação:

$$
\begin{aligned}
\Psi_{n}(\vec{r}) & =\sum_{l} f_{l}(\vec{r}) u_{l, \vec{k}_{0}}(\vec{r}) \\
\left|\Psi_{n}\right\rangle & =\sum_{l}\left|F_{l}, l\right\rangle \\
\left\langle\vec{r} \mid \Psi_{n}\right\rangle & =\Psi_{n}(\vec{r}) \\
\left\langle\vec{r} \mid F_{l}, l\right\rangle & =f_{l}(\vec{r}) u_{l, \vec{k}_{0}}(\vec{r})
\end{aligned}
$$

com $\Psi_{n}(\vec{r})$ a função de onda para uma dada banda de energia; $u_{l, \vec{k}_{0}}(\vec{r})$ o fator de Bloch do cristal no ponto de expansão, $\Gamma$; e a somatória em $l$ leva em conta todas as bandas de energia consideradas incluindo o spin.

Vamos calcular o produto interno entre duas dessas funções:

$$
\left\langle F_{m}, m \mid F_{n}, n\right\rangle=\int_{\Omega} \mathrm{d}^{3} r u_{m}^{*}(\vec{r}) f_{m}^{*}(\vec{r}) f_{n}(\vec{r}) u_{n}(\vec{r})
$$

Podemos reescrevê-la da seguinte forma:

$$
\left\langle F_{m}, m \mid F_{n}, n\right\rangle=\int_{\Omega} \mathrm{d}^{3} r \alpha(\vec{r}) \beta(\vec{r})
$$




$$
\alpha(\vec{r})=u_{m}^{*}(\vec{r}) u_{n}(\vec{r})
$$

e

$$
\beta(\vec{r})=f_{m}^{*}(\vec{r}) f_{n}(\vec{r})
$$

Como $\alpha(\vec{r})$ possui a mesma periodicidade da rede de Bravais do cristal, podemos expândila da seguinte maneira:

$$
\alpha(\vec{r})=\sum_{\vec{K}} \alpha(\vec{K}) e^{i \vec{K} \cdot \vec{r}}
$$

com

$$
\alpha(\vec{K})=\frac{1}{\Omega} \int_{\Omega} \mathrm{d}^{3} r \alpha(\vec{r}) e^{-i \vec{K} \cdot \vec{r}}
$$

que a expansão em Fourier com $\vec{K}$ pertencendo à rede recíproca.

Substituindo (B.0.6) em (B.0.3):

$$
\left\langle F_{m}, m \mid F_{n}, n\right\rangle=\sum_{\vec{K}} \alpha(\vec{K}) \int_{\Omega} \mathrm{d}^{3} r \beta(\vec{r}) e^{i \vec{K} \cdot \vec{r}}
$$

Reescrevendo a equação (B.0.8) deixando explicita a contribuição de cada célula unitária, ou seja, dividindo a integral no volume $\Omega$ como a soma de integrais nos volumes $\Omega_{i}$ das células unitárias, teremos:

$$
\left\langle F_{m}, m \mid F_{n}, n\right\rangle=\sum_{\vec{K}} \alpha(\vec{K}) \sum_{\vec{R}_{i}} \int_{\Omega_{i}} \mathrm{~d}^{3} \rho \beta\left(\vec{\rho}+\vec{R}_{i}\right) e^{i \vec{K} \cdot \vec{\rho}}
$$

usando o fato de que $i \vec{K} \cdot \vec{R}_{i}=2 \pi q$, com $q$ um número inteiro.

Como estamos assumindo que as funções envelopes variam mais lentamente que os fatores de Bloch, podemos expandir $\beta\left(\vec{\rho}+\vec{R}_{i}\right)$ usando a séria de Taylor, ficando com:

$$
\left.\beta\left(\vec{\rho}+\vec{R}_{i}\right) \approx \beta\left(\vec{R}_{i}\right)+\vec{\rho} \cdot[\nabla \overrightarrow{\beta(} \vec{\rho})\right]_{\vec{R}_{i}}+\mathcal{O}\left(\rho^{2}\right)
$$

e manter apenas a ordem zero. 
Assim, a equação (B.0.9) fica:

$$
\left\langle F_{m}, m \mid F_{n}, n\right\rangle=\sum_{\vec{K}} \alpha(\vec{K}) \sum_{\vec{R}_{i}} \beta\left(\vec{R}_{i}\right) \int_{\Omega_{i}} \mathrm{~d}^{3} \rho e^{i \vec{K} \cdot \vec{\rho}}
$$

Reconhecendo que:

$$
\int_{\Omega_{i}} \mathrm{~d}^{3} \rho e^{i \vec{K} \cdot \vec{\rho}}=\Omega_{i} \delta(\vec{\rho})
$$

e que

$$
\Omega_{i}=\int_{\Omega_{i}} \mathrm{~d}^{3} \rho
$$

e, usando a equação (B.0.7) para obter $\alpha(0)$, teremos finalmente a relação de ortonomalidade para a função de onda

$$
\left\langle F_{m}, m \mid F_{n}, n\right\rangle=\left[\frac{1}{\Omega_{0}} \int_{\Omega_{0}} \mathrm{~d}^{3} r^{\prime} \alpha\left(\vec{r}^{\prime}\right)\right]\left[\int_{\Omega} \mathrm{d}^{3} r \beta(\vec{r})\right]
$$

